\title{
Indicadores de desempenho logístico: estudo de múltiplos casos no setor de bens de capital agrícolas
}

Dissertação apresentada à Escola de Engenharia de São Carlos da Universidade de São Paulo, como parte dos requisitos para obtenção do título de Mestre em Engenharia de Produção

Área de Concentração: Processos e Gestão de Operações

Orientador: Prof. Dr. Marcel Andreotti Musetti 
AUTORIZO A REPRODUÇÄO E DIVULGAÇÄO TOTAL OU PARCIAL DESTE TRABALHO, POR QUALQUER MEIO CONVENCIONAL OU ELETRÔNICO, PARA FINS DE ESTUDO E PESQUISA, DESDE QUE CITADA A FONTE.

Ficha catalográfica preparada pela Seção de Tratamento

da Informação do Serviço de Biblioteca - EESC/USP

\begin{tabular}{|c|c|}
\hline \multirow[t]{3}{*}{ C2711 } & $\begin{array}{l}\text { Careta, Catarina Barbosa } \\
\text { Indicadores de desernenho logístico : estudo de } \\
\text { mútiplos casos no setor de bens de capital agricolas / } \\
\text { Catarina Barbosa Careta; orientador Marcel Andreotti } \\
\text { Musetti. -- São Carlos, } 2009 \text {. }\end{array}$ \\
\hline & $\begin{array}{l}\text { Dissertação (Mestrado-Programa de Pós-Graduação e Área } \\
\text { de Concentração en Engenharia de Produção) -- Escola de } \\
\text { Engenharia de São Carlos da Universidade de São Paulo, } \\
\text { 2009. }\end{array}$ \\
\hline & $\begin{array}{l}\text { 1. Logística. 2. Medição de desempenho. 3. Indicadores } \\
\text { de desempenho logistico. 4. Bens de capital agrícolas. } \\
\text { I. Titulo. }\end{array}$ \\
\hline
\end{tabular}




\section{FOLHA DE JULGAMENTO}

Candidata: Tecnóloga CATARINA BARBOSA CARETA.

Dissertação defendida e julgada em 07/07/2009 perante a Comissão Julgadora:

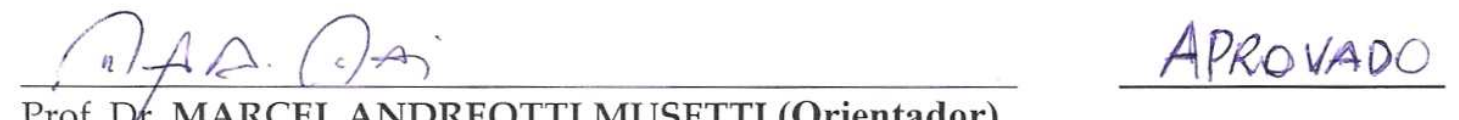

Prof. Dr. MARCEL ANDREOTTI MUSETTI (Orientador)

(Escola de Engenharia de São Carlos/USP)

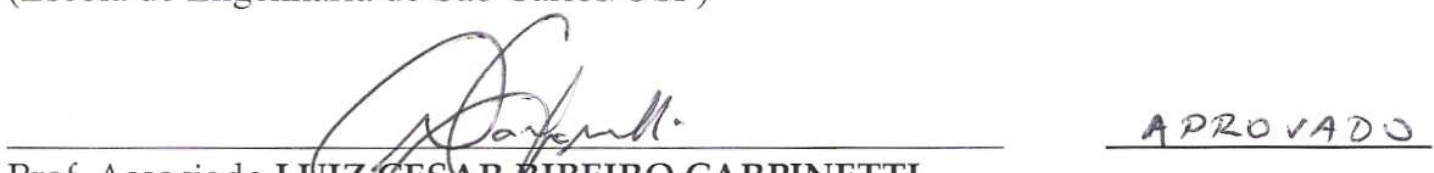

Prof. Associado LUIZ ESAB RIBEIRO CARPINETTI

(Escola de Engenharia de São Carlos/USP)

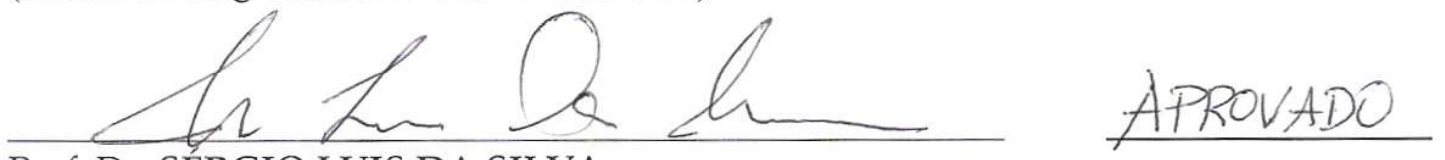

Prof. Dr. SERGIO LUIS DA SILVA

(Universidade Federal de São Carlos/UFSCar)
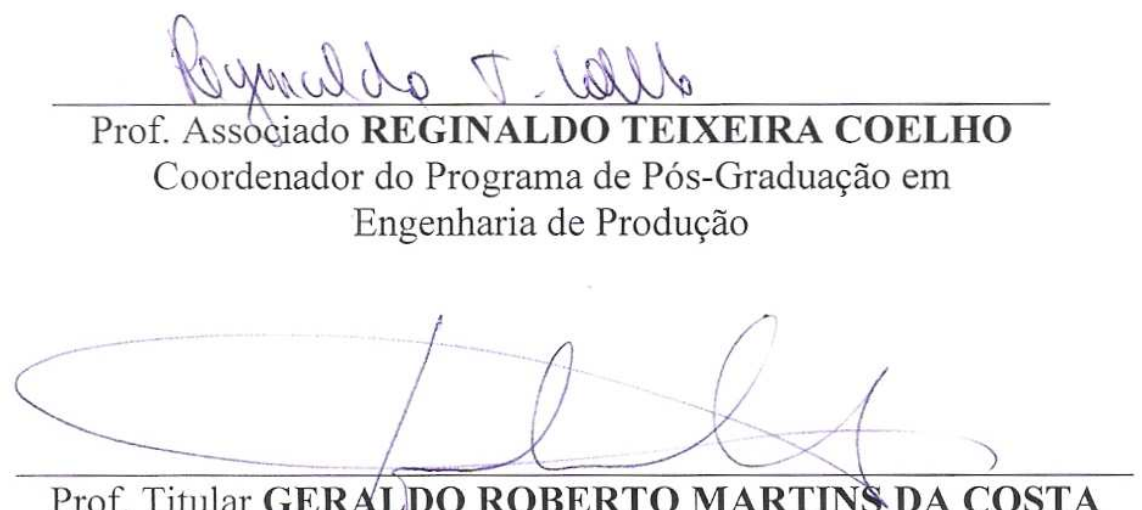

Presidente da Comissão da Pós-Graduação da EESC 

DEDICATÓRIA

Aos meus pais, José e Clélia

e à minha irmã, Claudelina. 



\section{AGRADECIMENTOS}

À Deus, aos meus pais e à minha irmã, razões de minha vida.

Ao Prof. Dr. Marcel Andreotti Musetti, pela oportunidade concedida ao possibilitar meu ingresso na pós-graduação e por sua extrema generosidade e paciência como orientador.

Ao Prof. Dr. Luiz Cesar Ribeiro Carpinetti e ao Prof. Dr. Sergio Luis da Silva, pelas pertinentes recomendações fornecidas durante o exame de qualificação e defesa desta dissertação.

Aos profissionais que colaboraram no desenvolvimento da pesquisa de campo, Dani Marcelo Marques, Oscar Celada, Pedro Gandini, Régis Tiecher e Renato Onnoda.

Aos colegas do Laboratório de Gestão de Operações e do Grupo de Pesquisa em Logística Integrada, em especial à Danilo Hisano Barbosa, Larissa Elaine Dantas de Araújo, Rosana Cristina Colombo Dionysio e Juliana Sayuri Kurumoto, pela amizade e atenção a mim dedicada.

Aos funcionários do Departamento de Engenharia de Produção, especialmente ao Sr. José Luiz Donizete Chiaretto.

Ao Instituto Fábrica do Milênio (IFM) e à Coordenação de Aperfeiçoamento de Pessoal de Nível Superior (CAPES), pelo apoio financeiro concedido. 



\section{RESUMO}

CARETA, C. B. Indicadores de desempenho logístico: estudo de múltiplos casos no setor de bens de capital agrícolas. 2009. 152p. Dissertação (Mestrado) - Escola de Engenharia de São Carlos, Universidade de São Paulo, São Carlos, 2009.

O setor de bens de capital agrícolas é um dos mais tradicionais da indústria brasileira e cumpre um papel de relevância na difusão de novas tecnologias e como dinamizador do desenvolvimento econômico, obtendo atualmente crescimentos acentuados de sua produção. Contudo as empresas deste setor enfrentam dificuldades para sustentar seus avanços produtivos e entre os principais problemas apontados está o custo da atividade logística. Sendo a atividade logística determinante para a obtenção de competitividade, a medição de desempenho passa a exercer um papel fundamental nas organizações, representando uma das mais importantes ferramentas a serem utilizadas na estratégia de gerenciamento de recursos e no alcance da melhor prática logística. Com base nestas considerações, o presente estudo objetivou identificar e analisar os indicadores de desempenho logístico e práticas associadas de empresas do setor de bens de capital agrícolas, por meio de revisão bibliográfica e estudo de múltiplos casos junto às empresas do setor. Os resultados apontaram os indicadores comuns às empresas e que práticas de gestão associadas a estes indicadores, possuem algumas diferenças significantes em relação ao recomendado pela literatura, no que se refere ao escopo de avaliação, aos envolvidos no processo de medição de desempenho e à comunicação de resultados. A abrangência da atividade logística desenvolvida pelas empresas e as características do setor de atuação surgem como prováveis fatores que influenciam o nível de adequação às boas práticas sugeridas pela literatura. Ao se utilizar casos de empresas de destaque no segmento de bens de capital agrícolas, espera-se que os resultados apontados sirvam para estas empresas e outras menos estruturadas deste segmento direcionarem avanços nos seus processos de avaliação das atividades logísticas.

Palavras-chave: Logística; Medição de Desempenho; Indicadores de Desempenho Logístico; Bens de Capital Agrícolas. 



\begin{abstract}
CARETA, C. B. Logistics performance indicators: study of multiples cases in agricultural capital goods sector. 2009. 152p. Dissertation (Master) - Engineering School of São Carlos, University of São Paulo, São Carlos, 2009.

The agricultural capital goods sector is one of the most traditional in the Brazilian industry and it has an important role in the diffusion of new technologies and in the economic development, obtaining nowadays accentuated growths of its production. However the companies of this sector face difficulties to sustain their productive progress and the main problem pointed is the cost of the logistics activity. Being the logistics activity decisive for the obtaining of competitiveness, the performance measurement exercise a fundamental role in the organizations, representing one of the most important tool to be used in the strategy of resources management and in the search of the logistics best practice. Based on these considerations, the present study aimed to identify and to analyze the logistics performance indicators used by companies of the agricultural capital goods sector, by means bibliographical revision and study of multiple cases in companies of the sector. The results indicated commons indicators and that the management practices associated with them have some important differences in relation to the literature indicated, as for the scope of evaluation, the involved in the process of performance measurement and the communication of results. The scope of the logistics activity developed by the companies and the characteristics of the sector of performance appear as probable factors that influence the adaptation level to the good practices suggested by the literature. When using cases of prominence companies in the agricultural capital goods sector, expects that the results serve for these companies and others less structured of this sector to guide progresses in their processes of evaluation of the logistics activities.
\end{abstract}

Keywords: Logistics; Performance Measurement; Logistics Performance Indicators; Agricultural Capital Goods. 



\section{LISTA DE FIGURAS}

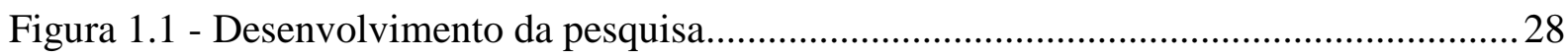

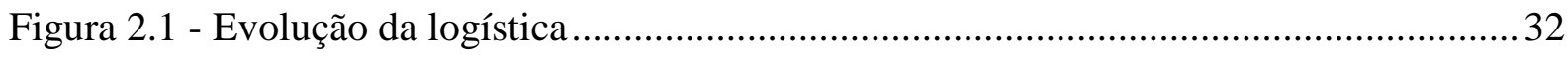

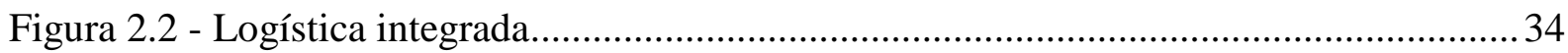

Figura 2.3 - Cadeia logística do setor de bens de capital agrícolas ..........................................36

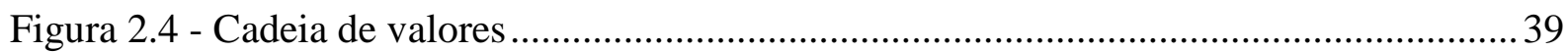

Figura 2.5 - Modelo de competência logística de Michigan State University .......................... 41

Figura 2.6 - Modelo de implementação de logística estratégica ............................................ 43

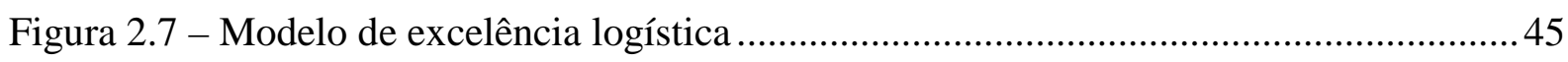

Figura 3.1 - Dimensões da medição de desempenho .........................................................50

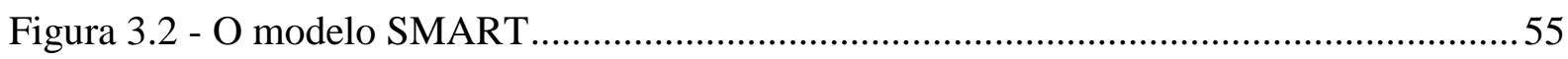

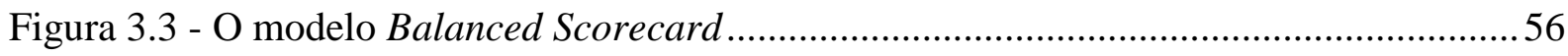

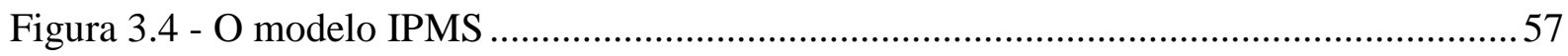

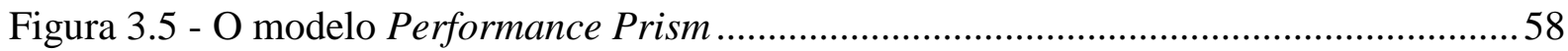

Figura 3.6 - Fases do processo de medição de desempenho ................................................. 60

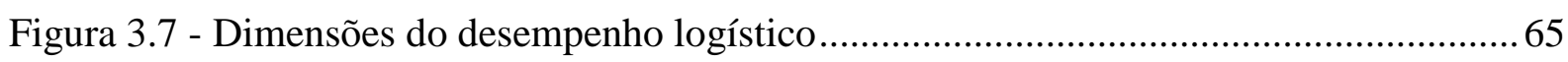

Figura 4.1 - Abrangência da pesquisa e pontos de análise .................................................... 80

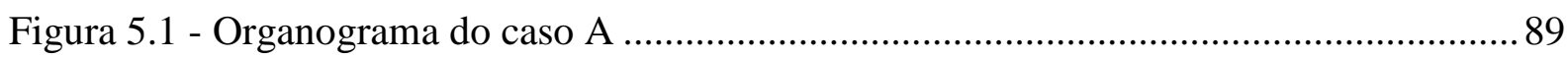

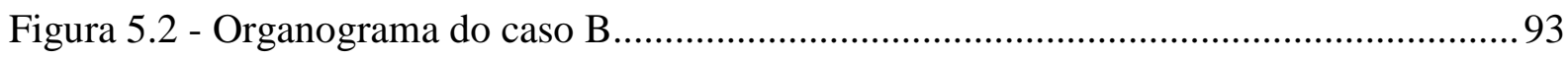

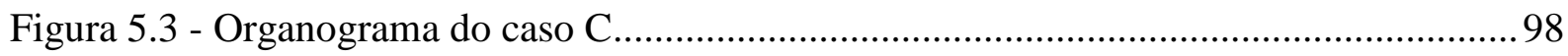

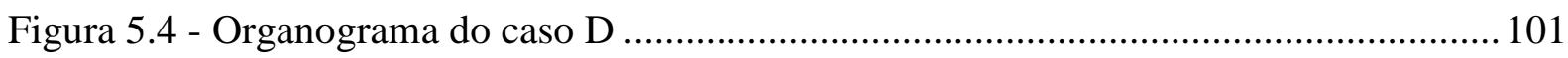

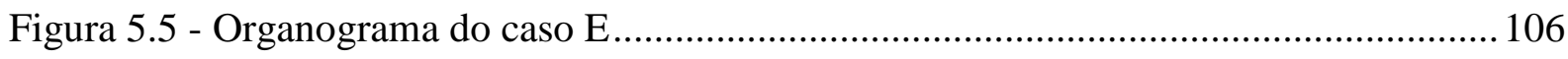





\section{LISTA DE QUADROS}

Quadro 2.1 - Principais dificuldades das empresas do setor BK agrícolas ................................35

Quadro 2.2 - Síntese dos modelos de estruturação estratégica............................................... 47

Quadro 3.1 - Modelos de medição de desempenho................................................................54

Quadro 3.2 - Síntese das características dos modelos de medição de desempenho ..................59

Quadro 3.3 - Definição de indicadores de desempenho ....................................................... 61

Quadro 3.4 - Procedimentos para desenvolvimento da medição de desempenho.....................64

Quadro 3.5 - Abrangência do processo de medição de desempenho logístico ......................... 72

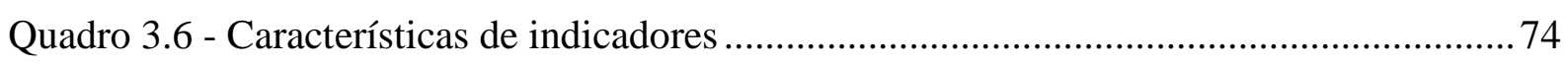

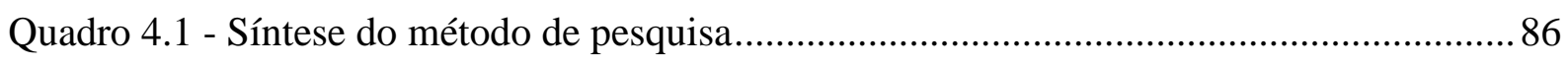

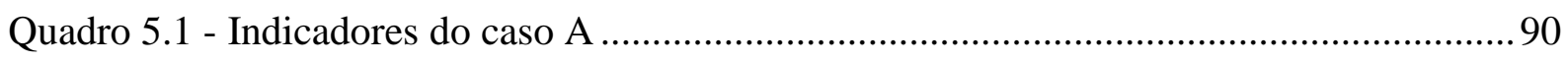

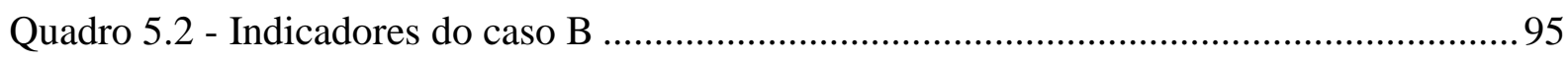

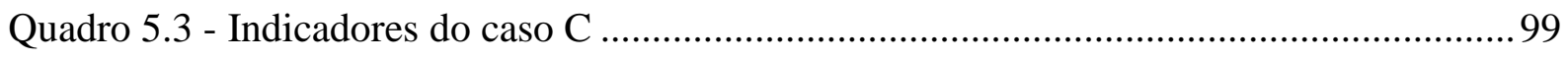

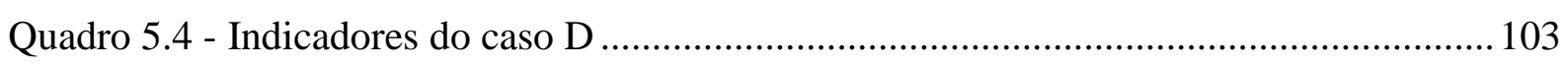

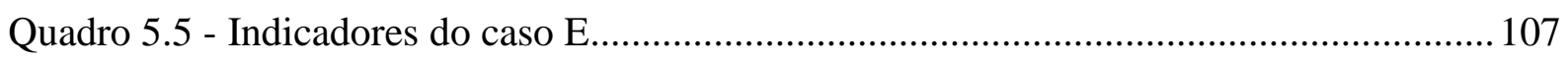

Quadro 6.1 - Indicadores de desempenho logístico comuns entre as empresas ..................... 111

Quadro 6.2 - Indicadores com maior grau de importância segundo gestores ...................... 115

Quadro 6.3 - Indicadores financeiros e não-finaceiros...................................................... 118

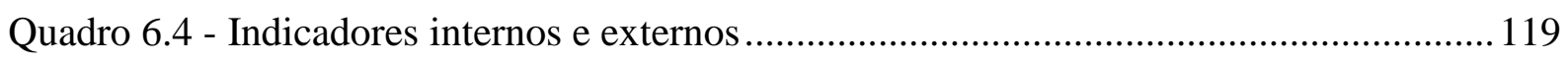

Quadro 6.5 - Síntese da análise de dados ...................................................................... 125 



\section{LISTA DE TABELAS}

Tabela 1.1 - Indicadores conjunturais da Indústria no ano de 2008 ..................................... 24

Tabela 1.2 - Produção física dos segmentos do setor de bens de capital em março de 2009 ... 25 



\section{LISTAS DE SIGLAS E ABREVIATURAS}

ABC - Activity Based Costing

ANFAVEA - Associação Nacional de Fabricantes de Veículos Automotores

BSC - Balanced Scorecard

CSCMP - Council of Supply Chain Management Professionals

ECR - Efficient Customer Response

EDI - Electronic Data Interchange

ERP - Enterprise Resource Planning

GLRT - Global Logistics Research Team

IBGE - Instituto Brasileiro de Geografia e Estatística

IBK - Indústria de bens de capital

ID - Indicadores de desempenho

IFM - Instituto Fábrica do Milênio

IPMS - Integrated Performance Measurement Systems

MASP - Método de análise e solução de problemas

PP - Performance Prism

ROAM - Return on Assets Managed

ROI - Return on Investment

SCM - Supply Chain Management

SMART - Strategic Measurement, Analysis and Reporting Technique

SMD - Sistema de medição de desempenho 



\section{SUMÁRIO}

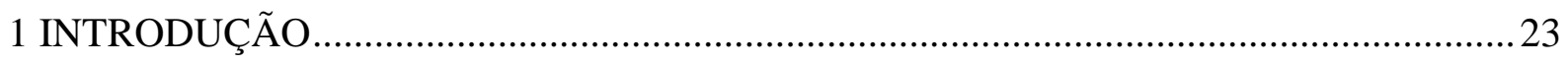

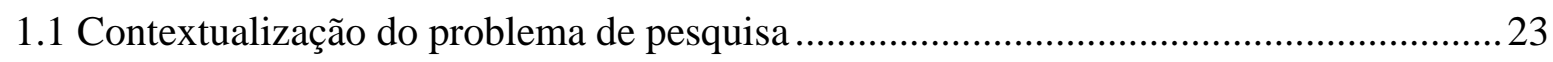

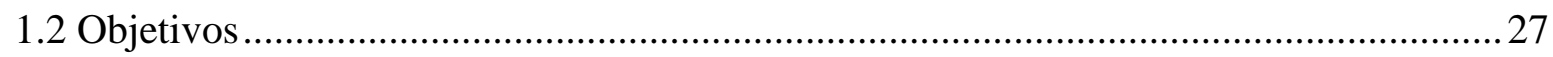

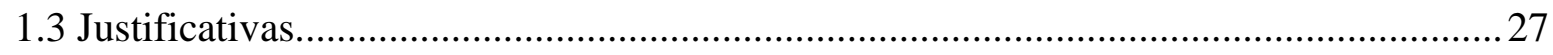

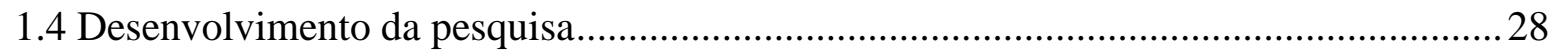

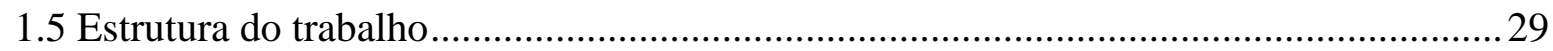

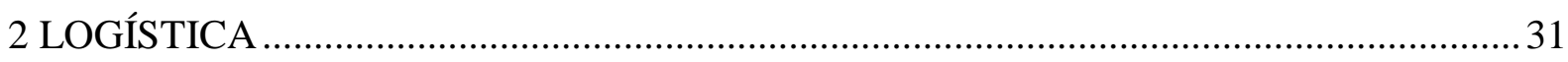

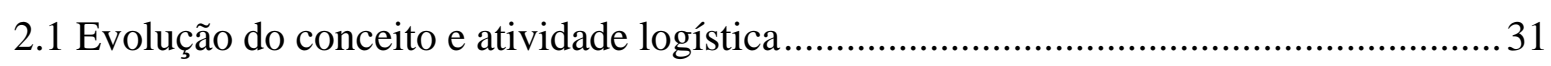

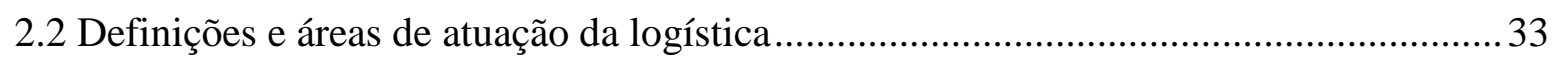

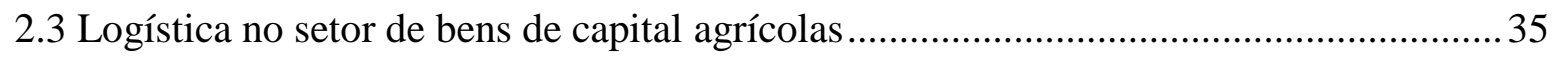

2.4 Logística como fonte de vantagem competitiva ........................................................... 38

2.5 Modelos de estruturação estratégica logística ........................................................... 40

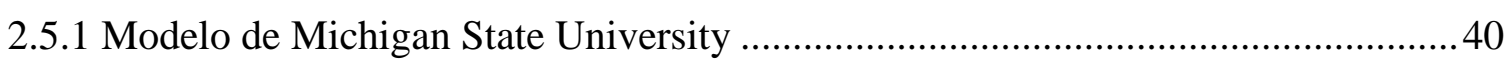

2.5.2 Modelo de Fawcett e Clinton ............................................................................. 42

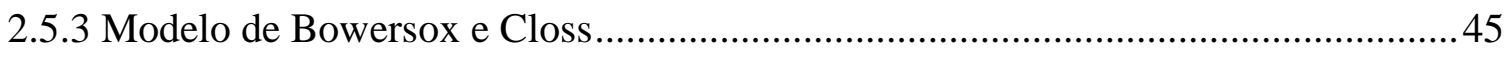

2.6 Síntese dos modelos: a medição de desempenho como estratégia comum .....................46

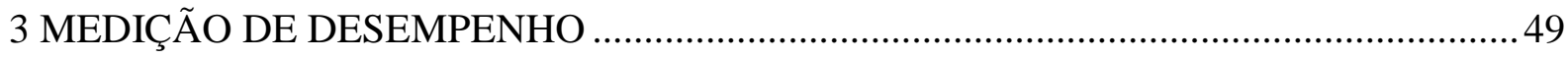

3.1 Definições para medição de desempenho .................................................................. 49

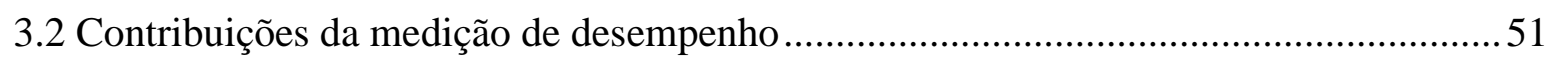

3.3 Evolução da medição de desempenho .....................................................................52

3.3.1 Modelos de sistemas de medição de desempenho .................................................54

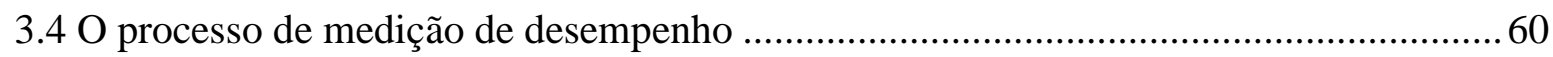

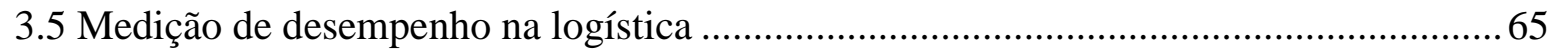

3.6 Abordagens sobre o processo de medição de desempenho na logística .........................66

3.6.1 Análise das abordagens sobre medição de desempenho na logística........................72

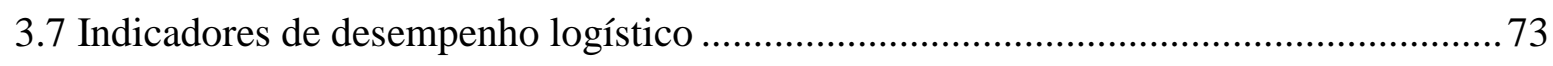

3.7.1 Classificação dos indicadores de desempenho utilizados na logística.....................76

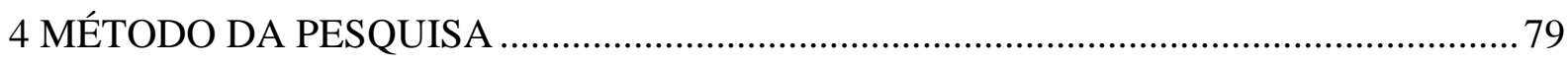

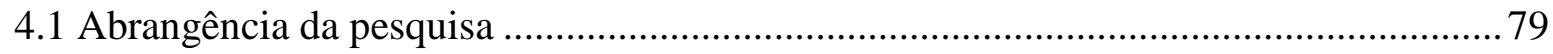

4.2 Caracterização do método da pesquisa .................................................................... 80

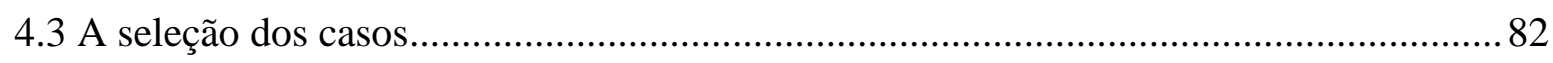




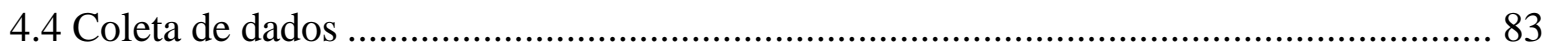

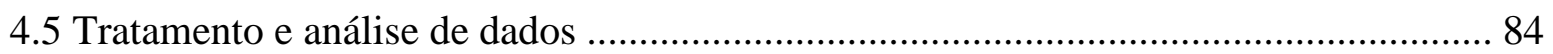

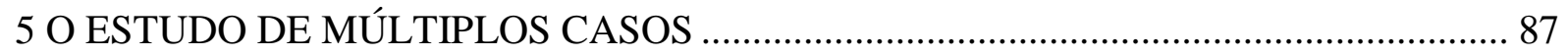

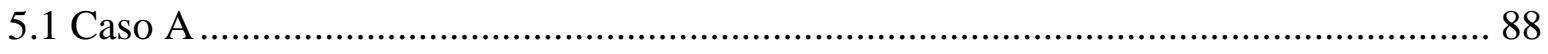

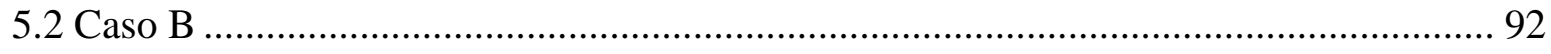

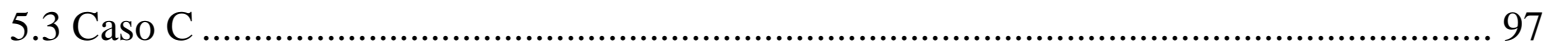

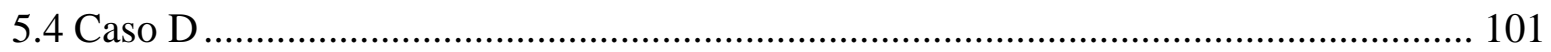

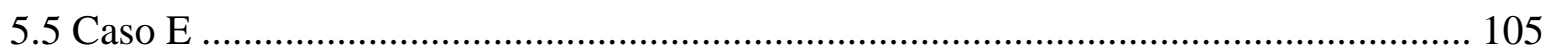

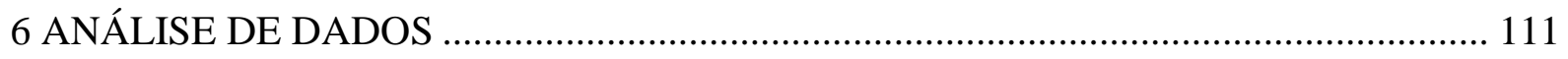

6.1 Os indicadores de desempenho logístico das empresas do setor de BK agrícola ........ 111

6.1.1 Alinhamento dos indicadores com a estratégia logística.................................... 114

6.1.2 A abrangência dos indicadores de desempenho logísticos................................. 117

$6.2 \mathrm{O}$ processo de medição de desempenho logístico .................................................... 120

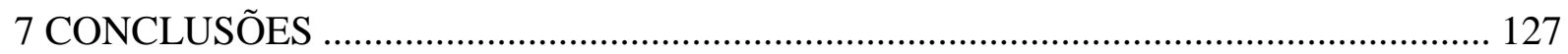

7.1 Quanto aos objetivos e questão de pesquisa ........................................................ 127

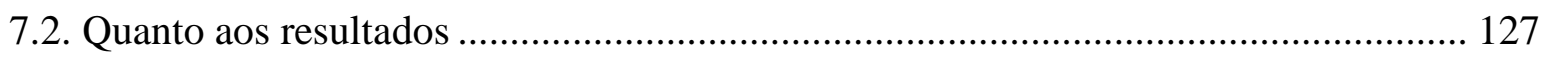

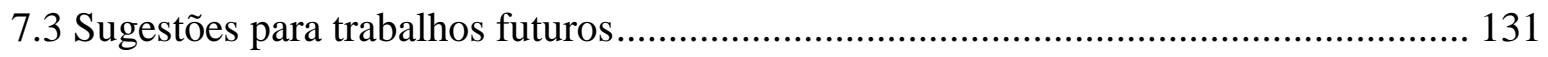

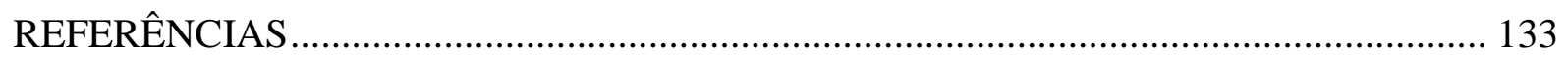

APÊNDICE A - Indicadores de desempenho logístico segundo literatura............................ 141

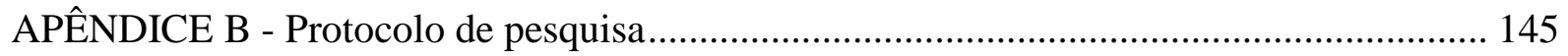

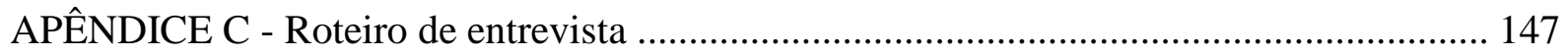




\section{INTRODUÇÃO}

Neste capítulo introdutório apresenta-se o problema e questões que norteiam o desenvolvimento da pesquisa, os objetivos principais, as justificas para sua execução, além do método e a estrutura de apresentação do texto.

\subsection{Contextualização do problema de pesquisa}

A indústria de bens de capital (IBK) é responsável pela produção de máquinas e equipamentos utilizados pelos demais setores para produzir bens e serviços. Segundo Weise (2000), Baark (2001), Vermulm e Erber (2002), Souza (2004), Alem e Pessoa (2005) e Avellar (2008) a IBK é ao mesmo tempo, produtora e usuária dos bens, dando origem a um círculo virtuoso de acumulação e crescimento. Para os autores, este processo é característico do setor e é ampliado pelo progresso técnico introduzido nos bens de capital, que faz com que as novas máquinas e equipamentos sejam mais produtivos do que suas antecessoras. Incorporando o progresso técnico e sendo utilizados pelos demais setores da economia, os bens de capital atuam como difusores do desenvolvimento tecnológico pelo resto do sistema econômico. Os papéis desempenhados pela indústria de bens de capital no processo de acumulação e na geração e difusão do progresso técnico tornam-na estratégica do ponto de vista do desenvolvimento econômico.

Em relação às especificidades técnicas, Alem e Pessoa (2005) afirmam que os bens de capital são classificados como:

- seriados: produzidos em larga escala, de forma padronizada, como máquinas agrícolas, tratores, ônibus e caminhões, e

- sob encomenda: produzidos segundo características técnicas associadas a determinado processo produtivo, como as prensas utilizadas pelas montadoras de automóveis, os altos-fornos das siderúrgicas, as turbinas das usinas hidrelétricas e as plataformas de petróleo.

Além da heterogeneidade dos produtos, Vermulm (2003) destaca como outra característica das IBKs, a grande variedade de porte das empresas envolvidas no setor; compreendendo desde empresas familiares (pequenas e médias) até grandes multinacionais. Conforme Alem e Pessoa (2005) e Avellar (2008) no mundo, a produção de bens de capital mais sofisticados está concentrada principalmente nos países desenvolvidos, como Estados 
Unidos, Japão, Alemanha e Itália. No que diz respeito aos países em desenvolvimento, além do Brasil, somente Coréia do Sul, Taiwan, China e México possuem um setor expressivo.

No parque industrial brasileiro coexistem equipamentos relacionados a paradigmas tecnológicos diversos. Em muitos casos, em uma mesma indústria são encontradas máquinas eletromecânicas operando ao lado de outras de comando computadorizado. Já os equipamentos concebidos e produzidos sob encomenda são, em sua maioria, mais sofisticados em termos tecnológicos do que os produzidos em série, para os quais existe uma padronização de projeto (ALEM e PESSOA, 2005).

No ano de 2008, segundo o Instituto Brasileiro de Geografia e Estatística (IBGE), o setor industrial brasileiro em geral, obteve um crescimento acumulado de $3,1 \%$ em sua produção, uma redução quando comparado ao índice de 6,0\%, observado em 2007. O cenário de queda generalizada, ilustrado na segunda e terceira coluna da tabela 1.1 a seguir, foi especialmente marcado pelo movimento de setores mais sensíveis à restrição de crédito e a queda das exportações de commodities, ocasionados por uma crise financeira mundial.

Tabela 1.1 - Indicadores conjunturais da Indústria segundo categoria de uso do ano de 2008

\begin{tabular}{lcccc}
\hline $\begin{array}{c}\text { Indicadores da Produção Industrial por } \\
\text { Categoria de Uso } \\
\text { Dezembro/2008 }\end{array}$ & Mês/Mês & Mensal & Variação (\%) & \multicolumn{2}{c}{$\begin{array}{c}\text { Acumulado } \\
\text { No Ano }\end{array}$} & $\mathbf{1 2}$ meses \\
\hline Bens de Capital & $-\mathbf{2 2 , 2}$ & $\mathbf{- 1 3 , 1}$ & $\mathbf{1 4 , 4}$ & $\mathbf{1 4 , 4}$ \\
Bens Intermediários & $-12,1$ & $-18,2$ & 1,6 & 1,6 \\
Bens de Consumo & $-9,3$ & $-10,2$ & 1,9 & 1,9 \\
Duráveis & $-34,3$ & $-42,2$ & 3,8 & 3,8 \\
Semiduráveis e não Duráveis & $-4,2$ & $-1,8$ & 1,4 & $\mathbf{3 , 1}$ \\
Indústria Geral & $\mathbf{- 1 2 , 4}$ & $\mathbf{- 1 4 , 5}$ & $\mathbf{3 , 1}$ & \\
\hline
\end{tabular}

Fonte: IBGE (2008)

Observa-se na quarta coluna da tabela 1.1, que a maior taxa de crescimento em 2008 ficou com o setor de bens de capital $(14,4 \%)$, única categoria que atingiu dois dígitos. Tais dados indicam, que além de sua importância como propagador de novas tecnologias, o setor de bens de capital influenciam na dinâmica econômica, dada a tendência de crescimento superior aos demais setores que sua produção física apresenta.

Dentre os segmentos que compõem este setor, o segmento responsável pela produção de máquinas e implementos agrícolas é um dos mais tradicionais do país e será o alvo de investigação do presente estudo. 
O segmento agrícola é caracterizado por uma estrutura heterogênea, da qual fazem parte empresas de grande porte, de capital estrangeiro, produtoras de maquinário automotriz, voltadas para o mercado nacional e internacional, mas também empresas de grande e médio porte, de capital nacional, que fabricam implementos agrícolas de tração mecânica tanto para o mercado doméstico quanto para o externo (TATSCH, 2008). Há, ainda, empresas de menor tamanho, de capital nacional, produtoras de equipamentos de menor complexidade, voltados para o mercado nacional, principalmente para o regional.

Segundo dados de março de 2009 divulgados pelo IBGE, constantes na tabela 1.2, o segmento agrícola apresentou um crescimento acumulado nos últimos doze meses de 11,53\%, enquanto que setor de bens de capital como um todo obteve crescimento de $4,9 \%$ e a indústria geral, um recuo de $1,9 \%$.

Tabela 1.2 - Produção física dos segmentos do setor de bens de capital em março de 2009

\begin{tabular}{lccc}
\hline \multicolumn{1}{c}{ Bens de Capital - Índices Conjunturais da Indústria } \\
\multicolumn{1}{c}{$\begin{array}{c}\text { Março/2009 } \\
\text { Segmentos }\end{array}$} & Mensal & \multicolumn{2}{c}{$\begin{array}{c}\text { Variação (\%) } \\
\text { Acumulada } \\
\text { No Ano }\end{array}$} \\
\hline Bens de Capital Para Fins Industriais & $-29,75$ & $-30,23$ & $-5,45$ \\
Bens de Capital Para Fins Industriais Seriados & $-33,74$ & $-35,02$ & $-8,20$ \\
Bens de Capital Para Fins Industriais Não-Seriados & $-4,38$ & $-1,04$ & 13,22 \\
Bens de Capital Agrícolas & $\mathbf{- 3 2 , 3 7}$ & $\mathbf{- 3 2 , 5 9}$ & $\mathbf{1 1 , 5 3}$ \\
Bens de Capital Peças Agrícolas & $-29,80$ & $-37,66$ & 23,14 \\
Bens de Capital para Construção & $-68,90$ & $-71,30$ & $-14,94$ \\
Bens de Capital para o Setor de Energia Elétrica & $-51,79$ & $-31,44$ & 0,68 \\
Bens de Capital Equipamentos de Transporte & $-3,09$ & 1,48 & 23,86 \\
Bens de Capital de Uso Misto & $-24,13$ & $-27,60$ & $-5,67$ \\
Bens de Capital Geral & $\mathbf{- 2 3 , 0 0}$ & $\mathbf{- 2 0 , 8 0}$ & $\mathbf{4 , 9 0}$ \\
Indústria Geral & $\mathbf{- 1 0 , 0 0}$ & $\mathbf{- 1 4 , 7 0}$ & $\mathbf{- 1 , 9 0}$ \\
\hline
\end{tabular}

Fonte: Adaptado de IBGE (2009)

Apesar do crescimento supracitado, estudos como o de Brandão (2003) e Zago (2008) indicam que o segmento de bens de capital agrícolas enfrenta dificuldades para sustentar sua expansão produtiva. Entre os principais problemas detectados pelos estudos, destaca-se a necessidade de que as empresas do segmento obtenham excelência na execução de atividades relacionadas à logística.

Competência na gestão logística atua como resposta às pressões que as empresas do segmento sofrem em relação à necessidade de redução dos níveis de estoque devido aos elevados custos de mantê-los, a necessidade de redução do prazo de entrega e aumento da disponibilidade dos produtos aos clientes. Especificamente neste segmento, o ambiente 
econômico e demanda influem de forma rigorosa no processo decisório de coordenação de várias atividades associadas à logística, como localização geográfica, armazenagem, disponibilização de recursos para a fabricação e distribuição final.

Ao considerar as atividades logísticas como de alta relevância na agregação de valor para a empresa e seus clientes, o desenvolvimento de um bom processo de monitoramento de desempenho é fundamental para o seu gerenciamento. Para Keebler et al. (1999), medição é fator chave no sistema de controle gerencial e seu meticuloso uso e aplicação são essenciais para o sucesso das empresas. Fawcett e Clinton (1996) afirmam que, as empresas de classe mundial reconhecem o papel central da medição em suas atividades, considerando-a como competência necessária para se obter a excelência em gestão e vantagem competitiva frente ao mercado.

A medição de desempenho tem um importante papel na gestão dos negócios, ao prover as informações necessárias para a tomada de decisões. Para Gunasekaran e Kobu (2007) e Griffis et al. (2007) o propósito da medição de desempenho organizacional é identificar as necessidades dos consumidores e ajudar as empresas a entender e identificar problemas em seus processos. Os autores afirmam, porém que em muitos casos as empresas falham ao considerar apenas as tradicionais medidas de desempenho, fortemente ligadas a informações financeiras e deixam de considerar medidas necessárias a compreensão do novo ambiente econômico.

Sobre a implementação da medição de desempenho, Neely, Gregory e Platts (2005) afirmam que o processo exige um trabalho criterioso, cuidadoso e abrangente, sob o risco de que os recursos nele despendidos não tragam os benefícios que podem ser esperados de bons sistemas de medição. Com isto, defende-se que o esforço empreendido na escolha das medidas pode trazer ainda um ganho indireto, uma vez que obriga os gerentes das organizações a pensarem, discutirem e explicitarem suas prioridades de desempenho, alinhando opiniões e percepções antes antagônicas.

Diante do exposto sobre a importância da definição de um conjunto de indicadores condizentes com as necessidades das empresas e do papel direcionador que a medição de desempenho exerce sobre a atividade logística das empresas, têm-se como questão de pesquisa:

Quais são os indicadores de desempenho logístico e como estes se inserem no processo de medição de desempenho adotado por empresas do setor de bens de capital agrícolas? 


\subsection{Objetivos}

Como objetivo principal, a pesquisa buscou identificar, caracterizar e analisar os indicadores de desempenho logístico utilizados por empresas do setor de bens de capital agrícolas. Visando o alcance do objetivo principal e colaborar para uma discussão mais ampla sobre o assunto buscou-se também, identificar e analisar a prática de medição de desempenho adotadas por estas empresas.

Especificamente, buscou-se:

- Por meio de uma revisão bibliográfica, identificar na literatura as características fundamentais e boas práticas da medição de desempenho;

- Propor com base na revisão bibliográfica, uma classificação para os indicadores e uma estrutura de análise para o processo de medição de desempenho logístico das empresas do setor;

- Por meio de estudo de múltiplos casos com empresas do segmento, identificar indicadores comuns ao setor e as práticas de medição de desempenho adotadas por estas empresas.

\subsection{Justificativas}

A execução da presente pesquisa pode ser justificada por meio das afirmações de autores como Gunaserakaran e Kobu (2007) de que indicadores de desempenho são essenciais para a gestão das operações logísticas, de Bowersox, Closs e Copper (2006), ao destacarem que empresas empenhadas numa avaliação de desempenho abrangente obtêm melhoria na produtividade geral e nas constatações de Fawcett e Clinton (1997) sobre a existência de uma alta correlação entre níveis superiores de desempenho logístico e o uso de sofisticados métodos de avaliação de desempenho.

A pesquisa tem relevância tanto em sua dimensão teórica quanto no aspecto prático, pois ao se utilizar os casos de empresas de destaque no segmento de bens de capital agrícolas, espera-se que os resultados apontados sirvam para empresas menos estruturadas deste segmento, direcionarem avanços nos seus processos logísticos, obtendo-se assim um maior desenvolvimento de um setor tão representativo para nosso país, detentor da vocação de exportador de commodities agrícolas.

Cabe ainda ressaltar que a pesquisa em tela pertence ao quadro de projetos do Instituto Fábrica do Milênio (IFM), organização que agrega mais de 800 pesquisadores em diversas 
instituições de ensino superior e que tem em seu perfil de atuação, a pesquisa em manufatura voltada para as necessidades nacionais da indústria. O projeto Instituto Fábrica do Milênio II (IFM II) ao qual esta pesquisa é vinculada visou o estudo do setor de bens de capital e teve como propósito principal pesquisar, desenvolver e disseminar de forma integrada e colaborativa um corpo de conhecimento capaz de contribuir para a busca de sustentabilidade em nível mundial à cadeia produtiva brasileira de bens de capital.

\subsection{Desenvolvimento da pesquisa}

Para atingir os objetivos expostos, o desenvolvimento da pesquisa foi divido em três fases. Na primeira fase foi realizada uma revisão bibliográfica junto às principais bases de dados sobre os temas do estudo: logística e medição de desempenho. Na segunda fase, referente ao levantamento de dados, a revisão bibliográfica efetuada foi base para a proposição de uma estrutura para análise dos indicadores e práticas de medição de desempenho e também para o desenvolvimento e aplicação do roteiro de entrevista. Na terceira fase da pesquisa, a relação de indicadores e práticas de gestão destes indicadores obtidas nos casos foram confrontadas com as recomendações da literatura, para que os indicadores e as práticas do processo de medição de desempenho comuns ao segmento em estudo pudessem ser caracterizados e analisados. A figura 1.1 apresentada a seguir, ilustra esquematicamente os passos de desenvolvimento da pesquisa.

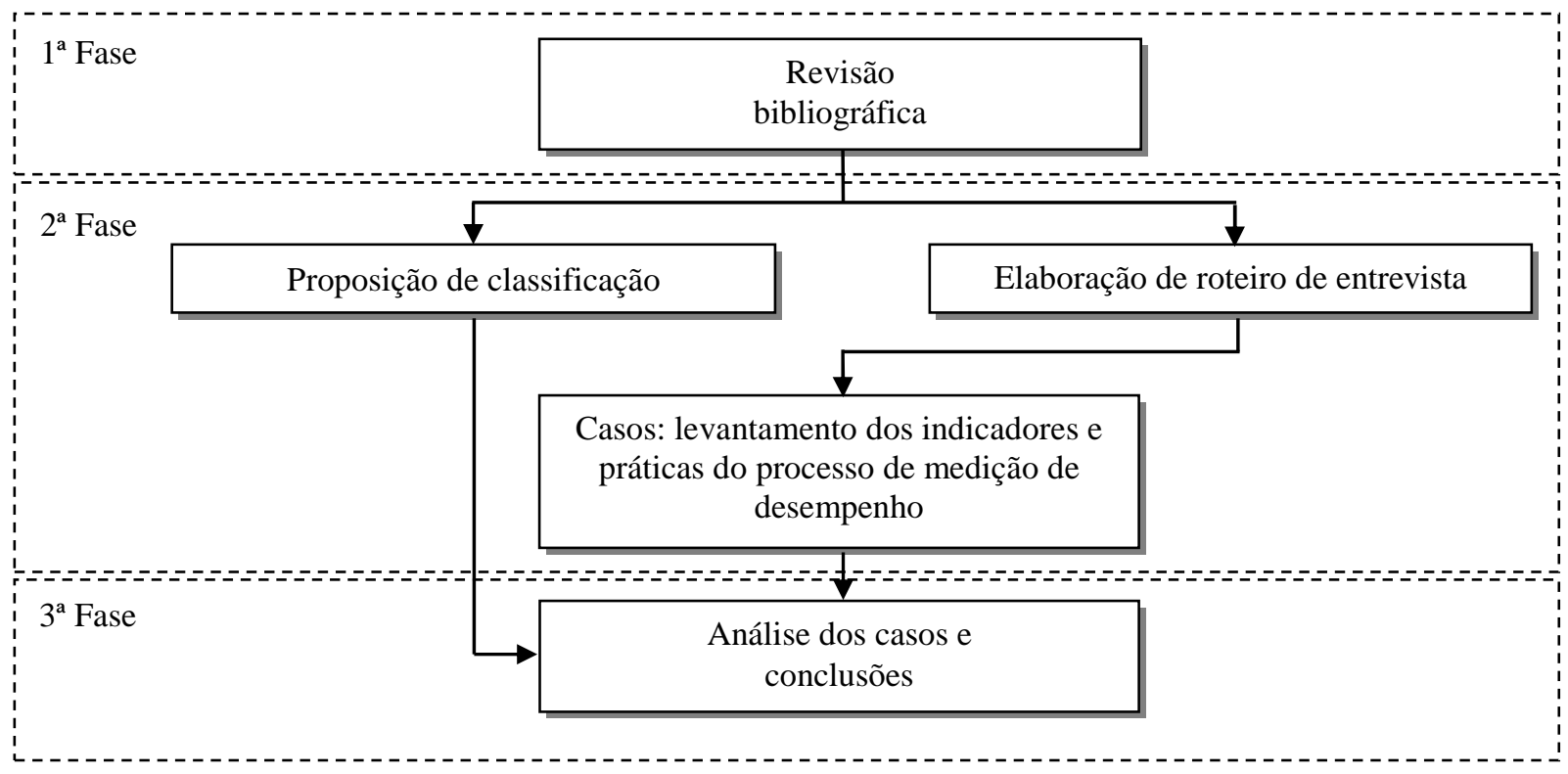

Figura 1.1 - Desenvolvimento da pesquisa 


\subsection{Estrutura do trabalho}

Além deste capítulo introdutório que apresentou os aspectos fundamentais da investigação científica, como problema e questões de pesquisa, objetivos, justificativas e o método de desenvolvimento da pesquisa, esta dissertação é composta por mais seis capítulos.

A revisão bibliográfica está divida em dois capítulos. O capítulo 2 apresenta as principais definições de logística, seu campo de atuação e seu papel estratégico junto às empresas. Modelos de estruturação estratégica apontam a importância da excelência logística para a competitividade das empresas e de suas áreas-chaves constituintes, entre elas a medição de desempenho.

O capítulo 3 descreve os principais conceitos sobre medição de desempenho. Contempla a evolução histórica e seu desdobramento para abordagens mais atuais dos Sistemas de Medição de Desempenho (SMDs). De uma visão mais ampla para uma mais específica, apresenta-se na seqüência, a revisão bibliográfica sobre medição de desempenho na logística. Características relevantes para a medição de desempenho das atividades logísticas são apontadas por autores da área. Exemplos de indicadores utilizados nos processos logísticos são também apresentados e servirão de base para a análise dos dados e conclusão do estudo. Objetivou-se com esta revisão mostrar a relevância da medição de desempenho para a formulação de estratégias e a tomada de decisões dos gestores da atividade logística.

No capítulo 4, é apresentada a metodologia adotada no desenvolvimento da pesquisa, expõe-se suas características e principais fases de execução, por meio da definição da amostra, instrumento de coleta de dados e a forma de tratamento e análise dos resultados da pesquisa.

O capítulo 5 apresenta a descrição dos dados obtidos na pesquisa de campo junto a cinco empresas do setor de bens de capital agrícola.

No capítulo 6 é exposta a análise dos dados, apontando as principais tendências, obtidas pelo confronto dos dados com as recomendações da literatura.

E no capítulo 7, apresenta-se as conclusões da pesquisa, suas contribuições e sugestões para trabalhos futuros. 


\section{LOGÍSTICA}

O presente capítulo tem como objetivo apresentar abordagens existentes na literatura sobre a evolução da atividade logística, definições de seu escopo de atuação, sua importância na estratégia das organizações e modelos de estruturação estratégica que apontam requisitos gerenciais que devem ser considerados na obtenção de um diferencial competitivo.

\subsection{Evolução do conceito e atividade logística}

Para La Londe (1994) um dos desafios de se escrever sobre a evolução do conceito da logística, esta em determinar o seu princípio. Na literatura da área não há consenso na determinação de uma data ou fato que aponte seu início. Em relação à origem do termo, La Londe (1994) afirma que este trata-se de uma variação do termo francês logistique, título dado a um oficial do exército de Napoleão Bonaparte, responsável pelo aquartelamento das tropas e pela busca de forragem para cavalos e outros animais.

Autores como Bowersox, Closs e Copper (2006), Ballou (2006) e Christopher (2007) apontam que até os anos 50, funções hoje aceitas como logísticas eram geralmente vistas como trabalho de apoio ou facilitação. Atividades-chave em logística estavam fragmentadas pela empresa. Transporte era encontrado freqüentemente sob controle gerencial da produção; os estoques eram responsabilidade de marketing, finanças ou produção e o processamento de pedidos era comandado por finanças ou vendas.

Em um melhor detalhamento desta evolução, Wood e Zuffo (1998) e Figueiredo e Arkader (2000), com semelhante posicionamento dividem a evolução logística em fases. Tais abordagens se complementam, permitindo que se trace um panorama da evolução do conceito e das funções relacionadas à atividade logística.

A primeira fase teve seu início na virada para o século XX, sendo a economia agrária sua principal influência teórica. A preocupação central, nesta fase, era com questões de transporte para o escoamento da produção agrícola. A segunda fase estendeu-se de 1940 ao início da década de 60. O pensamento logístico estava voltado para a identificação dos principais aspectos da eficiência no fluxo de materiais, em questões relacionadas à gestão de estoques, compras, armazenagem e transporte, tratadas separadamente no contexto da distribuição de bens. A terceira era foi do início da década de 60 até os primeiros anos da década de 70. É o começo de uma visão integrada nas questões logísticas, explorando-se 
aspectos como custo total e abordagem de sistemas de informações. O foco deixa de recair na distribuição física para englobar um espectro mais amplo de funções, sob a influência da economia industrial. A era seguinte, estendendo-se do início dos anos 70 até meados dos anos 80, corresponde ao "foco no cliente", com ênfase na aplicação de métodos quantitativos às questões de produtividade logística. É neste período que se irá identificar uma intensificação do interesse pelo ensino e pesquisa nas escolas de administração.

A quinta fase que vai de meados da década de 80 até o presente, tem ênfase estratégica, como indica a denominação que lhe foi dada: "Logística como elemento diferenciador". Tem como perspectiva a gestão da cadeia de suprimentos, Supply Chain Management (SCM), acrescido do Efficient Customer Response (ECR), termo traduzido por resposta eficiente ao consumidor e que se refere a um conjunto de metodologias que visam diminuir as barreiras entre parceiros comerciais. Nessa fase o foco é mais abrangente e aplicase no amplo uso de alianças estratégicas, sub-contratação e canais alternativos de distribuição.

A figura 2.1 sintetiza estas abordagens em ordem cronológica.

\begin{tabular}{|c|c|c|c|c|c|}
\hline 1900 & $\begin{array}{c}1950 \\
\perp \\
\end{array}$ & $\begin{array}{c}1960 \\
+ \\
\end{array}$ & $\begin{array}{c}1980 \\
\perp \\
\end{array}$ & $\begin{array}{c}1990 \\
\perp \\
\end{array}$ & $\begin{array}{c}2000 \\
\perp \\
\end{array}$ \\
\hline $\begin{array}{l}\text { Era do "campo } \\
\text { ao mercado" }\end{array}$ & $\begin{array}{c}\text { Era da } \\
\text { especialização }\end{array}$ & $\begin{array}{c}\text { Era da integração } \\
\text { interna }\end{array}$ & $\begin{array}{l}\text { Era do foco no } \\
\text { cliente }\end{array}$ & Era & \\
\hline $\begin{array}{c}\text { Escoamento da } \\
\text { produção } \\
\text { agrícola }\end{array}$ & Funções segmentadas & \multicolumn{2}{|c|}{ Logística Integrada } & Supply Ch & ement \\
\hline $\begin{array}{l}\text { Foco: } \\
\text { - Transporte } \\
\text { - }\end{array}$ & $\begin{array}{l}\text { Foco: } \\
\text { - Gestão de estoques } \\
\text { - Gestão de compras } \\
\text { - Gestão de materiais } \\
\text { - Otimização do sistema de } \\
\text { transporte }\end{array}$ & \multicolumn{2}{|c|}{$\begin{array}{l}\text { Foco: } \\
\text { - Visão sistêmica } \\
\text { - Integração por sistemas de } \\
\text { informações }\end{array}$} & $\begin{array}{l}\text { Foco: } \\
\text { - Visão sist } \\
\text { de fornece } \\
\text { distribuiç̧̃ } \\
\text { - Alianças e } \\
\text { parcerias } \\
\text { - ECR }\end{array}$ & $\begin{array}{l}\text { inclusão } \\
\text { hais de } \\
\text { e }\end{array}$ \\
\hline
\end{tabular}

Figura 2.1 - Evolução da logística

Fonte: Adaptado de Wood e Zuffo (1998) e Figueiredo e Arkader (2000)

A vertente mais atual do pensamento em logística é o de SCM. Ela conjuga os processos logísticos que tratam do fluxo de materiais dentro e fora das empresas, com os relacionamentos que surgem ao longo da cadeia para assegurar seus melhores resultados em termos de redução de desperdício e agregação de valor. Segundo Cooper, Lambert e Pagh (1997) a força motriz por trás da gestão da cadeia de suprimentos é o reconhecimento da tendência à sub-otimização, em que cada empresa dentro da cadeia de abastecimento deixa de preocupar-se em otimizar seus próprios resultados e passa a integrar metas e atividades com as outras para a ampliação dos resultados da cadeia. 
Ao lidar com os relacionamentos entre empresas, Figueiredo e Arkader (2000) afirmam que é natural que o pensamento logístico aborde como questão afim, as parcerias e alianças estratégicas logísticas. Essas estratégias colaborativas promovem a união de forças de empresas - cliente e fornecedor, cliente e cliente ou fornecedor e fornecedor, visando explorar as atividades logísticas em busca de vantagens mútuas.

Segundo Bowersox, Closs e Cooper (2006) a logística serve para relacionar e sincronizar a cadeia de suprimentos geral em um processo contínuo e é essencial para a conectividade efetiva da cadeia de suprimentos. Para os autores, enquanto a finalidade da logística se mantém essencialmente a mesma nas últimas décadas, a maneira pela qual o trabalho é desempenhado continuará a mudar rumo à adequação as necessidades do mercado.

\subsection{Definições e áreas de atuação da logística}

Como mencionado, o conceito de logística evoluiu ao longo dos anos e ainda hoje há dificuldade na compreensão do limite e do papel das funções que englobam esta atividade. Cabe, a presente seção destacar algumas das definições dadas à logística pela literatura.

Definições apresentadas por Lambert, Stock e Vantine (1998), Ballou (2006) e Christopher (2007) se assemelham em muitos aspectos a oferecida pelo Council of Supply Chain Management Professionals (CSCMP) em 2009. A síntese comparativa de tais abordagens apresenta como definição comum, logística como o processo que planeja, implementa e controla o fluxo de produtos e informações associadas, do ponto de origem ao ponto de consumo, com o objetivo de atender as exigências dos consumidores.

Uma outra definição, baseada em uma visão sistêmica, é dada por Bowersox e Closs (2001). Para os autores, as empresas capazes de desenvolver eficazmente a atividade logística, apresentarão um diferencial competitivo no futuro, bem como concentrarão na integração o fator determinante para o desenvolvimento de seus potenciais logísticos. Para que possa ser gerenciada de forma integrada, a logística deve ser tratada como um sistema, ou seja, um conjunto de componentes interligados, trabalhando de forma coordenada, voltado ao atendimento de um objetivo comum. Neste contexto Bowersox e Closs (2001) definem a logística integrada como uma competência que vincula a empresa a seus clientes e fornecedores. A figura 2.2 ilustra a definição apresentada por estes autores, indicando os pontos de conexão da logística com clientes e fornecedores. 


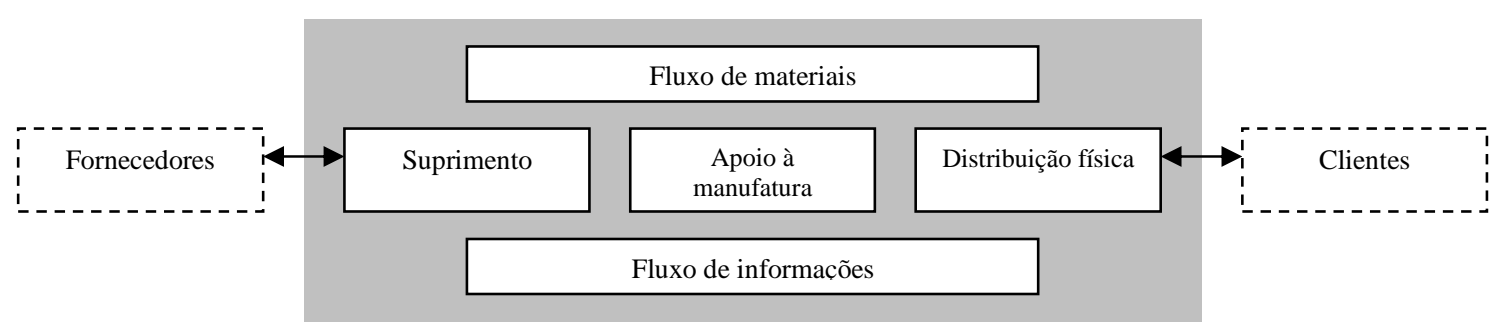

Figura 2.2- Logística integrada

Fonte: Bowersox e Closs (2001)

Informações recebidas de clientes e sobre eles fluem por meio das atividades de venda, previsões de demanda e pedidos. Estas informações são filtradas em ordens de compra e produção, que geram conseqüentemente o abastecimento de produtos e materiais. Junto a estes materiais são criados valores através de suas transformações no processo produtivo, resultando em produto acabado ao cliente, correspondendo ao fluxo de material.

A definição apresentada por Bowersox e Closs (2001) remete ainda a caracterização das áreas de atuação da logística. A gestão da logística pode ser dividida em três funções. Estas funções, apresentadas na figura 2.2, são: suprimento, apoio à manufatura e distribuição (PIRES, 2001; BOWERSOX e CLOSS, 2001). Segundo Ballou (1993) estas são atividades consideradas primárias, por serem essenciais a coordenação e cumprimento dos objetivos logísticos de custo e nível de serviço.

A função de suprimento, também conhecida como logística inbound, está relacionada com as atividades de obtenção de produtos e matérias de fornecedores externos, que têm como objetivo principal dar apoio à produção ou à revenda, proporcionando compras em tempo hábil, ao menor custo total. Responsabiliza-se pela execução do planejamento de recursos, localização de fontes de suprimento, negociação, colocação de pedidos, transporte de saída, recebimento e inspeção, armazenagem e manuseio e garantia da qualidade e também pela coordenação com fornecedores em áreas como programação, continuidade de suprimento e investigação, assim como pesquisas que levem a novas fontes ou programas de suprimentos.

A função de apoio à manufatura, também denominada como logística interna relaciona-se com atividades de planejamento, programação e apoio às operações de produção. Incluem o planejamento do programa mestre e a execução de atividades de armazenagem do estoque semi-acabado, manuseio, transporte e seqüenciamento de componentes, responsabilizando-se pela armazenagem de estoque em locais de fabricação e pela máxima flexibilidade na coordenação de postergação, tanto de montagem final quanto geográfica, entre operações de produção e distribuição. 
A função de distribuição ou logística outbound são as atividades associadas à coleta, armazenamento e distribuição de produtos para clientes, incluindo assim, recebimento e processamento de pedidos, posicionamento de estoques, armazenagem e manuseio e transporte dentro de um canal de distribuição. Segundo Ballou (1993), esta costuma ser a atividade mais importante em termos de custo para a maioria das empresas e sendo assim seu principal objetivo é ajudar na geração de receita, prestando níveis estrategicamente desejados de serviço ao cliente, ao menor custo total. $\mathrm{O}$ auxílio na coordenação do planejamento de marketing em áreas como formação de preços, apoio promocional, níveis de serviço ao cliente, padrões de entrega, manuseio de mercadorias devolvidas e apoio ao ciclo de vida correspondem a algumas das responsabilidades atribuídas a esta função.

\subsection{Logística no setor de bens de capital agrícolas}

As empresas alvo desta pesquisa têm suas vendas atreladas ao volume de recursos e às condições do crédito agrícola, tal característica tem efeito direto sobre a atividade logística. Devido à crescente internacionalização e ao aumento das exportações, criou-se a necessidade por uma logística mais eficiente e sofisticada, principalmente na gestão de estoques, a qual exige maior exatidão na previsão da demanda de produtos (PASQUAL e PEDROZO, 2007).

Em um levantamento desenvolvido junto a empresas do setor, Brandão (2003) identificou que entre as principais dificuldades enfrentadas pelas empresas, está presente a questão logística, caracterizada pelo alto custo da atividade e maior exigência nos prazos de entrega. O quadro 2.1, apresenta este levantamento.

\begin{tabular}{|l|c|c|}
\hline Principais dificuldades & Citações & $\mathbf{\%}$ \\
\hline 1. Necessidade de redução de custos & $\mathbf{5 8}$ & $\mathbf{2 3 , 4}$ \\
\hline 2. Aumento do nível de concorrência & 32 & 12,9 \\
\hline 3. Diferenças tributárias & 19 & 7,7 \\
\hline 4. Maior exigência de prazo de entrega & $\mathbf{1 8}$ & $\mathbf{7 , 3}$ \\
\hline 5. Necessidade de inovação & 18 & 7,3 \\
\hline 6. Custos de logística & $\mathbf{1 4}$ & $\mathbf{5 , 6}$ \\
\hline 7. Falta de capacidade de produção & 13 & 5,2 \\
\hline 8. Falta de qualidade assegurada & 9 & 3,6 \\
\hline 9. Falta de volume de produção & 9 & 3,6 \\
\hline 10. Concorrência de produtos importados & 8 & 3,2 \\
\hline
\end{tabular}

Quadro 2.1 - Principais dificuldades das empresas do segmento de bens de capital agrícolas Fonte: Brandão (2003) 
Ainda segundo este autor, o estudo permite concluir que entre as principais deficiências das empresas do segmento estão: a baixa integração horizontal e vertical, a falta de posicionamento de mercado, a baixa capacitação em gestão de custos e qualidade e a baixa eficiência logística. Tais afirmações reforçam, portanto o exposto por autores como Pasqual e Pedrozo (2007) e Zago (2008) sobre a importância de um adequado posicionamento da atividade logística nestas empresas.

Zawislak (2000), Castro (2004), Pasqual e Pedrozo (2007) e Zago (2008) em estudos desenvolvidos junto ao segmento, identificaram em seus resultados características peculiares da atividade logística destas empresas. Algumas delas são descritas a seguir:

- A cadeia logística do segmento, apresentada na figura 2.3, é composta por cinco elos, dos fornecedores de matérias-primas e componentes até o consumidor final, que na maioria das vezes, adquire os produtos por intermédio de revendedores.

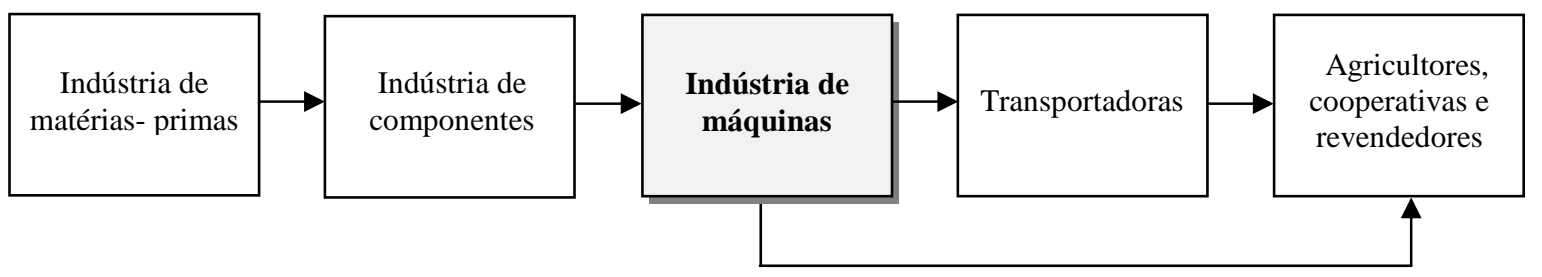

Figura 2.3 - Cadeia logística do setor de bens de capital agrícolas Fonte: Adaptado de Zawislak (2000)

- As empresas do segmento apresentam deficiência na gestão do ciclo de pedidos, devido a oscilações e peculiaridades da cadeia agroindustrial, que torna difícil a acuracidade na previsão e gerenciamento da demanda e que impacta no planejamento da produção destinada aos mercados e gerenciamento dos pedidos, estoques e volume de produção. Devido à diversidade de mercados atendidos, há uma prioridade de produção de acordo com o destino do produto, devendo ser respeitado o lead e o transit time, do mesmo, pelas diferentes áreas das empresas. Essa perspectiva se reflete na gestão de estoques e armazenagem, no momento em que as empresas possuem itens faltantes (críticos), ou mesmo que possam vir a faltar, quando ocorre uma replanejamento da produção e das necessidades de materiais;

- Sobre a função de apoio à produção tem-se que a decisão de coordenação do fluxo de produtos, nas empresas de grande porte, é totalmente puxada; nas pequenas, a maior parte das decisões é tomada partindo do consumidor final (puxada), mas 
com uma parcela de participação do elo inicial da cadeia (empurrada); nas de porte médio, as decisões são fortemente baseadas no elo inicial da cadeia que coordena o fluxo (empurrada), isto é, a coordenação reage fortemente às informações de um cliente principal, ou seja, de uma demanda real de venda em tempo real (visibilidade da demanda);

- O acionamento da fabricação de produtos acabados, relacionada à definição da política de produção das empresas, verificou-se que: nas empresas de grande porte, independentemente do produto, o planejamento do fluxo de produtos é totalmente baseado no pedido feito pelo cliente. Esses resultados se justificam na medida em que, quando o produto tem um custo elevado, existe uma maior propensão para produzir contrapedido;

- A decisão de alocação de estoques, com base no número de instalações em que são armazenados os produtos, independentemente do porte das empresas do setor, a decisão está basicamente voltada à centralização. Isso em virtude de o giro de estoques serem baixos e de a perecibilidade e obsolescência dos produtos não acarretarem necessariamente em encalhe ou perda;

- A localização destas empresas, concentradas na Região Sul do país e no estado de São Paulo, deve-se aos benefícios logísticos da proximidade com os principais consumidores destes equipamentos, entre eles os países do Mercosul e com importantes portos brasileiros, utilizados tanto para o escoamento da produção agrícola quanto para o recebimento de componentes para as indústrias;

- Na estratégia de distribuição, comercialização e serviços de pós-venda e assistência técnica, há uma rede de concessionárias espalhadas por diferentes regiões brasileiras, estando próximas dos clientes e dos grandes centros produtores. Os clientes da região centro-oeste são os principais consumidores, em virtude de ser um produtor aliado aos estados do sul do país;

- Quanto maior o nível de complexidade e porte da organização maior sua preocupação com áreas como materiais e integração entre as áreas da empresa, sejam elas compras, logística e distribuição, marketing e vendas, financeiro e produção, visando gerar benefícios não só a empresa, mas ao cliente final e quanto menor o volume de atividades e de produção a empresa está mais próxima dos clientes finais, procurando estabelecer parcerias para atrair e reter seus clientes, bem como conscientizar seus fornecedores do seu potencial competitivo; 
- Tem-se ainda que empresas maiores apresentam uma rede de informação e conhecimento maior, devido a integração da unidades brasileiras às demais fábricas do grupo e a matriz, havendo preocupação na precisão das informações e no aprimoramento dos colaboradores, tendo em vista a perspectiva de crescimento na empresa.

Verifica-se, portanto que a logística deve ser adotada como resposta às pressões que as empresas sofrem em relação à necessidade de redução dos níveis de estoque devido aos elevados custos de mantê-los, a necessidade de redução do prazo de entrega e aumento da disponibilidade dos produtos aos clientes. Especificamente no segmento estudado, o ambiente econômico e demanda influem de forma rigorosa no processo decisório de localização geográfica, armazenagem e disponibilização de recursos à fabricação e distribuição final.

\subsection{Logística como fonte de vantagem competitiva}

Mudanças econômicas e nas expectativas dos clientes transformaram a natureza dos mercados, gerando alterações no fluxo de mercadorias e informações dentro das empresas. Neste ambiente, Fleury (2000) afirmam que a logística deixou de ser apenas uma ferramenta gerencial, para se tornar também uma importante atividade econômica, que contribui de forma significativa para a estrutura de custos das empresas, assim como para o desenvolvimento das nações.

A logística adiciona valor para o cliente. Um produto ou serviço tem pouco valor se não estiver disponível aos clientes no tempo e no lugar em que eles desejam consumi-lo. Quando uma empresa incorre em custos para movimentar os produtos em direção aos clientes ou tornar um estoque disponível de maneira oportuna, o valor que não estava lá antes foi criado para o cliente. Para Ballou (2006), esse valor é tão seguro quanto aquele criado através da produção de um produto de qualidade ou através de preço baixo.

A logística é importante para a estratégia da empresa. Quando a gerência reconhece que a logística afeta uma parte significativa dos custos da empresa e que o resultado das decisões tomadas sobre a cadeia de suprimentos leva a altos níveis de serviços ao cliente, ela está em condições de usá-la de maneira eficaz para penetrar em novos mercados, ampliar sua participação no mercado e elevar os lucros (FLEURY, 2000; BALLOU, 2006). 
Bowersox e Closs (2001) afirmam que empresas que desfrutam de competência logística conseguem ganhar vantagem competitiva proporcionando aos clientes um serviço superior. E embora seja difícil atender aos pedidos de maneira perfeita, quando empresas apresentam desempenho acima da média em termos de disponibilidade de estoque, velocidade e consistência de entrega, passam a ser vistas como fornecedores e parceiros ideais. Para Porter (1992) a concorrência está na essência do sucesso ou do fracasso das empresas, determinando a adequação das atividades que podem contribuir para seu desempenho.

Porter (1992) aponta em seu livro "Vantagem Competitiva", as fontes de vantagens competitivas por meio do modelo de cadeia de valores. Neste modelo ilustrado pela figura 2.4, o autor identifica as atividades de valor de uma empresa. Atividades que quando bem geridas podem criar valor ao cliente. Segundo o autor estas atividades podem ser classificadas em primárias e de apoio.

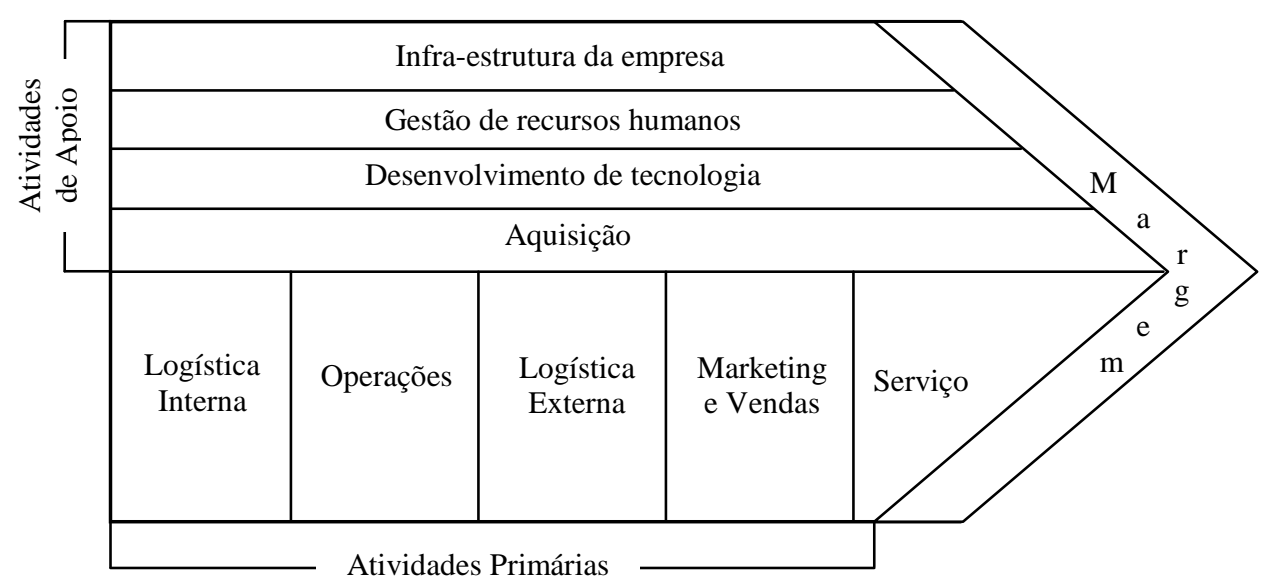

Figura 2.4 - Cadeia de valores

Fonte: Porter (1992)

As atividades primárias estão relacionadas com a criação do produto/serviço e sua transferência ao cliente e contemplam: a logística interna, as operações, a logística externa, marketing/vendas e serviços. As atividades de apoio atuam como suporte as atividades primárias, sendo responsáveis pela infra-estrutura da empresa, pela aquisição e gestão de recursos humanos e insumos e pelo desenvolvimento e disseminação de tecnologia.

Percebe-se na presente abordagem o destaque dado por Porter a atividade logística. Neste sentido Bowersox e Closs (2001) apontam que para explorar eficazmente a sua competência logística, uma empresa deve considerar uma ampla variedade de fatores operacionais que necessitam ser sincronizados a fim de se criar uma estratégia integrada. Sob o mesmo ponto de vista, Daugherty, Ellinger e Gustin (1996) afirmam que a utilização da logística como fonte de vantagem competitiva pelas empresas baseia-se no seu gerenciamento 
de forma integrada. Para os autores o gerenciamento integrado dos diversos componentes do sistema logístico é uma condição necessária para que as empresas consigam atingir excelência operacional com baixo custo. Para atingir esse objetivo, as empresas necessitam conhecer muito bem os trade-offs inerentes à sua operação logística e possuir sistemas e organização adequados para tomar as decisões de forma integrada.

Stock e Lambert (1992) definem empresas de excelência como aquelas que fornecem um produto de qualidade acompanhado de serviço superior ao consumidor a um preço competitivo. Já para ser um competidor de classe mundial requer compromisso com a excelência e o reconhecimento de que a empresa não pode ser boa em tudo, mas deve realizar poucas coisas excepcionalmente bem. Para compreensão de como a estruturação de estratégias pode se dar na logística, apresenta-se a seguir modelos que sugerem práticas gerenciais que direcionam as empresas a excelência logística.

\subsection{Modelos de estruturação estratégica logística}

Diversos modelos presentes na literatura como os de Andersen Consulting (1989), Bowersox et al. (1992), Michigan State University (1995), Fawcett e Clinton (1996), Bowersox e Closs (1997), Morash (2001) e Lapide (2006) buscam estabelecer as ações necessárias que conduzem as atividades logísticas para o alto desempenho e o alinhamento com as estratégias organizacionais. Denominados também como modelos de excelência, segundo Musetti (2000) estes modelos indicam os requisitos gerenciais, técnicos e infraestruturais que aliados ao envolvimento estratégico dos processos logísticos, podem levar às organizações a obterem um diferencial competitivo frente à concorrência. Devido ao enfoque mais detalhado que dão para o tema central desta pesquisa, medição de desempenho, apresenta-se nas próximas seções os modelos de Michigan State University (1995), de Fawcett e Clinton (1996) e de Bowersox e Closs (1997).

\subsubsection{Modelo de Michigan State University}

O modelo proposto pelo Global Logistics Research Team (GLRT) da Michigan State University é componente de uma série de pesquisas desenvolvidas desde 1986, com o objetivo de estudar fatores que determinam ou influenciam a qualidade da prática logística.

A primeira pesquisa realizada teve como objetivo entender o que constituía a melhor prática na então emergente disciplina da logística. A pesquisa resultou em 1989, na 
publicação do livro "Leading Edge Logistics". Os autores conseguiram evidências para validar suas hipóteses de que a melhor prática logística era extremamente similar independentemente da indústria, posição no canal de distribuição e tamanho da empresa. Outro resultado da pesquisa foi o desenvolvimento de um modelo denominado "The leading edge best practice".

A segunda pesquisa, publicada em 1992, buscou fundir as capacitações gerais das empresas líderes em desempenho logístico em um modelo relacional que poderia servir aos gerentes como um guia na renovação da logística. O resultado da pesquisa foi publicado no livro "Logistical Excellence: It's not business as usual" (MICHIGAN STATE UNIVERSITY, 1995).

A pesquisa que derivou o modelo apresentado nesta seção foi iniciada em 1993 e publicada em 1995 sob o título "World Class Logistics: the challenge of managing continuous change" e tinha como objetivos: compreender aspectos fundamentais da performance logística superior, verificar se esta melhor prática podia ser generalizada através das fronteiras nacionais e ambientes culturais; entender como os gerentes implementam com sucesso mudanças de alto impacto; e finalmente desenvolver evidência factual e circunstancial para dar suporte à discussão de que faz diferença ter uma logística de classe mundial (MICHIGAN STATE UNIVERSITY, 1995). O modelo resultante desta pesquisa identificou quatro competências que levam as organizações a praticarem a atividade logística em padrões de classe mundial. A figura 2.5 representa este modelo conhecido como "World Class Logistics" e suas dimensões.

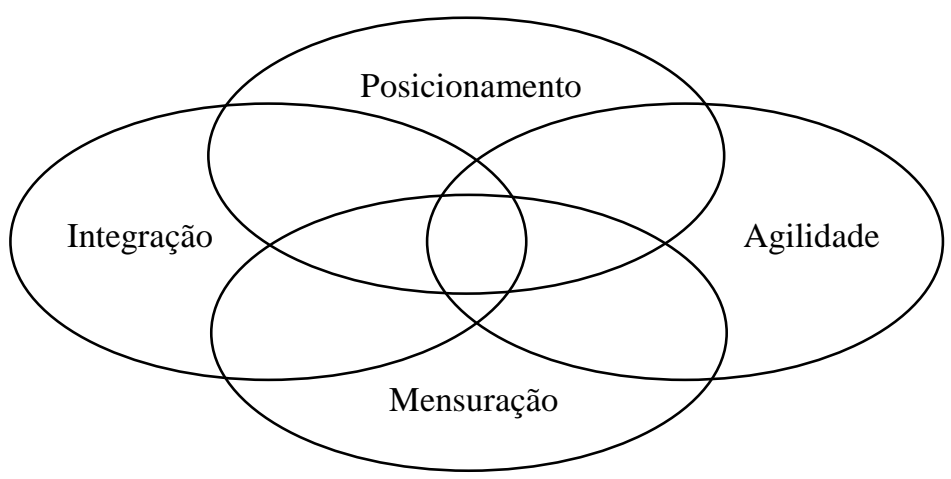

Figura 2.5 - Modelo de competência logística de Michigan State University Fonte: Michigan State University (1995)

No modelo destacam-se as competências: posicionamento, integração, agilidade e mensuração. Para os autores do modelo, o desempenho logístico de classe mundial é resultado 
de um alto nível de desempenho ou da busca em melhor desempenhar estas quatro competências.

A primeira competência, posicionamento, refere-se a escolha da estratégia e estrutura das operações logísticas. Para os autores a estratégia estabelece os objetivos e os meios para atingi-los, enquanto a estrutura é a forma como os recursos humanos e materiais estão organizados para suportar a implementação da estratégia. Desta forma a competência posicionamento está ligada à forma pela qual a empresa compete, o tipo de serviço ofertado, o grupo de consumidores alvo e a sua comparação à oferta dos concorrentes.

A segunda competência, integração, está relacionada com o que e como fazer para criar uma operação logística de excelência. Segundo os autores a empresa integrada está comprometida com iniciativas específicas, seguindo regras formalizadas e procedimentos projetados para facilitar o atingimento dos objetivos da empresa. Integrações internas e externas determinam como a empresa de classe mundial desempenha sua atividade logística e se comporta em seus relacionamentos na cadeia de suprimentos.

Agilidade, a terceira competência está ligada à capacidade de reagir às mudanças das necessidades dos clientes de tal modo que estes não apenas se mantenham fiéis, mas também proporcionem oportunidades de crescimento. É a competência que sustenta o desempenho, sendo a base para as demais competências.

A quarta competência é a mensuração, habilidade que através de medidas de avaliação proporciona base para a realização de ajustes nas outras três competências logísticas. É exercida por meio de avaliação funcional, avaliação de processos e benchmarking.

Apesar da identificação das quatro competências como fundamentais e universais para o alcance do status "de nível mundial", na pesquisa não foram identificadas empresas que se destacassem em todas as competências simultaneamente.

\subsubsection{Modelo de Fawcett e Clinton}

Apontando a logística como fator estratégico para a obtenção de sucesso em longo prazo no mercado global e através de um survey (levantamento), aplicado a alta gerência de 671 empresas americanas de manufatura, os autores Fawcett e Clinton propõem um modelo de excelência composto de sete áreas básicas para se implementar a estratégia logística competitiva. O modelo é ilustrado pela figura 2.6, apresentada a seguir. 


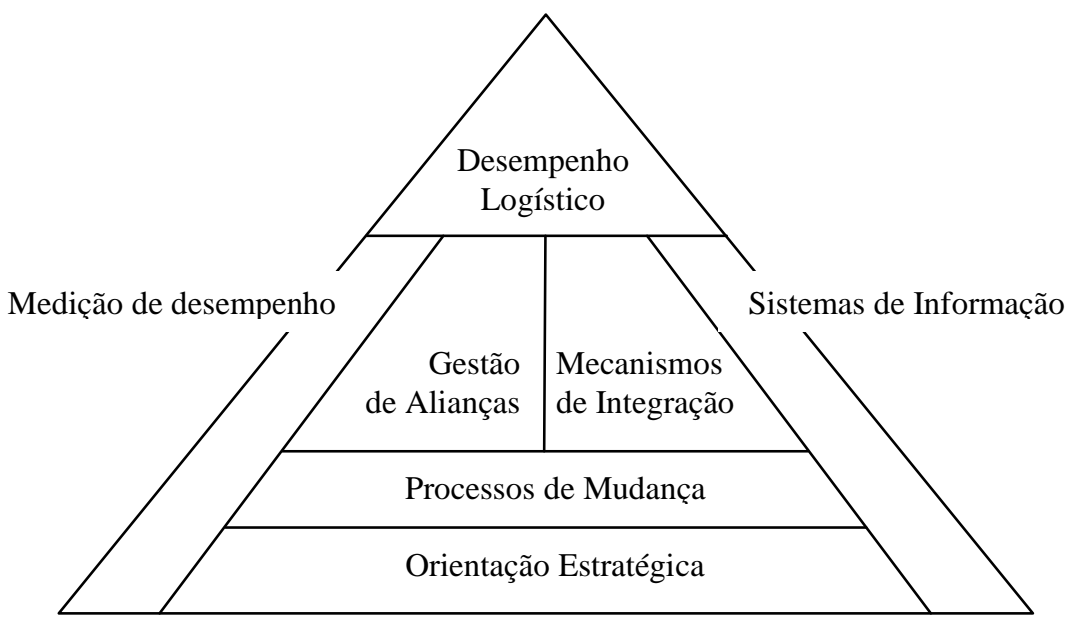

Figura 2.6 - Modelo de implementação de logística estratégica Fonte: Fawcett e Clinton (1996)

A identificação das áreas do modelo baseou-se nas práticas de empresas consideradas de alto desempenho. Do total, 102 empresas foram classificadas como de alto desempenho, com base nos seguintes critérios:

- mudanças nos níveis de estoque médio nos últimos cinco anos;

- mudanças no giro de estoque nos últimos cinco anos;

- flexibilidade para atender pedidos especiais dos clientes;

- mudanças no número de medidas de desempenho adotadas nos últimos cinco anos, $\mathrm{e}$

- grau de integração dos sistemas de informação logística.

Sobre orientação estratégica, área base do modelo, os autores colocam que a mesma é composta pelo planejamento estratégico e que os executivos precisam estar envolvidos neste planejamento. Como resultado deste envolvimento, passa-se a desenvolver e disseminar a missão logística, tornando claros os objetivos logísticos e guiando a utilização dos recursos. Conforme a pesquisa, empresas com alto desempenho formalizam melhor seu planejamento e sua missão logística, além de focarem mais suas estratégias para os serviços aos clientes, do que as empresas normais que visam à minimização de custos. Outra diferença apontada refere-se à abordagem mais agressiva adotada pelas empresas de alto desempenho quanto a integração de processos, que permite não só a diferenciação mas também o alto nível dos serviços prestados. 
A área de gestão do processo de mudança, diz respeito à transição de uma visão reativa, baseada em custos funcionais, para uma visão mais proativa, orientada ao cliente. Neste sentido a pesquisa aponta que as empresas com alto desempenho investem em práticas de reengenharia, reestruturação e simplificação de processos, visando o atendimento ao cliente e a inserção deste no planejamento da estratégia logística.

Outras duas áreas do modelo estão relacionadas a mecanismos de integração e gestão de alianças, que focam a coordenação e integração das atividades internas e externas, que adicionam valor através da cadeia. Como mecanismo de integração interna cita-se a consistência entre os objetivos operacionais interdepartamentais, o uso de medidas de desempenho equivalentes através dos departamentos e a alocação de empregados entre membros da cadeia. Sobre a gestão de alianças, os autores colocam que a questão mais importante para o sucesso das alianças, relaciona-se com o estabelecimento dos ganhos e riscos, envolvendo a divisão dos custos e benefícios e o comprometimento e dependência mutua entre os membros da aliança. A pesquisa levantou que as empresas com alto desempenho embora sejam melhores no uso de medidas de desempenho, apresentam inconsistência do processo ao longo dos departamentos.

As áreas de medidas de desempenho e sistemas de informação são consideradas facilitadores, atividades de apoio às demais. Medidas de desempenho direcionam as estratégias logísticas e monitoram suas implementações. A pesquisa aponta que tanto as empresas normais quanto as de alto desempenho enfatizam a importância da melhoria de seus sistemas de medição. Os autores citam como abordagens atuais, o uso do método de custo ABC (custeio baseado em atividades) e a inserção da visão do cliente no processo de medição. Com igual importância os sistemas de informação logística unem as diversas atividades, permitindo o controle de estoques ao longo da cadeia de suprimentos e servindo de base para estratégias competitivas. A pesquisa constatou que os dois grupos de empresas reconhecem a importância da gestão da informação e procuram investir em tecnologias como EDI (intercâmbio eletrônico de informações), mas que nas empresas de alto desempenho tem mais sucesso na implementação destes sistemas.

A área representada pelo topo do modelo é o desempenho logístico, que é o resultado da integração e investimentos em todas as áreas da estrutura. A pesquisa levantou como já esperado, que as empresas de alto desempenho são as que melhor estruturaram as cinco áreas, mas que ambos os grupos atingiram altos níveis de desempenho, evidenciando assim a melhoria da competência em gerir as atividades logísticas, possibilitando melhores níveis de serviços e adequação de atendimento as distintas necessidades dos clientes. 


\subsubsection{Modelo de Bowersox e Closs}

Para Bowersox e Closs (1997) logística vai além de uma atividade que promove baixos custos operacionais, estando relacionada à adequação das operações, o que possibilita o aumento de qualidade e produtividade e conseqüente diferenciação frente à concorrência. No artigo publicado na revista Gestão e Produção, os autores afirmam que a excelência logística pode ser descrita em termos de seis iniciativas gerenciais inter-relacionadas. As dimensões do modelo proposto estão representadas na figura 2.7 .

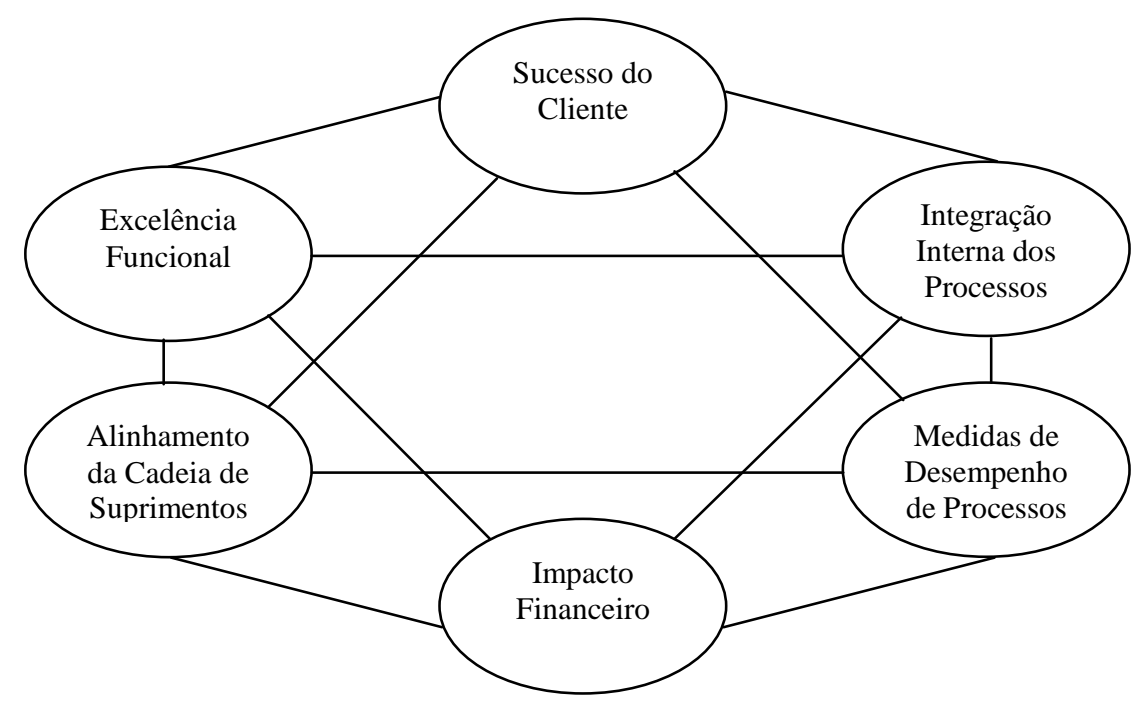

Figura 2.7 - Modelo de excelência logística

Fonte: Bowersox e Closs (1997)

A dimensão sucesso do cliente corresponde ao entendimento e atendimento às necessidades deste. Conforme os autores o atendimento aos requisitos do cliente deve ir muito além de um serviço básico. A empresa deve buscar a identificação dos requisitos fundamentais e desenvolver soluções logísticas que tragam melhorias operacionais e a satisfação do cliente.

Excelência funcional diz respeito à implementação das melhores práticas e à eficiência operacional. Na abordagem deste modelo a eficiência operacional deve ocorrer simultaneamente à criação de valor ao cliente.

Integração interna dos processos logísticos relaciona-se com a coordenação interfuncional e comprometimento entre áreas como vendas, marketing, produção, compras e distribuição. A relação entre excelência funcional e a integração interna dos processos é direta 
e pode justificar o aumento de custo específico se o resultado final desta integração for à redução no custo total de entrega ou aumento no nível de desempenho.

Alinhamento da cadeia de suprimentos refere-se à integração de processos logísticos externos à organização. $\mathrm{O}$ foco desta dimensão é o aumento de eficiência pela eliminação da duplicação de atividades não produtivas existentes entre a relação dos membros da cadeia.

Os indicadores de desempenho possibilitam a monitoração de avanços ao longo do tempo, sendo usado como suporte para as decisões gerenciais. Os indicadores de desempenho adotados devem contemplar as atividades de processo e funcionais, que tradicionalmente se dividem em cinco categorias: custo, serviço ao cliente, produtividade, gestão de ativos e qualidade.

Impacto financeiro está associado aos padrões financeiros da empresa e à capacidade de junção de diversas realizações específicas para o interesse de todos. Os autores do modelo afirmam que os gestores devem compreender e adotar medidas financeiras como retorno sobre investimento (ROI - Return on Investment) e retorno na gestão de bens (ROAM Return on Assets Managed).

\subsection{Síntese dos modelos: a medição de desempenho como estratégia comum}

Os modelos de excelência logística apresentam alguns pontos em comum, principalmente quando se refere ao destaque dado às suas áreas-chave ou dimensões. Nos modelos apresentados neste estudo, fica evidente a presença da medição de desempenho e seu papel como direcionador de estratégias no processo de busca de uma estrutura de excelência em logística.

Sendo objetivo da logística o atendimento aos requisitos dos clientes por meio de um nível de serviço e custo adequados, tem se que para alcançar excelência em logística deve-se ter em vista a busca da qualidade do serviço como pré-requisito e não apenas como fator de diferenciação. Assim, estratégias para as atividades logísticas devem basear-se na avaliação contínua de desempenho, já que o desempenho logístico reflete diretamente no nível de serviço oferecido ao cliente e na qualidade do produto que chega às mãos deste.

O quadro 2.2 apresenta uma síntese dos modelos no que se refere às abordagens dadas à medição de desempenho para as atividades logísticas. 


\begin{tabular}{|c|c|c|}
\hline Modelo & Descrição & Abordagem dada à medição de desempenho \\
\hline $\begin{array}{l}\text { Michigan } \\
\text { (1995) }\end{array}$ & $\begin{array}{l}\text { Para alcance da excelência logística deve } \\
\text { haver o desenvolvimento simultâneo de } \\
\text { quatro competências chaves: } \\
\text { posicionamento, agilidade, integração e } \\
\text { mensuração. }\end{array}$ & $\begin{array}{l}\text { Competência referente ao monitoramento interno e } \\
\text { externo das operações logísticas. Proporciona a } \\
\text { base para a identificação potencial necessária às } \\
\text { mudanças. A preocupação com esta competência é } \\
\text { maior nas empresas de classe mundial em } \\
\text { logística. } \\
\text { Três capabilidades caracterizam a competência: } \\
\text { avaliação funcional; avaliação de processos } \\
\text { (processos internos e externos, voltados ao cliente, } \\
\text { custeio ABC) e benchmarking. }\end{array}$ \\
\hline $\begin{array}{l}\text { Fawcett e } \\
\text { Clinton } \\
\text { (1996) }\end{array}$ & $\begin{array}{l}\text { Seis áreas que levam a empresa a um alto } \\
\text { desempenho logístico: orientação } \\
\text { estratégica, processos de mudança, gestão } \\
\text { de alianças, mecanismos de integração, } \\
\text { sistemas de informação e medição de } \\
\text { desempenho. }\end{array}$ & $\begin{array}{l}\text { Área suporte para as demais. Direciona o projeto } \\
\text { da estratégia logística e monitora a sua } \\
\text { implementação. Tendências apontam para a } \\
\text { inserção do cliente nos sistemas de medição de } \\
\text { desempenho e para o uso das práticas de custo } \\
\text { ABC. }\end{array}$ \\
\hline $\begin{array}{l}\text { Bowersox e } \\
\text { Closs (1997) }\end{array}$ & $\begin{array}{l}\text { Melhores empresas focam na exploração } \\
\text { da competência logística através de seis } \\
\text { iniciativas gerenciais: sucesso do cliente, } \\
\text { excelência funcional, alinhamento da } \\
\text { cadeia de suprimentos, integração interna } \\
\text { dos processos, medidas de desempenho } \\
\text { de processos e impacto financeiro. }\end{array}$ & $\begin{array}{l}\text { Iniciativa dirigida pelo conhecido ditado: "se não } \\
\text { pode medir, não pode gerenciar". Métricas devem } \\
\text { combinar atividades de processo e funcionais com } \\
\text { o intuito de avaliar a eficiência e a eficácia do } \\
\text { desempenho geral logístico, são dividas em cinco } \\
\text { categorias: custo, serviço ao cliente, produtividade, } \\
\text { gestão de ativos e qualidade. }\end{array}$ \\
\hline
\end{tabular}

Quadro 2.2 - Síntese dos modelos de estruturação estratégica quanto à área-chave medição de desempenho

Os modelos relatam além da importância estratégica, algumas características para o processo de medição de desempenho, determinando dimensões de desempenho para os indicadores e ferramentas que devem ser consideradas na avaliação da atividade logística. Contudo estes modelos não detalham claramente como se deve proceder para a implementação da medição de desempenho e como sustentar este processo de avaliação, os autores Fawcett e Clinton (1996), por exemplo, não citam quais os indicadores adequados para o monitoramento da denominada excelência logística. Visando a obtenção de tais informações e colaborar para uma discussão mais aprofundada sobre o assunto, apresenta-se no próximo capítulo o levantamento bibliográfico efetuado sobre medição de desempenho. 


\section{MEDIÇÃO DE DESEMPENHO}

Este capítulo inicia-se com a apresentação de uma revisão bibliográfica de conceitos sobre medição de desempenho, focando em aspectos relacionados a definições, contribuições do uso, evolução e o processo de implementação da medição de desempenho nas organizações. Partindo para uma abordagem mais específica, apresenta-se na seqüência a revisão sobre medição de desempenho na logística, sua importância estratégica na atividade, abordagens de alguns autores e uma relação dos principais indicadores de desempenho logístico.

\subsection{Definições para medição de desempenho}

Para Sink e Tuttle (1993) o desempenho de uma organização é função de um complexo inter-relacionamento de vários critérios como: qualidade, produtividade, inovação e lucratividade. Dada a abrangência dos critérios que podem definir o desempenho, verifica-se que a medição de desempenho não é uma tarefa simples e seu conceito envolve conforme Bond (2002), uma estrutura física e lógica, composta de equipamentos, pessoas e informações e que depende da visão do corpo gerencial da empresa, da estrutura hierárquica e da infraestrutura de suporte ao sistema de medição.

Segundo a definição de Lebas (1995), medir desempenho significa traduzir a realidade de um sistema, processo ou atividade em informações úteis para a tomada de decisões. Com semelhante visão Hronec (1994) afirma que as medidas de desempenho são sinais vitais da organização, que qualificam e quantificam o modo como as atividades de um processo atingem suas metas.

Na definição de Neely, Gregory e Platts (1995) medição de desempenho é o processo de quantificar a eficiência e eficácia de uma ação, em que medição é o processo de quantificação e ação que leva ao desempenho.

Os termos eficiência e eficácia são usados precisamente neste contexto. Eficácia refere-se à extensão que as necessidades dos consumidores são atendidas, enquanto que eficiência é a medida de como economicamente os recursos da empresa são utilizados quando provem um dado nível de satisfação ao consumidor. Este é um importante ponto porque os autores não só identificam duas dimensões fundamentais do desempenho, mas também destacam o fato de que podem existir razões tanto internas, quanto externas para ações específicas. O nível de desempenho que um negócio atinge é uma função de eficiência e 
eficácia das ações que ele empreende. Em um detalhamento da definição proposta, os autores apontam:

- Medição de desempenho como o processo de quantificação da eficiência e eficácia da ação;

- Uma medida de desempenho (indicador) como uma métrica usada para quantificar a eficiência e/ou eficácia de uma ação, e

- Um sistema de medição de desempenho (SMD) como um conjunto de métricas usado para quantificar ambas a eficácia e eficiência de ações.

Para Neely, Gregory e Platts (1995) o sistema de medição de desempenho não é único, difere com relação à cultura e as necessidades da empresa. Um SMD é formado por um conjunto de medidas de desempenho individuais e é influenciado pelo ambiente no qual está inserido. A figura 3.1 ilustra este relacionamento sugerido entre as medidas de desempenho, o sistema de medição de desempenho e o ambiente em que o mesmo atua.

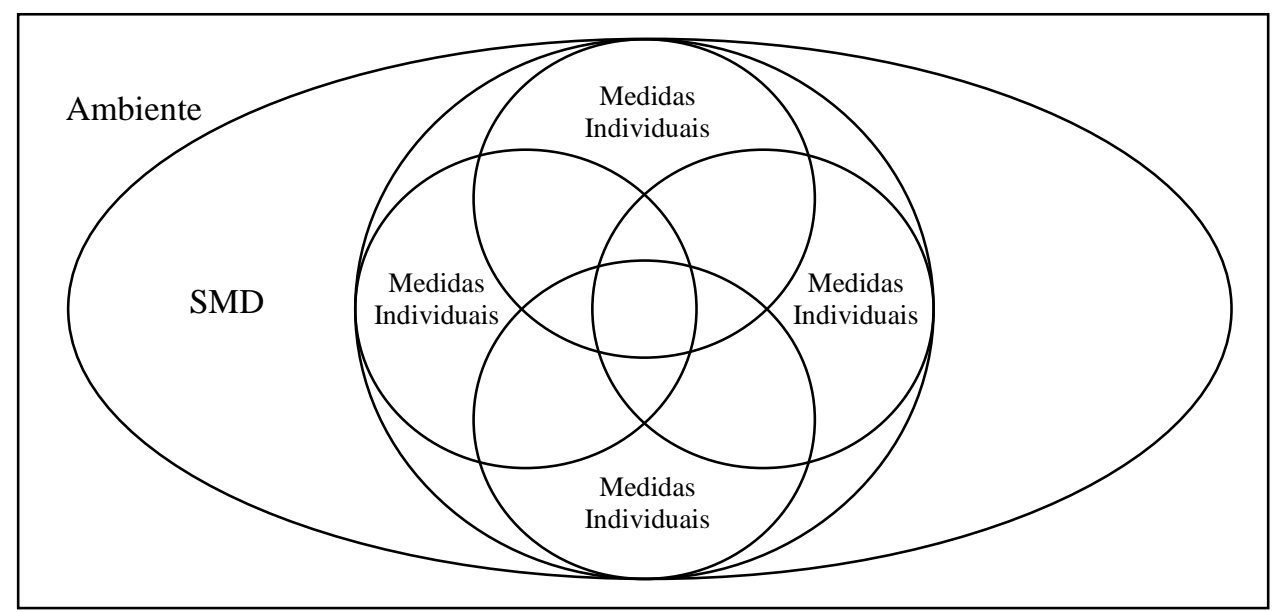

Figura 3.1 - Dimensões da medição de desempenho Fonte: Neely, Gregory e Platts (1995)

A abordagem desses autores é considerada por Attadia e Martins (2003) o elemento fundamental da medição de desempenho. As medidas de desempenho podem ser agrupadas de maneira a formar um conjunto delas. Esse conjunto, por sua vez, seguindo uma lógica, pode formar um sistema de medição de desempenho. E, em um último estágio ocorre a integração do sistema com o ambiente organizacional, tanto interno quanto externo. 


\subsection{Contribuições da medição de desempenho}

A medição de desempenho tem recebido forte ênfase enquanto prática gerencial. Segundo Kaydos (1991) a medição de desempenho é um dos elementos centrais da gestão organizacional, dada a percepção de que o desempenho é em grande parte resultado das tomadas de decisões e que neste sentido, a qualidade da decisão é limitada pela informação qualitativa e quantitativa disponível sobre o desempenho.

Contudo, além do entendimento de que o objetivo principal da medição de desempenho é controlar e monitorar, indicando se as empresas estão adequadamente direcionadas para atingir suas metas estratégicas, Kaydos (1991) apresenta como objetivos secundários da medição de desempenho: comunicar estratégia e clarear valores; identificar

problemas e oportunidades, entender processos; definir responsabilidades; melhorar o controle e planejamento; mudar comportamentos; envolver pessoas e fazer parte ativa da remuneração funcional.

Para Neely (1998), a medição de desempenho por si, não provê melhoria de desempenho, contudo ela pode agir como promotora de progresso de várias maneiras. Algumas das contribuições da medição de desempenho para as empresas citadas com maior freqüência pela literatura são:

- Prover elementos para a tomada de decisões (KAYDOS, 1991; NEELY et al., 1997; FAWCETT e COOPER, 1998);

- Dar sustentação ao planejamento estratégico e monitorar o cumprimento das estratégias (KAPLAN e NORTON, 1992; BOURNE, KENNERLEY e FRANCO, 2003; LOHMAN, FORTUIN e WOUTERS, 2004);

- Comunicar a estratégia e criar entendimento sobre os objetivos e metas a serem perseguidos (KAYDOS, 1991; KAPLAN e NORTON, 1996; FAWCETT e COOPER, 1998; HOLMBERG, 2000; BOURNE, KENNERLEY e FRANCO, 2003);

- Modelar o comportamento dos envolvidos (ECCLES, 1991; KAYDOS, 1991; NEELY et al., 1997; FAWCETT e COOPER, 1998);

- Induzir comportamento almejado, ao se associar melhorias de desempenho à recompensas (ECCLES, 1991; KAPLAN e NORTON, 1992; BOURNE, KENNERLEY e FRANCO, 2003); 
- Promover aprendizado, aperfeiçoando a elaboração de estratégias (KAPLAN e NORTON, 1996; NEELY et al., 1997; FAWCETT e COOPER, 1998; LOHMAN, FORTUIN e WOUTERS, 2004).

\subsection{Evolução da medição de desempenho}

Segundo Eccles (1991), Harrington (1993) e Neely (1999) a atividade de medição de desempenho apresenta uma evolução da avaliação tradicional financeira, para a ênfase nas medidas de desempenho balanceadas e integradas, mais apropriadas às novas condições operacionais das empresas.

O processo de medição de desempenho teve sua origem na Contabilidade de Custos. Baseadas essencialmente em critérios financeiros, as formas tradicionais de medição caracterizam-se por conduzirem à otimização de curto prazo, em detrimento de uma estruturação organizacional em longo prazo, como competitividade em ambientes dinâmicos e satisfação dos stakeholders (clientes, funcionários e acionistas). Sobre estas deficiências, Kaplan e Norton (1996) comentam que as medições tradicionais contêm apenas uma visão financeira limitada e dificultam a avaliação de novos investimentos e a introdução de novos produtos. Além disso, falham ao não considerar medidas sobre qualidade, estoques e produtividade.

Segundo Bititci, Carrie e Mcdevitt (1997), os sistemas de medição de desempenho baseados em medidas financeiras, por estarem ocupados em processos de controle isolados, não reconhecem a necessidade de integração do negócio. Ao não considerarem a empresa como um todo e basearem suas avaliações em dados históricos, os sistemas passam a ser incompatíveis com as necessidades dos gestores que atuam em ambientes dinâmicos.

Neely (1998) lista como principias limitações da medição de desempenho tradicional:

- encorajar visão de curto prazo;

- falta de foco estratégico e falta de dados referentes a qualidade, entrega e flexibilidade;

- encorajar a otimização local, como por exemplo, produzir produtos para estoque com o objetivo de manter máquinas e operadores trabalhando;

- encorajar a minimização de variâncias, ao invés de incentivar a melhoria contínua;

- não fornecer informações sobre clientes e concorrência.

Dada as limitações expostas, bem como, clientes mais exigentes e mercados mais competitivos, fez surgir a necessidade de habilidade melhorada de resposta, assim como de se 
agregar aspectos externos às considerações. E então, segundo Kaplan e Norton (1996), em torno dos anos 80, desenvolveu-se a conscientização de que as medidas financeiras não seriam mais suficientes para suportar a gestão de empresas nos mercados modernos.

Segundo Martins (1999) o novo ambiente competitivo das empresas, caracterizado pela forte concorrência por nichos específicos de mercado, começou a exigir determinadas características do produto (representados, em grande parte, pelos critérios qualificadores e ganhadores de pedidos em termos de estratégia de manufatura) com rápida inovação tecnológica e curto ciclo de vida. As empresas passam assim, a necessitar na grande maioria dos casos, desenvolver estratégias de diferenciação e utilizar novas formas de se medir o desempenho, que precisam estar em concordância com os padrões de produção emergentes e com a estratégia competitiva da empresa. Assim, conforme o autor passou-se a requerer como características adequadas às novas condições ambientais das empresas, um processo de medição de desempenho que:

- seja congruente com a estratégia competitiva;

- tenha medidas financeiras e não-financeiras;

- direcione e suporte a melhoria contínua;

- identifique tendências e progressos;

- facilite o entendimento das relações de causa-e-efeito;

- seja facilmente inteligível para os funcionários;

- abranja todo o processo, desde o fornecedor até o cliente;

- tenha informações disponíveis em tempo real para toda a organização;

- seja dinâmico;

- influencie a atitude dos funcionários, e

- avalie o grupo e não o indivíduo.

Essas características se referem às medidas de desempenho que buscam exprimir a eficácia e a eficiência das ações, devendo ser elas internas (de processo) e externas (de resultado) e segundo Martins (1999), muitos esforços foram empreendidos na proposição de sistemas de medição de desempenho que contivessem as características descritas.

Após a publicação dos primeiros artigos e livros alertando para a inadequação dos sistemas de medição de desempenho tradicionais, de uma maneira crescente, inicialmente lenta na década de 80 e mais rápida na década de 90, novos modelos começaram a ser propostos. Um dos modelos propostos mais conhecido é o Balanced Scorecard (BSC). Criado por Kaplan e Norton (1992), este modelo tem como idéia básica, a partir da visão e estratégia 
da empresa, poder medir o seu desempenho sob quatro perspectivas: a financeira, a do cliente, a dos processos internos e a de aprendizado e crescimento organizacional. O BSC expandiu o conjunto de objetivos da unidade de negócio analisada, para além das medidas financeiras. Os gestores poderiam assim, medir como sua unidade de negócio cria valor para clientes atuais e futuros e, como podem aumentar as capacidades internas através de investimento em pessoas, sistemas e procedimentos necessários para melhorar o desempenho futuro.

\subsubsection{Modelos de sistemas de medição de desempenho}

Vários autores focaram seus estudos na definição de modelos de medição de desempenho, com a proposição de características, escopo e etapas para o processo de medição. Dentre os modelos de medição de desempenho, os que mais se destacam na literatura são apresentados no quadro 3.1.

\begin{tabular}{|l|l|}
\hline Modelo SMD & Fonte \\
\hline Balanced Scorecard (BSC) & $\begin{array}{l}\text { Kaplan e Norton (1992); Kaplan e } \\
\text { Norton (1993); Kaplan e Norton } \\
(1997)\end{array}$ \\
\hline Desempenho Quantum & Hronec (1994) \\
\hline Estrutura de Indicadores de Gestão & Muscat e Fleury (1992) \\
\hline Integrated Dynamic Performance Measurement System (IDPMS) & Gahalyini et al. (1997) \\
\hline Integrated Perfomance Measurement Systems (IPMS) & Bititci et al. (1997) \\
\hline Modelo de Medição de Desempenho para Gestão por Processos & Rummler e Brache (1994) \\
\hline Performance Measurement Questionnaire (PQM) & $\begin{array}{l}\text { Mcmann e Nanni (1994); Rummler e } \\
\text { Brache (1994); De Ron (1995) }\end{array}$ \\
\hline Performance Prism (PP) & $\begin{array}{l}\text { Neely e Adams (2001) } \\
\text { (1990) }\end{array}$ \\
\hline
\end{tabular}

Quadro 3.1 - Modelos de medição de desempenho Fonte: Adaptado de Martins (1999)

Apresenta-se a seguir, breve descrição do Strategic Measurement, Analysis and Reporting Technique (SMART), o Balanced Scorecard (BSC), o Integrated Performance 
Measurement Systems (IPMS) e o Performance Prism (PP), modelos destacados como de relevância ao estudo de medição de desempenho, segundo os trabalhos de Martins (1999) e Galdaméz (2007).

\section{Strategic Measurement, Analysis and Reporting Technique (SMART)}

O modelo SMART, também conhecido por Performance Pyramid, foi proposto por Cross e Lynch (1990) e tem como objetivo a melhoria de processos. O modelo utiliza uma estrutura piramidal, dividida em quatro níveis hierárquicos, apresentada na figura 3.2, como meio para traduzir a visão corporativa em objetivos financeiros e de mercado para as atividades operacionais.

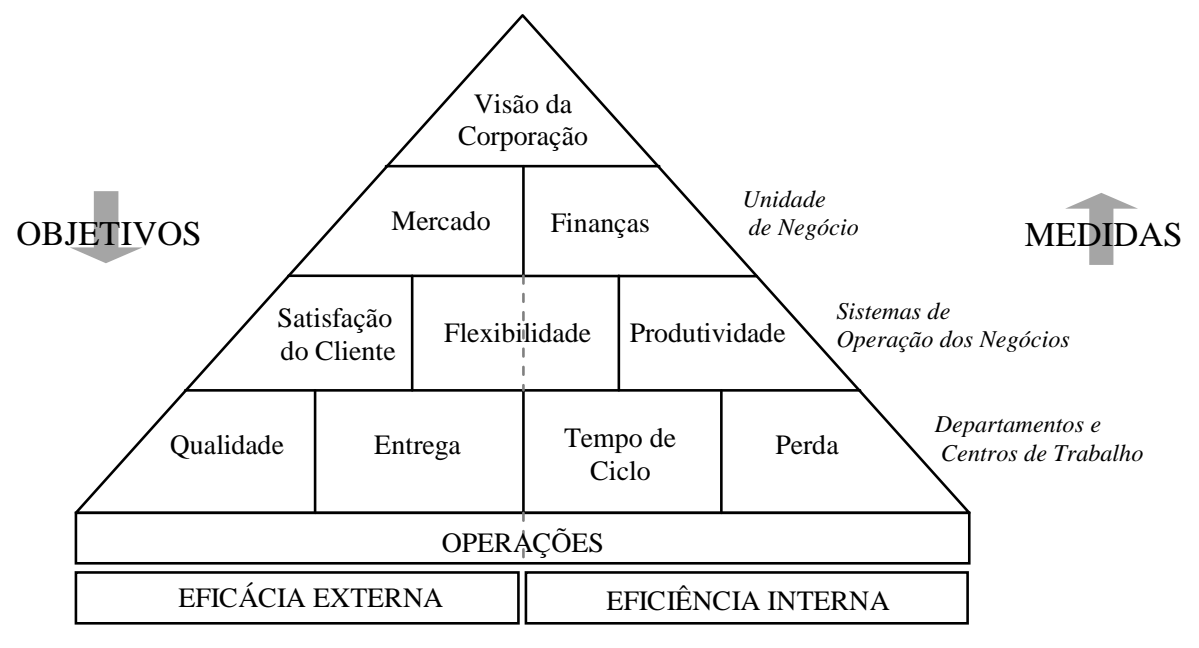

Figura 3.2- O modelo SMART

Fonte: Cross e Lynch (1990)

O modelo SMART permite uma comunicação top-down necessária para instituir a visão estratégica através da organização. Segundo esta abordagem, os objetivos são traduzidos em metas específicas para cada nível hierárquico. Os indicadores de desempenho são divididos em dois grupos: aqueles que medem a eficiência interna das atividades e dos departamentos expressos para a alta administração, em termos financeiros, e para as operações, em termos físicos (tempo de ciclo e perdas); e aqueles que medem a efetividade externa em termos de mercado.

De acordo com Cross e Lynch (1990), os indicadores de desempenho somente induzirão a atitude desejada nas atividades do dia-a-dia se tiverem uma relação de causa e efeito válida com os objetivos estratégicos. Assim, a organização adota uma visão para prover soluções de qualidade elevada para seus clientes. Após a organização ter feito melhorias significantes nas medidas de serviços aos clientes, seu foco é voltado para produtividade, isto 
é, satisfazer os requerimentos do cliente mais eficientemente que o concorrente. Cada departamento apóia os objetivos por meio de medidas específicas direcionadas a melhorar qualidade e reduzir o tempo de ciclo, e assim diminuir possíveis perdas no processo produtivo.

\section{Balanced Scorecard (BSC)}

O conceito de Balanced Scorecard foi introduzido em 1992, por Robert S. Kaplan e David R. Norton. O modelo propõe o balanceamento entre indicadores financeiros e nãofinanceiros, através da adoção de indicadores externos e internos. O BSC procura definir a estratégia de forma lógica, baseada em relações de causa e efeito, vetores de desempenho e relação com os fatores financeiros. Kaplan e Norton (1992) afirmam que deve se decompor objetivos, indicadores, metas e iniciativas, em quatro dimensões ou perspectivas de negócio: financeira, clientes, processos internos e aprendizado e crescimento.

O BSC permite aos executivos avaliar até que ponto suas unidades de negócios geram valores para os clientes atuais e futuros, e como devem aperfeiçoar as capacidades internas e investimentos necessários em pessoal, sistemas e procedimentos, visando melhorar o desempenho futuro. Capta as atividades críticas na geração de valor criadas por funcionários e executivos capazes e motivados da empresa, preservando o desempenho de curto prazo, através da perspectiva financeira, revelando vetores para um desempenho financeiro e competitivo superior a longo prazo. A figura 3.3 ilustra o BSC e suas dimensões.

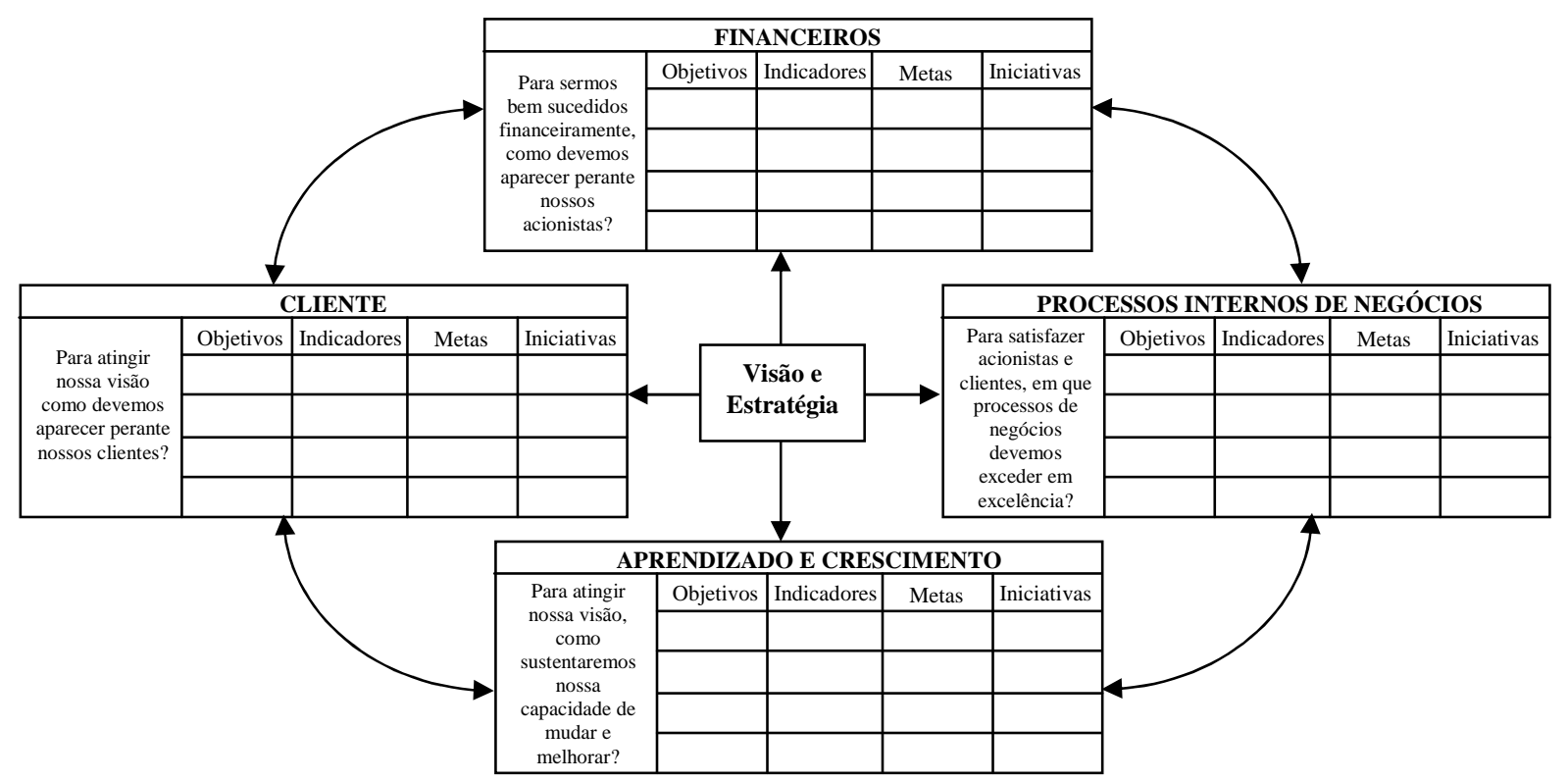

Figura 3.3 - O modelo Balanced Scorecard Fonte: Kaplan e Norton (1992) 
Com sua evolução e uso, este instrumento tornou-se uma importante ferramenta de gestão estratégica, motivando melhorias não incrementais em áreas criticas como desenvolvimento de produtos, processos, clientes e mercados.

\section{Integrated Performance Measurement System (IPMS)}

O modelo Integrated Performance Measurement System (IPMS) proposto por Bititci, Carrie e Mcdevitt (1997), foi desenvolvido a partir de pesquisa junto às melhores práticas da indústria. A estrutura que contempla o modelo é divida em quatro níveis: de negócio, de unidades de negócio, de processos de negócio e de atividades.

Segundo os autores do modelo, para cada nível da estrutura são identificados cinco fatores-chave: os requisitos dos stakeholders, os critérios de controle, as métricas externas, os objetivos de melhoria e as métricas internas da empresa. Para integração desta estrutura são utilizados os conceitos de gestão pelas diretrizes, definição de processos críticos, o planejamento normativo e o monitoramento das atividades. A figura 3.4 apresenta a estrutura do modelo.

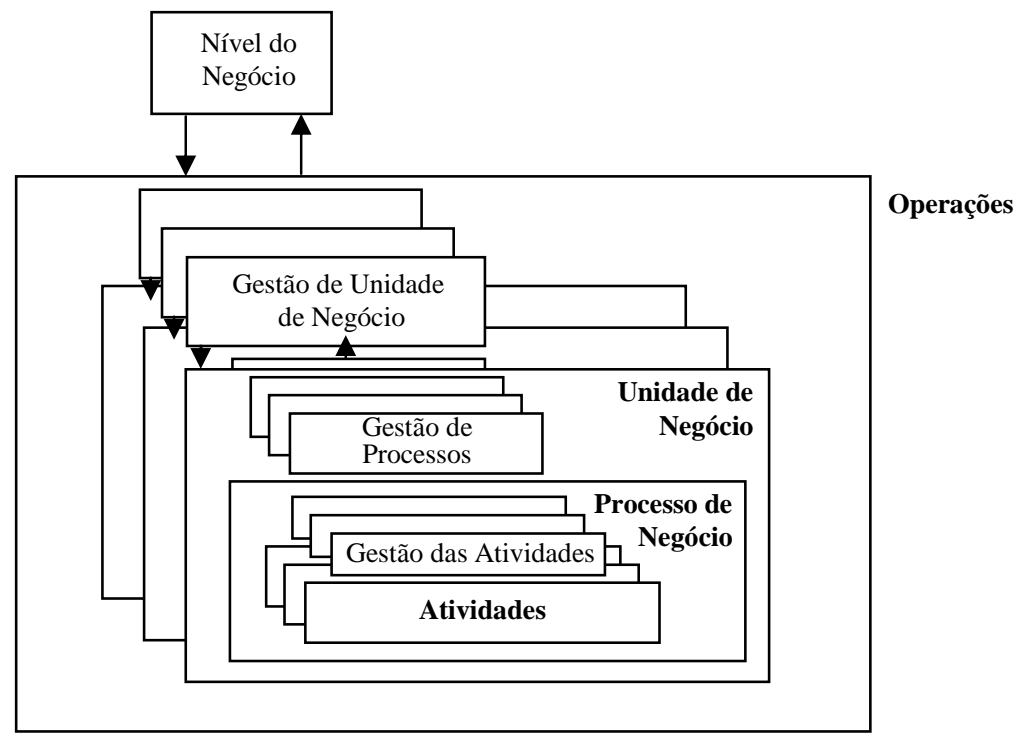

Figura 3.4 - O modelo IPMS

Fonte: Bititci, Carrie e Mcdevitt (1997)

Para Bititci, Carrie e Mcdevitt (1997) este modelo de sistema de medição de desempenho viabiliza o loop fechado de desdobramento e de feedback do sistema, ele é o meio para desdobrar (traduzir em objetivos) a visão e as estratégias da organização e permite o controle se os objetivos foram atingidos ou não. Nesse sentido, o sistema de medição de desempenho integra os esforços na organização. As duas considerações críticas no modelo 
dizem respeito à estrutura e a configuração, isto é, da integridade do sistema e do desdobramento.

\section{Performance Prism}

O Performance Prism, proposto por Nelly e Adams (2000) é um modelo tridimensional, composto de cinco faces. A face superior e inferior do prisma representam a satisfação dos stakeholders e a contribuição dos mesmos, respectivamente. As faces laterais são estratégias, processos e capacidades. Os resultados de uma organização são advindos do quanto estas três faces laterais contribuem para o atendimento às faces superior e inferior do prisma. Segundo os autores, o modelo auxilia no processo de seleção das métricas de desempenho mais adequadas. A figura 3.5 apresentada a seguir ilustra o modelo.

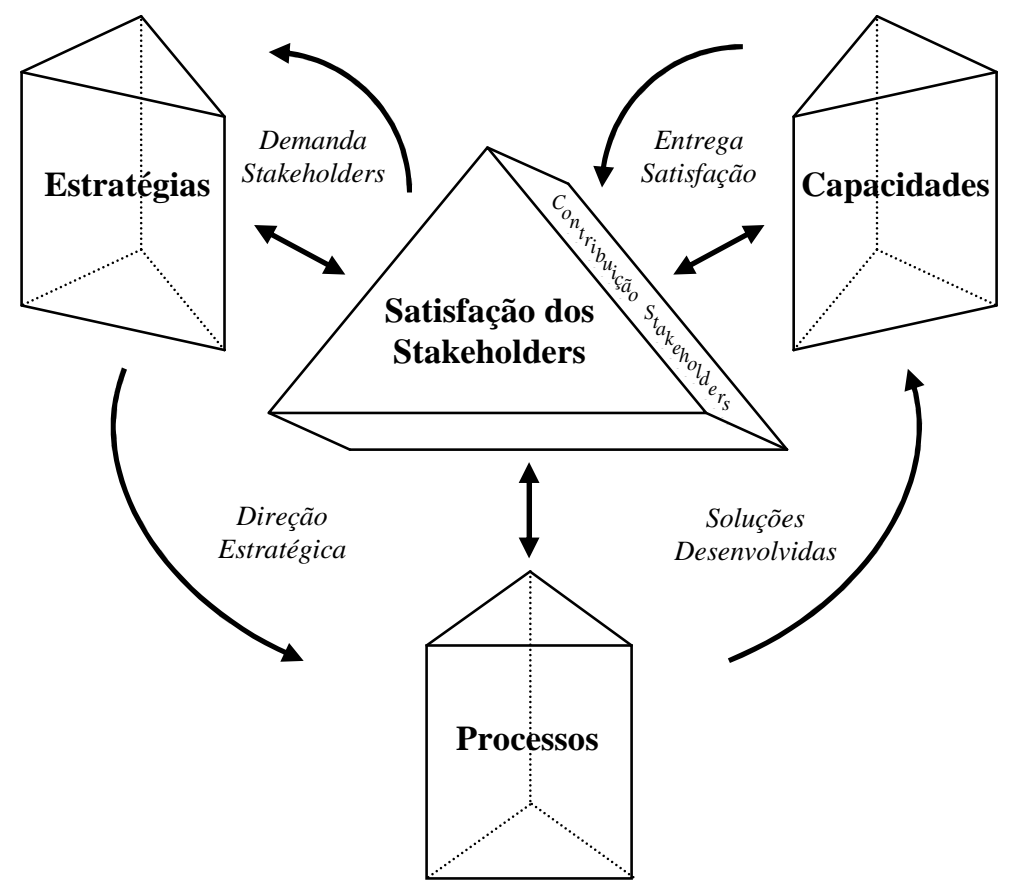

Figura 3.5 - O modelo Performance Prism Fonte : Neely e Adams (2000)

De acordo com Neely e Adams (2000), as organizações que aspiram ter êxito no longo prazo têm um quadro excepcional de quem são seus stakeholders fundamentais e o que eles desejam e necessitam. Elas definiram que estratégias usar para assegurar a satisfação dos stakeholders. Elas entendem quais processos são requeridos para essas estratégias e definiram que capacidades são necessárias para operar esses processos. Algumas ainda refletiram cuidadosamente sobre quais informações a organização quer obter de seus stakeholders. 
Segundo esses autores, tais organizações têm um modelo de negócio claro e um entendimento do que constitui e direciona um bom desempenho.

O quadro 3.2, apresenta uma síntese das características destes modelos de medição de desempenho, realizada por Galdaméz (2007). Trata-se de uma adaptação dos trabalhos de Hudson (2005) e Garengo et al. (2005), objetivando a comparação das principais características destas ferramentas e ilustração das práticas consideradas mais atuais para a medição de desempenho.

\begin{tabular}{|c|c|c|c|c|}
\hline Características dos SMDs & SMART & BSC & IPMS & $\mathbf{P P}$ \\
\hline \multicolumn{5}{|l|}{ Prática de MD } \\
\hline Definir as necessidade e contribuições dos stakeholders & & $\mathrm{x}$ & & $\mathrm{x}$ \\
\hline Derivar da estratégia da empresa & $\mathrm{x}$ & $\mathrm{x}$ & $\mathrm{x}$ & \\
\hline Integrar as operações com as metas estratégicas & $\mathrm{x}$ & $\mathrm{x}$ & $\mathrm{x}$ & $\mathrm{x}$ \\
\hline Estimular a melhoria contínua & & $\mathrm{x}$ & $\mathrm{x}$ & $\mathrm{x}$ \\
\hline Assegurar o feedback & $\mathrm{x}$ & & $\mathrm{x}$ & $\mathrm{x}$ \\
\hline Definir claramente o propósito & & $\mathrm{x}$ & $\mathrm{x}$ & $\mathrm{x}$ \\
\hline Ser simples para usar e entender & $\mathrm{X}$ & $\mathrm{x}$ & $\mathrm{x}$ & $\mathrm{x}$ \\
\hline \multicolumn{5}{|l|}{ Desenvolvimento da MD } \\
\hline Avaliar as métricas que existem na empresa & $\mathrm{x}$ & & $\mathrm{x}$ & $\mathrm{x}$ \\
\hline Identificar os objetivos estratégicos & & $\mathrm{x}$ & $\mathrm{x}$ & $\mathrm{x}$ \\
\hline Assegurar o desenvolvimento das métricas & & $\mathrm{x}$ & $\mathrm{x}$ & $\mathrm{x}$ \\
\hline Fornecer uma estrutura de manutenção & & & $\mathrm{X}$ & $\mathrm{x}$ \\
\hline Estabelecer um número balanceado de métricas & $\mathrm{x}$ & $\mathrm{x}$ & $\mathrm{x}$ & $\mathrm{x}$ \\
\hline Envolver os usuários & $\mathrm{x}$ & & $\mathrm{x}$ & \\
\hline Dar suporte na gestão do negócio & $\mathrm{x}$ & $\mathrm{x}$ & $\mathrm{x}$ & $\mathrm{x}$ \\
\hline Dar suporte aos funcionários & $\mathrm{x}$ & $\mathrm{x}$ & $\mathrm{x}$ & $\mathrm{x}$ \\
\hline Ter os objetivos claros e explícitos & & $\mathrm{x}$ & $\mathrm{x}$ & $\mathrm{x}$ \\
\hline Ter uma escala de tempo & & $\mathrm{x}$ & & $\mathrm{x}$ \\
\hline \multicolumn{5}{|l|}{ Categorias de desempenho } \\
\hline Qualidade & $\mathrm{x}$ & $\mathrm{x}$ & $\mathrm{x}$ & $\mathrm{x}$ \\
\hline Flexibilidade & $\mathrm{x}$ & $\mathrm{x}$ & $\mathrm{x}$ & $\mathrm{x}$ \\
\hline Tempo & $\mathrm{x}$ & $\mathrm{x}$ & $\mathrm{x}$ & $\mathrm{x}$ \\
\hline Finanças & $\mathrm{x}$ & $\mathrm{x}$ & $\mathrm{x}$ & $\mathrm{x}$ \\
\hline Satisfação do consumidor & $\mathrm{x}$ & $\mathrm{x}$ & $\mathrm{x}$ & $\mathrm{x}$ \\
\hline Recursos humanos & $\mathrm{x}$ & $\mathrm{x}$ & $\mathrm{x}$ & $\mathrm{x}$ \\
\hline
\end{tabular}

Quadro 3.2 - Síntese das características dos modelos de medição de desempenho Fonte: Adaptado de Galdaméz (2007)

A presente caracterização revela o posicionamento atual da prática de medição de desempenho, com particular destaque sobre a necessidade de que os indicadores de desempenho devão ser derivados da estratégica organizacional e dos requisitos dos stakeholders. Verifica-se ainda que cada modelo possui abordagens diferentes para o desdobramento e organização dos indicadores, contudo todos apresentam como objetivo criar um SMD que não se prenda apenas a medidas financeiras e operacionais. 
Nas seções apresentadas até o momento buscou-se levantar as questões relacionadas à inadequação dos modelos de medição de desempenho tradicionais e as soluções advindas com o surgimento dos novos modelos de desempenho aqui exemplificados. As boas práticas de medição de desempenho advindas destes novos modelos, serviram de base para discutir e analisar a questão da medição de desempenho na logística, foco deste estudo.

\subsection{O processo de medição de desempenho}

Apesar de a literatura apresentar modelos com várias recomendações para o desenvolvimento de SMDs, poucos são os trabalhos que detalham o desenvolvimento do SMD e definição do conjunto de indicadores adequados que irão compor o sistema. Dentro do levantamento bibliográfico efetuado para esta pesquisa, localizou-se o estudo de Neely et al. (2000) que apresenta uma abordagem que preenche parte desta lacuna. Para os autores o processo de medição de desempenho compreende, inicialmente, a obtenção de informações qualitativas e quantitativas sobre o objeto em questão (seja um processo, uma empresa ou mesmo um conjunto de empresas) julgadas de acordo com determinados princípios (objetivos, estratégia ou outros), como essenciais para monitoramento o desempenho.

Segundo Neely et al. (2000) o processo de medição de desempenho pode ser divido em quatro fases: projeto, implementação, uso e revisão. Os autores sugerem ainda que devem ser considerados quatro pontos associados: pessoas, processos, cultura e infraestrutura. A figura 3.6 apresenta a abordagem destes autores.

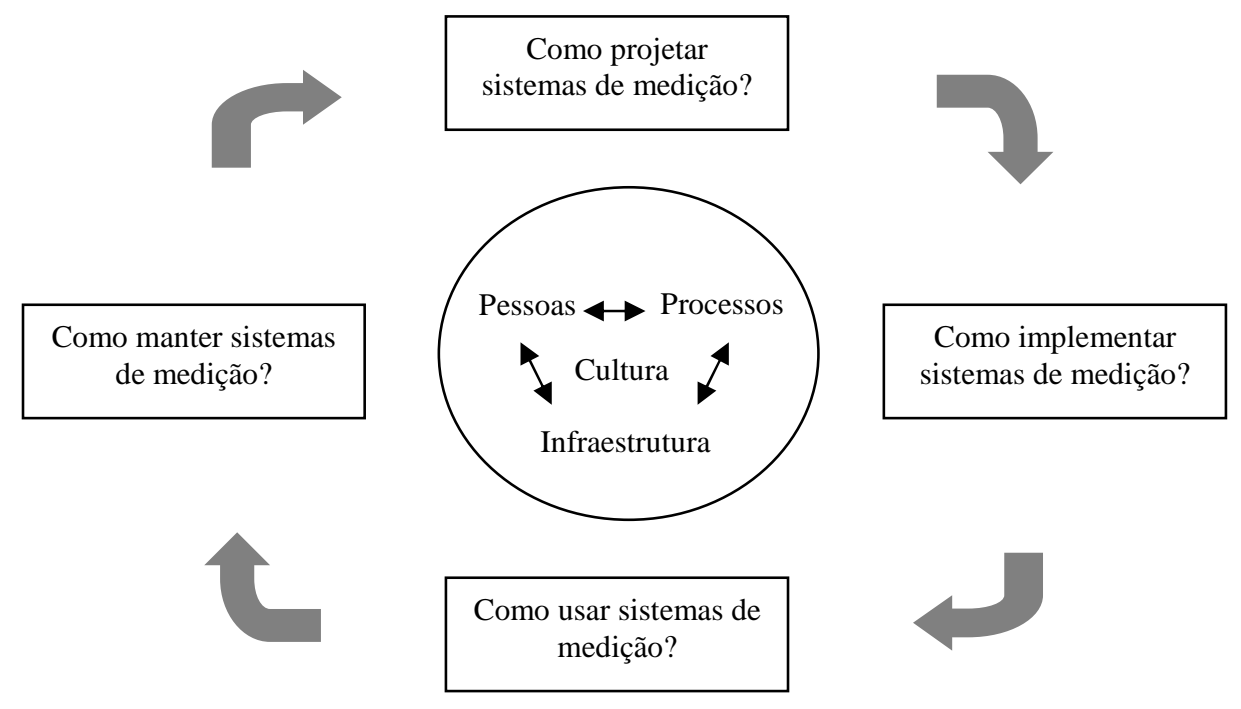

Figura 3.6 - Fases do processo de medição de desempenho Fonte: Adaptado de Neely et al. (2000) 


\section{Projeto do sistema de medição de desempenho}

Segundo Neely et al. (2000) poucas empresas têm processos estruturados para o projeto de seus sistemas de medição de desempenho. Autores como Kaplan e Norton (1996) e Kennerley e Bourne (2003) colocam que o conjunto de indicadores adotados deve estar alinhado à estratégia da organização. Neste sentido Neely et al. (2000) afirmam que a fase de projeto pode ser dividida em: identificação dos objetivos estratégicos a serem perseguidos e definição dos indicadores associados.

Um ponto de destaque literatura é a necessidade dos indicadores de desempenho serem definidos e comunicados de maneira que seu significado e objetivo fiquem claros para todos na organização, especialmente para seus usuários. Desta forma sugere-se que, a fase de projeto do sistema de medição conte com a participação de todos os membros do processo (funcionários, fornecedores e clientes) e inclua a especificação das fórmulas e das fontes de dados a serem utilizadas.

Objetivando a redução de mal entendidos na compreensão dos indicadores, Neely et al. (1997) sugerem um conjunto de definições e detalhamentos a serem aplicados a cada um dos indicadores quando de sua adoção no sistema de medição de desempenho. Este conjunto de definições está relacionado no quadro 3.3.

\begin{tabular}{|l|l|}
\hline Detalhe & Objetivo \\
\hline Título & Explicar o que é o indicador e por que é importante \\
\hline Propósito & Mostrar o que está sendo medido e com que propósito \\
\hline Relacionada a & Ligar o indicador aos objetivos de desempenho da organização \\
\hline Escopo & Definir que áreas da organização estão envolvidas \\
\hline Meta & Especificar nível de desempenho desejado e prazo para alcançá-lo \\
\hline Fórmula & Definir exatamente como calcular o indicador \\
\hline Unidades de medida & Definir a(s) unidade(s) usada(s) \\
\hline Freqüência de medição & Definir com que freqüência o indicador será calculado e relatado \\
\hline Freqüência de revisão & Definir com que freqüência o indicador será revisto \\
\hline Quem mede? & Especificar a pessoa responsável por coletar e relatar os dados \\
\hline Fonte dos dados & Especificar a exata fonte dos dados a serem usados para o cálculo \\
\hline Quem são os donos da medida? & Especificar os proprietários do indicador \\
\hline O que eles fazem? & Explicitar suas atribuições \\
\hline Quem age sobre os dados? & Definir quem é o responsável por agir sobre os resultados do indicador \\
\hline O que eles fazem? & $\begin{array}{l}\text { Definir de maneira geral que processo gerencial deverá ser seguido em } \\
\text { função do desempenho }\end{array}$ \\
\hline
\end{tabular}

Quadro 3.3 - Definição de indicadores de desempenho Fonte: Adaptado de Neely et al. (1997) 


\section{Implementação do sistema de medição de desempenho}

A segunda fase do processo de medição de desempenho visa à implementação do sistema e procedimentos necessários para a coleta e o processamento dos dados. Neste sentido, inclui-se na presente fase a atenção aos sistemas computacionais que suportaram a coleta de dados e a sua disponibilização.

Progressos em tecnologia da informação, como código de barras, troca eletrônica de dados (EDI - Electronic Data Interchange), bases de dados integradas e comunicações por satélite, são responsáveis pela disponibilização de informações relevantes e precisas (FAWCETT e COOPER, 1998).

Apesar dos métodos manuais poderem ser usados para análises pontuais, é necessário que os sistemas de medição de desempenho que são acessados regularmente sejam automatizados, que facilitem atividades como a emissão de relatórios e a exportação de dados (BOURNE et al., 2000). Neste sentido, o envolvimento de especialistas em tecnologia de informação desde o início do processo e a aplicação de ferramentas de coleta e tratamento dos dados pode otimizar o tempo utilizado na implementação de sistemas.

\section{Uso do sistema de medição de desempenho}

Um aspecto a ser priorizado durante o uso dos sistemas de medição refere-se à disponibilidade de informações. Especificamente Neely et al. (2000) apontam que é preciso que as informações estejam disponíveis na hora certa, pois se o tempo necessário para realizar a coleta de dados, calcular o indicador e reportá-lo for muito longo, pode ser que a informação perca a validade antes mesmo de poder ser usada para apoiar a decisão.

Sistemas de medição devem fornecer feedbacks rápidos e uma forma simples de relatá-lo. Para Neely et al. (1997) o SMD precisa estar alinhado a estratégia da empresa para que o seu uso efetivo no processo de tomada de decisões conduza à consistência de ações e, portanto, à estratégia implementada.

Outro aspecto apontado pela literatura e que deve ser considerado durante o uso de um SMD refere-se à discussão dos resultados e das ações a serem tomadas. Conforme Bourne et al. (2000) a participação do alto nível gerencial de forma regular nas reuniões e dos responsáveis pelos resultados é de grande importância para o uso do sistema.

A fase de uso do processo de medição inclui também a associação de metas de desempenho aos indicadores e sob este contexto diversos fatores devem ser considerados. 
Entre eles Brown (1996) cita a adoção de metas associadas ao desempenho dos principais competidores, através de benchmarking competitivo (com empresas concorrentes) ou cooperativo (com empresas de outra indústria).

Um aspecto discutido na literatura e que deve ser considerado no uso do sistema de medição é o comprometimento dos funcionários com os indicadores e suas metas. Conforme autores como Bourne, Kennerly e Franco (2003) o comprometimento dos funcionários pode ser enaltecido, caso as medidas estejam atreladas a algum sistema de recompensas.

\section{Revisão do sistema de medição de desempenho}

O processo de medição de desempenho deve ser sustentado por meio de revisões. O conjunto de indicadores selecionados deve ser revisto periodicamente, à medida que novas informações sobre a estratégia, os clientes, os processos tornam-se disponíveis (BOURNE et al., 2000).

As empresas ao introduzem novos indicadores, falham por não descartarem indicadores relacionados a objetivos antigos. Como resultado desse processo, antigos e novos indicadores, pouco correlacionados, passam a coexistir nos sistemas de medição, levando-os à perda de consistência (NEELY et al., 2000).

Diante dos procedimentos mencionados, constata-se que o processo de medição de desempenho exige que o esforço empreendido na escolha dos indicadores seja abrangente e criterioso, a fim de agregar ao seu escopo a estratégia da empresa e atender as necessidades de controle e previsão, indispensáveis a tomada de decisão.

O quadro 3.4 apresenta uma síntese dos procedimentos levantados, que orientaram o desenvolvimento do roteiro utilizado na análise do processo de medição das empresas foco desta pesquisa. 


\begin{tabular}{|c|c|c|}
\hline $\begin{array}{c}\text { Fase do } \\
\text { processo }\end{array}$ & Procedimentos & Ações sugeridas \\
\hline \multirow[t]{3}{*}{ Projeto } & $\begin{array}{l}\text { Indicadores devem ser definidos de modo } \\
\text { simples e claro e ter seus objetivos } \\
\text { comunicados a toda a organização }\end{array}$ & $\begin{array}{l}\text { O indicador deve ser detalhado, devendo } \\
\text { estar ligado aos objetivos estratégicos da } \\
\text { empresa }\end{array}$ \\
\hline & $\begin{array}{l}\text { Todos os envolvidos devem participar do } \\
\text { processo de definição dos indicadores }\end{array}$ & $\begin{array}{l}\text { Devem participar gerentes, funcionários, } \\
\text { clientes e fornecedores na definição dos } \\
\text { indicadores }\end{array}$ \\
\hline & $\begin{array}{l}\text { O sistema de medição deve contemplar } \\
\text { medidas não-financeiras em seu escopo de } \\
\text { avaliação }\end{array}$ & $\begin{array}{l}\text { Utilizar indicadores financeiros e não- } \\
\text { financeiros }\end{array}$ \\
\hline Implementação & $\begin{array}{l}\text { A implementação do SMD deve contemplar } \\
\text { a automatização da coleta e acesso de dados } \\
\text { e o apoio especialistas de TI nesta } \\
\text { implementação }\end{array}$ & $\begin{array}{l}\text { Automatizar processo de coleta, cálculo e } \\
\text { disponibilização dos dados através de } \\
\text { sistemas }\end{array}$ \\
\hline \multirow[t]{5}{*}{ Uso } & $\begin{array}{l}\text { O sistema de medição precisam dar } \\
\text { feedbacks rápidos e apoiar a tomada de } \\
\text { decisões }\end{array}$ & $\begin{array}{l}\text { Indicadores devem ser recalculados com a } \\
\text { agilidade necessária para apoiarem a } \\
\text { tomada de decisões }\end{array}$ \\
\hline & $\begin{array}{l}\text { Reuniões são necessárias para a discussão } \\
\text { dos resultados e das ações a serem tomadas }\end{array}$ & $\begin{array}{l}\text { As reuniões devem ser periódicas e terem } \\
\text { como participantes o alto nível gerencial e } \\
\text { os responsáveis pelos resultados }\end{array}$ \\
\hline & Indicadores requerem metas associadas & $\begin{array}{l}\text { A definição de metas devem estar } \\
\text { associadas a desempenhos passados ou } \\
\text { benchmarking }\end{array}$ \\
\hline & $\begin{array}{l}\text { A remuneração dos funcionários vinculada } \\
\text { ao resultado das medidas aumenta o } \\
\text { comprometimento dos funcionários }\end{array}$ & $\begin{array}{l}\text { Programas de remuneração baseados em } \\
\text { resultados podem ser implantados }\end{array}$ \\
\hline & $\begin{array}{l}\text { A existência de um responsável por } \\
\text { coordenar a medição facilita o processo de } \\
\text { medição }\end{array}$ & $\begin{array}{l}\text { Uma pessoa ou área deve ser responsável } \\
\text { pelo cálculo, relato dos resultados e } \\
\text { acompanhamento das ações }\end{array}$ \\
\hline Revisão & $\begin{array}{l}\text { O sistema de medição deve ter um processo } \\
\text { estruturado de revisão }\end{array}$ & $\begin{array}{l}\text { As revisões das medidas devem ocorrer } \\
\text { com periodicidade e com base nas } \\
\text { mudanças de estratégia }\end{array}$ \\
\hline
\end{tabular}

Quadro 3.4 - Procedimentos para desenvolvimento da medição de desempenho

Um ponto de destaque entre as recomendações da literatura é a importância do ambiente no qual a empresa opera, que influi no processo de medição, devendo, portanto ser considerado na definição de medidas adequadas. Objetivando elucidar como o processo de medição de desempenho ocorre no ambiente logístico, apresenta-se nas próximas seções abordagens dadas à avaliação da atividade logística. 


\subsection{Medição de desempenho na logística}

Inúmeras pesquisas identificaram relação entre níveis superiores de desempenho logístico e o uso de sofisticados métodos de avaliação ou de capacitações voltadas para a medição de desempenho e ainda que, empresas empenhadas numa avaliação de desempenho abrangente obtinham melhorias na produtividade geral da atividade logística (MICHIGAN, 1995; FAWCETT e CLINTON, 1996; BOWERSOX e CLOSS, 1997; BOWERSOX e CLOSS, 2001). Novas pesquisas continuam a sustentar a tese de que empresas de vanguarda possuem um comprometimento quase compulsivo com relação à medição de desempenho.

Conforme Christopher (2007) e Forslund (2007), uma vez que o gerenciamento logístico é um conceito orientado para o fluxo, com o objetivo de integrar recursos ao longo de todo o trajeto que se estende desde os fornecedores até os clientes finais, é desejável que se tenha um meio de avaliar os custos e o desempenho deste fluxo. Segundo os autores, a falta de informações sobre desempenho é um dos motivos mais importantes para a dificuldade que muitas companhias têm sentindo para a adoção de uma abordagem integrada para a logística.

A base de uma medição eficaz é uma análise de fatores de sucesso para todo o processo logístico, que deve ser orientado pela estratégia, garantindo assim, coerência entre as ações e os indicadores utilizados para a monitoria do processo (DORNIER et al., 2000; WOUTERS e WILDEROM, 2008). Sobre a abrangência da avaliação do desempenho logístico, Bowersox, Closs e Cooper (2006) afirmam que o objetivo mais importante de um desempenho logístico superior é o de melhorar o valor para o acionista e o cliente, portanto um sistema de avaliação abrangente precisa tocar os pontos cruciais de impacto no valor para ambos. A figura 3.7, ilustra este posicionamento.

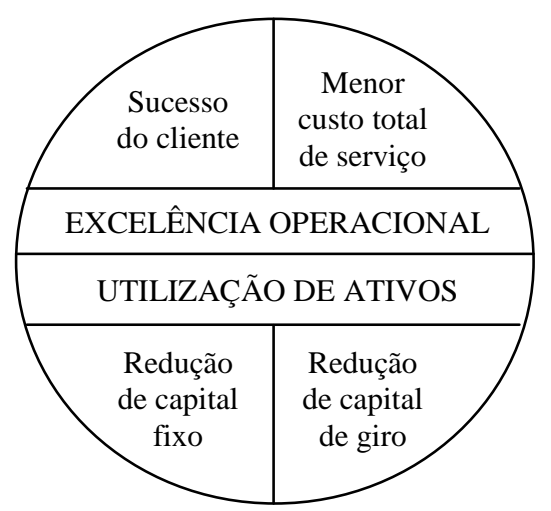

Figura 3.7 - Dimensões do desempenho logístico Fonte: Bowersox, Closs e Cooper (2006) 
A estrutura apresentada considera tanto a excelência operacional quanto a utilização de ativos no desempenho logístico. Na dimensão da excelência operacional, as métricas-chaves focalizam o atendimento otimizado aos clientes, de modo a contribuir para seu sucesso ainda maior e reduzir o custo total dos serviços. A utilização de ativos reflete a eficiência da gestão dos ativos fixos da empresa e do seu capital de giro. Capital de giro representa o dinheiro em espécie, o investimento em inventário e o diferencial em investimentos relativos às contas a receber/pagar. Em particular, ao gerenciar de forma mais efetiva os ativos relativos às operações logísticas, a empresa pode liberar ativos da base existente. Esse capital liberado é conhecido como giro de caixa, que pode ser usado para reinvestimento em outras áreas da organização. A utilização de ativos como um todo é particularmente importante para os acionistas e também para a empresa, na forma como ela é vista pelos mercados financeiros.

\subsection{Abordagens sobre o processo de medição de desempenho na logística}

Segundo Dornier et al. (2000) a integração da logística tem grandes implicações sobre o projeto e uso de indicadores de desempenho. Técnicas e medidas de desempenho adaptadas às realidades logísticas são críticas, pois o controle eficaz da gestão de custos e operações demanda informações apropriadas sobre o desempenho integrado. A tomada de decisão, sobretudo quanto às funções de caráter logístico, necessita de um conjunto de medidas que apresentem alto grau de sinergia.

Sobre as características do processo de medição de desempenho logístico é relevante a consulta a algumas abordagens específicas existentes na literatura. Devido ao detalhamento fornecido e aos distintos períodos em que foram desenvolvidos, destacam-se a seguir as abordagens de Michigan State University (1995), Lambert, Stock e Vantine (1998), Beamon (1999), Bowersox e Closs (2001), Gunasekaran, Patel e Tirtiroglu (2001) e Christopher (2007).

\section{Abordagem de Michigan State University}

Pesquisa realizada pelo GLRT da Michigan State University (1995) evidenciou que as organizações com logística de classe mundial percebem a medição de desempenho como uma competência crítica e mostram maior proficiência que seus competidores nesta atividade. De 
acordo com esta abordagem, as medidas de desempenho empregadas pelas empresas de classe mundial pertencem a quatro dimensões:

- serviço ao cliente e qualidade;

- custos;

- produtividade, e

- gerenciamento de ativos .

A pesquisa considera ainda que a competência de mensuração se traduz em três perspectivas: a avaliação funcional, a avaliação por processos e o benchmarking. Segundo os autores a avaliação funcional se dá como forma de identificar problemas potenciais e prover bases para um desempenho superior, escolhe-se então em medir as quatro grandes áreas já citadas: medidas dos ativos utilizados na condução da logística; controle de custos; nível de serviço ao cliente e produtividade dos recursos humanos e equipamentos. A avaliação de processos, conforme abordagem parte da necessidade de criar valor na percepção dos usuários e neste sentido a mensuração por processos exige novas métricas, voltadas para a cadeia de suprimentos, representadas pelas métricas de custo em suas diferentes formas, a orientação ao cliente e as medidas da cadeia de suprimentos propriamente dita. Como última perspectiva tem-se o benchmarking, como forma de comparar o desempenho obtido com outras atividades internas ou externas a empresa e também com operações concorrentes, realizadas fora do domínio da organização.

\section{Abordagem de Lambert, Stock e Vantine}

Para Lambert, Stock e Vantine (1998) o foco da medição de desempenho logístico é baseado no controle financeiro das empresas. Para os autores a busca pela redução dos custos logísticos, pela melhoria dos serviços prestados aos clientes e a diminuição de conflitos logísticos interdepartamentais foram por décadas as grandes metas do gerenciamento logístico. Aliados às mudanças nas estratégias de transportes, nas técnicas de controle de inventário, nas políticas de armazenagem, nos sistemas de processamento de pedidos e na comunicação logística, os gestores logísticos conseguiram alcançar grande parte das metas desenhadas, porém, falhas na determinação dos custos logísticos envolvidos acabaram por acarretar o não cumprimento integral destes objetivos.

Sob essa perspectiva, os autores propõem que a chave para administrar a função logística é a análise do custo total, onde a partir de um dado nível de serviço ao cliente a administração deve minimizar o custo logístico total e não tentar minimizar o custo de 
atividades individuais. Para os autores a tentativa de redução de custos logísticos quando efetuada de forma separada, sem um enfoque integrado com as demais funções da empresa, pode não ser ótima para o sistema como um todo, inclusive levando a geração de custos totais mais elevados.

Sobre a análise do custo total deve-se saber claramente quais são os custos e receitas logísticas envolvidos nos processos produtivos da empresa e como serão alterados caso haja mudanças no sistema logístico atual. Resumindo, deve-se determinar a contribuição de um produto no lucro da empresa com base no quanto a receita, despesas e lucratividade da organização serão alteradas se a linha de produtos deixar de existir (ou for desativada). Logicamente, a falta de dados contábeis ou a não confiabilidade nos mesmo tendem a prejudicar em grande parte a aplicação com sucesso desta abordagem.

Uma das formas de buscar a solução para o problema da insuficiência de dados seria aplicar o método de custeio baseado em atividades (ABC), fazendo o contraponto ao modelo popularmente utilizado de alocar despesas gerais da empresa com base na mão de obra direta. $\mathrm{O}$ sistema baseado em atividades examina as demandas de determinados produtos (ou clientes) sobre os recursos indiretos, focando os recursos caros; enfatizando os recursos cujo consumo varia significativamente por produto e tipo de produto e; focando os recursos cujas demandas não têm relação com os métodos tradicionais de alocação, tais como mão de obra direta ou custo de materiais.

\section{Abordagem de Beamon}

Segundo Beamon (1999) um sistema de medição de desempenho deve estar baseado nas dimensões tempo, qualidade e flexibilidade e em três tipos de medidas: recursos (níveis de eficiência), saídas (níveis de serviço ao cliente) e flexibilidade (habilidade de responder a mudanças). Para a autora um SMD deve conter pelo menos uma medida individual de cada um dos três tipos indicados. As medidas individuais escolhidas de cada tipo devem estar alinhadas com os objetivos estratégicos da organização e com a satisfação dos clientes e assim, possibilitar a interação entre as medidas e também, garantir um nível mínimo de desempenho nas diferentes áreas da cadeia.

Sobre medidas de recursos, Beamon (1999) coloca que estas geralmente objetivam a redução de seus níveis ao longo do tempo. Estas medidas são representadas por: níveis de inventário, necessidade de pessoal, utilização de equipamentos e custos. 
Em relação às medidas de saídas, a autora aponta que estas visam à avaliação dos níveis de serviço ao cliente, como número de itens produzidos, tempo de produção e número de entregas no prazo. Devem ser incluídos também medidas qualitativas como satisfação dos clientes e qualidade do produto.

Medidas de flexibilidade referem-se à avaliação da habilidade de respostas rápidas a alterações no fluxo produtivo, como aumento no volume de produção e flutuações da demanda de consumidores ou da programação de fornecedores. Incluem medidas como número de pedidos devolvidos e habilidade de responder a variações de demanda.

\section{Abordagem de Bowersox e Closs}

Segundo Bowersox e Closs (2001), os objetivos principais do desenvolvimento e da implementação de sistemas de medição de desempenho incluem monitorar, controlar e direcionar as operações logísticas e nesse sentido os autores colocam que a medição de desempenho pode assumir perspectivas que variam desde medidas baseadas em funções até medidas inteiramente relacionadas a processos.

As medidas baseadas em funções concentram-se em tarefas individuais necessárias para processar e expedir pedidos. Essas medidas registram o nível de atividade (por exemplo, número de caixas) e, em alguns casos, o nível de produtividade (caixas por hora de trabalho). E embora as medidas baseadas em atividades se concentrem na eficiência e na eficácia das tarefas primárias, elas normalmente não avaliam o desempenho do processo completo para satisfação dos clientes. E por esse motivo, é importante que algumas medidas de desempenho adotem uma perspectiva de todo o processo. As medidas de processo consideram a satisfação do cliente proporcionada por toda a cadeia de suprimento. Essas medidas examinam o tempo total do ciclo de atividades ou a qualidade total do serviço, que por sua vez representam à eficácia coletiva de todas as atividades necessárias para satisfazer aos clientes.

Os autores ainda classificam as medidas em internas e externas. Medidas internas concentram-se na comparação de atividades e processos com metas ou operações anteriores. São medidas utilizadas freqüentemente, pois possibilitam aos gestores a compreensão da origem das informações e a facilidade de coletá-las. As medidas internas podem ser classificadas nas seguintes dimensões:

- custo, relacionado com o quanto é gasto para se atingir objetivos operacionais;

- serviço ao cliente, referente à capacidade da empresa em satisfazer a seus clientes; 
- produtividade, a relação entre o resultado produzido e a quantidade de recursos utilizados para gerar o resultado;

- ativos, que concentra-se nos investimentos despedidos em instalações e equipamentos e em estoques necessários para atingir as metas logísticas, e

- qualidade, utilizadas para determinar a eficácia de um conjunto de atividades logísticas e que representam o resultado percebido pelos clientes.

Para Bowersox e Closs (2001) enquanto as medidas internas são importantes para a avaliação organizacional detalhada, as medidas de desempenho externas são necessárias para monitorar, entender e manter uma perspectiva orientada ao cliente e também se comparar com outras organizações cujas atividades guardem alguma semelhança com as atividades logísticas da organização em foco. Este processo se dá por:

- mensuração regular da percepção dos clientes, com pesquisas ou acompanhamento sistemático dos pedidos dos clientes,

- benchmarking, que compara o desempenho com as práticas de outras organizações ou grupos independentes dentro da mesma organização, atuantes em áreas geográficas ou condições de operações diferentes.

Segundo os autores, benchmarking é um aspecto essencial para uma avaliação abrangente de desempenho, pois identifica medidas de desempenho-chave e níveis de desempenho atuais e históricos. A empresa que está fazendo o benchmarking pode determinar os níveis de serviço ao cliente que são fundamentais para a satisfação do cliente e assim se equiparar a estes padrões de desempenho.

\section{Abordagem de Gunasekaran, Patel e Tirtiroglu}

Gunasekaran, Patel e Tirtiroglu (2001) realizaram revisões bibliográficas sobre a definição de indicadores de desempenho e desenvolveram uma proposta que classifica os indicadores logísticos com base nos níveis hierárquicos: estratégico, tático e operacional. $\mathrm{O}$ estudo destes autores revelou ainda que os indicadores de desempenho estão crescendo em escopo e importância e indicou tendências como a mudança de foco do método da contabilidade tradicional de custos para uma técnica de custeio baseada em atividades e o impacto dessas atividades em outras funções como no serviço ao consumidor, utilização dos ativos, produtividade e qualidade. Com base nestas tendências os indicadores podem ser classificados também como: financeiros e não financeiros. 
Considerando as atividades produtivas da cadeia logística. Os autores afirmam que já que as atividades operacionais de uma empresa começam com o recebimento de pedidos, a forma como estes pedidos são geridos irá determinar o desempenho de atividades da cadeia e os níveis de inventário, e, portanto a primeira fase de um processo de avaliação de desempenho deve contemplar as atividades relacionadas aos pedidos. Outro aspecto colocado como determinante para a avaliação de desempenho, é a gestão de relacionamentos entre os membros da cadeia de suprimentos. Segundo esta abordagem, é necessária a avaliação do nível de parceria que existe entre eles para que melhorias possam ser propostas. Após o planejamento dos pedidos, a próxima fase que deve ser analisada é o desempenho da produção. Neste momento, informações relacionadas a custos, qualidade, velocidade, flexibilidade e confiabilidade, são impactantes no levantamento do nível de desempenho da produção. No processo final da cadeia, na atividade de distribuição, que está diretamente ligada ao consumidor, Gunasekaran, Patel e Tirtiroglu (2001), indicam que deve se medir o desempenho do sistema como um todo e as relações entre os seus elos, uma vez que falhas na atividade de distribuição acabam por afetar a percepção que o consumidor tem do sistema como um todo.

Outras dimensões citadas pelos autores como de relevância para o processo de medição são os níveis de serviço e a satisfação do consumidor. Destacam ainda os indicadores financeiros e de custos logísticos, em que o desempenho financeiro da cadeia pode ser avaliado pela determinação dos custos totais logísticos.

\section{Abordagem de Christopher}

Segundo a abordagem de Christopher (2007) a avaliação de desempenho logístico deve ocorrer com base em benchmarking e custo.

$\mathrm{O}$ autor coloca que o custo deve ser medido de forma incremental, através de uma análise da variação dos custos totais causadas por mudança nas operações e decisões logísticas e a influência destes no sistema como um todo. Nesta abordagem a avaliação do desempenho financeiro pode se dar pela análise de: custos totais de distribuição; custos de transporte; custos de armazenagem; custos de processamento de pedido e custos de entregas locais.

Benchmarking o outro foco de avaliação, é segundo o autor, fundamental para comparar as melhores práticas em termos relativos à concorrência, sendo extremamente importante num ambiente altamente competitivo. Este processo se dá em três dimensões: 
- em relação ao cliente que deve ser à base de referência para medição;

- pela comparação com a melhor prática da classe e

- também pela avaliação de processos e não só de produtos.

\subsubsection{Análise das abordagens sobre medição de desempenho na logística}

A partir da revisão bibliográfica sobre as abordagens específicas para medição de desempenho da logística, pôde-se observar que as propostas, ao elencar dimensões e indicadores de desempenho, apresentam, apesar de suas especificidades, concordância quanto à necessidade da adoção de indicadores balanceados para avaliação da logística. O quadro 3.5 sintetiza o escopo do processo de medição de desempenho segundo cada abordagem.

\begin{tabular}{|l|l|}
\hline Abordagem & Abrangência do processo de medição \\
\hline Michigan State University (1995) & $\begin{array}{l}\text { Medição em três dimensões: avaliação funcional (serviço ao cliente e } \\
\text { qualidade; custos; produtividade e gerenciamento de ativos), } \\
\text { avaliação por processos e o benchmarking }\end{array}$ \\
\hline Lambert, Stock e Vantine (1998) & $\begin{array}{l}\text { Medição de desempenho é baseado no controle financeiro das } \\
\text { empresas }\end{array}$ \\
\hline Beamon (1999) & $\begin{array}{l}\text { Medição de desempenho deve estar baseado nas dimensões tempo, } \\
\text { qualidade e flexibilidade e em três tipos de medidas: recursos (níveis } \\
\text { de eficiência), saídas (níveis de serviço ao cliente) e flexibilidade } \\
\text { (habilidade de responder a mudanças) }\end{array}$ \\
\hline Bowersox e Closs (2001) & $\begin{array}{l}\text { Classificam as medidas em internas (custo, serviço ao cliente, } \\
\text { qualidade, produtividade e gerenciamento de ativos) externas } \\
\text { (percepção do cliente e benchmarking) }\end{array}$ \\
\hline Gunasekaran, Patel e Tirtiroglu (2001) & $\begin{array}{l}\text { Indicadores podem ser classificados como financeiros e não } \\
\text { financeiros; e também com base nos níveis hierárquicos: estratégico, } \\
\text { tático e operacional }\end{array}$ \\
\hline Christopher (2007) & $\begin{array}{l}\text { Avaliação de desempenho logístico deve ocorrer com base em } \\
\text { benchmarking e custo }\end{array}$ \\
\hline
\end{tabular}

Quadro 3.5 - Abrangência do processo de medição de desempenho segundo literatura sobre logística

Como recomendação comum entre as abordagens exemplificadas está a referencia à necessidade de que a medição de desempenho contemple dimensões referentes a nível de serviço (tais como tempo e flexibilidade), gestão de ativos e custo. Considerando o atual contexto competitivo, no qual oferecer um produto no momento correto, a um preço adequado, representa função vital na adição de valor aos stakeholders, é fundamental que a medição de desempenho contemple dimensões relacionadas a estes objetivos primários da logística. 
Observa-se, porém que existe uma falta de visão sistêmica por parte de alguns modelos, como o de Lambert, Stock e Vantine (1998) e Christopher (2007), que atribuem maior importância ao uso de indicadores financeiros. Sendo a logística uma atividade integrada, composta de funções cujo relacionamento é primordial para o sucesso global do processo logístico, constata-se que para uma adequada avaliação do desempenho logístico é necessário o uso de indicadores que avaliem o processo como um todo (BOWERSOX e CLOSS, 2001).

Uma lacuna encontrada refere-se à inexistência de menção a dimensões relacionadas à avaliação da aprendizagem organizacional e inovação, amplamente citadas por autores como Kaplan e Norton (1996) e também a questões sociais e ambientais, debatidas atualmente em todas as áreas de gestão.

Destaque deve ser dado para a ênfase à prática de benchmarking (MICHIGAN STATE UNIVERSITY, 1995; BOWERSOX E CLOSS, 2001 e CHRISTOPHER, 2007) e sua importância na definição de indicadores e metas associadas. O uso desta ferramenta será considerado juntamente com as demais recomendações destacadas, na análise das práticas das empresas pesquisadas.

\subsection{Indicadores de desempenho logístico}

Dada à importância da medição de desempenho, os indicadores podem ser considerados como o centro do entendimento de uma organização. Portanto a definição dos indicadores exige um trabalho cuidadoso, sob o risco de não se considerar medidas necessárias à compreensão do novo ambiente econômico e de que os recursos despendidos neste processo não tragam os benefícios que podem ser esperados de bons sistemas de desempenho (NEELY, GREGORY e PLATTS, 2005 e GRIFFIS et al., 2007).

Especificamente sobre as características dos indicadores, autores como Dornier et al. (2000) e Pires (2001) afirmam que o objetivo da medida é ser capaz de atuar sobre as causas e que um conjunto de indicadores de desempenho balanceados são necessários para um bom processo de medição. O quadro 3.6 apresenta algumas características importantes para os indicadores de desempenho, segundo Keebler et al. (1999). Tais características são aplicadas a indicadores que atuem na avaliação de qualquer atividade e se assemelham as recomendações apontadas pela literatura como necessárias ao SMD como um todo. 


\begin{tabular}{|c|c|}
\hline Características & Descrição \\
\hline Quantificável & Indicador deve expressar um valor objetivo \\
\hline Fácil compreensão & Indicador deve conduzir ao que está sendo medido e como é derivado \\
\hline Motiva comportamento adequado & $\begin{array}{l}\text { Indicador é equilibrado para recompensar o comportamento adequado e } \\
\text { desencorajar o simples cumprimento de regras }\end{array}$ \\
\hline Visível & $\begin{array}{l}\text { Efeitos do indicador são prontamente aparentes para todos os } \\
\text { envolvidos no processo medido }\end{array}$ \\
\hline Bem definida e compreensível & $\begin{array}{l}\text { Indicadores são definidos em concordância com todos os processos- } \\
\text { chave participantes, internos ou externos }\end{array}$ \\
\hline Engloba tanto entradas quanto saídas & Indicador integra fatores de todas as faces do processo medido \\
\hline Mede apenas o que é relevante & $\begin{array}{l}\text { O indicador foca apenas desempenho chave, que realmente são } \\
\text { significativos para o gerenciamento do processo }\end{array}$ \\
\hline Visa economia de esforços & Benefício do uso de indicadores supera os custos de obtenção e análise \\
\hline Facilita a confiança & Indicadores validam a participação dos vários envolvidos \\
\hline
\end{tabular}

Quadro 3.6 - Características de indicadores

Fonte: Adaptado de Keebler et al. (2000)

Sobre a escolha de indicadores, Dornier et al. (2000) afirmam que este é um dos passos mais críticos para o processo de medição de desempenho e suas adoções devem ser validadas de acordo com os objetivos buscados pela empresa. Ao relacionar o desempenho logístico com o nível de serviço ao cliente, Ballou (2006) coloca que encontrar uma medição com abrangência suficiente para garantir uma avaliação efetiva do desempenho da logística dos serviços ao cliente é uma tarefa trabalhosa, considerando-se as inúmeras dimensões dos serviços aos mesmos. O tempo total do ciclo do pedido e suas variabilidades são provavelmente as melhores medidas dessa logística, uma vez que incorporam muitas variáveis consideradas importantes para os clientes. Entre as mensurações mais comuns do desempenho, Ballou (2006) aponta o processamento dos pedidos, acuracidade na documentação dos pedidos, transporte, disponibilidade de produto e estoque, produtos danificados e tempo de processamento da produção e armazenagem. Segundo o autor muitos outros indicadores podem ser usados, devendo ser adaptados ao projeto do sistema logístico operado pela empresa.

Segundo Daugherty, Ellinger e Gustin (1996) e Stank et al. (1999) Wouters e Wilderom (2008) há pouco entendimento sobre uma definição apropriada de desempenho e pouco conhecimento sobre quais fatores constituem os melhores indicadores de desempenho. Enquanto o desempenho tem sido avaliado pela análise da informação em relatórios de desempenho, os indicadores podem não ser apropriados ou relevantes quando o objeto da 
análise é o desempenho de uma atividade de negócio ou um processo específico como a logística.

O desempenho logístico é multidimensional, envolvendo vários objetivos e nenhum indicador é suficiente ou basta para medir o desempenho logístico (CHOW, 1994; WOUTERS, 2009). Neste sentido, o objetivo dos pesquisadores e gerentes é encontrar um conjunto de indicadores que, coletivamente, capturem a maior parte possível, se não toda, das mais importantes dimensões do desempenho a longo e curto prazo.

Estudo realizado por Chow (1994) sobre a definição de avaliação de desempenho logístico revelou uma imensa variedade de definições operacionais e indicadores existentes sobre o tema. Para o autor, uma das fontes de variedade dos indicadores de desempenho é a abrangência dada à atividade logística, uma vez que inúmeros estudos sobre indicadores de desempenho são sobre as atividades logísticas (transporte, armazenagem, etc.), outros sobre as funções logísticas e outros sobre o desempenho da empresa.

Para Holmberg (2000) o número e a variedade de indicadores utilizados nas empresas tendem a crescer com o passar dos anos, requerendo mais e mais recursos para serem produzidos. Uma vez introduzido um indicador de desempenho, o mesmo é raramente removido e, com o tempo, ele se torna obsoleto como a estratégia, sendo, que as atividades continuam mudando. Neste sentido, para Gunasekaran, Patel e Tirtiroglu (2001), há a necessidade de se estudar os indicadores e sua utilização diante dos seguintes problemas:

- Falta de uma distinção clara de medidas para o nível estratégico, tático e operacional, uma vez que as medidas utilizadas nos indicadores de desempenho influenciam as decisões tomadas nos níveis organizacionais; e

- Falta de uma aproximação balanceada: várias empresas compreenderam a importância de indicadores de desempenho financeiros e não financeiros. Para os autores, indicadores de desempenho financeiros são importantes para as decisões estratégicas e relatórios externos; já o controle do dia a dia das operações de produção e distribuição, é melhor realizado com indicadores não financeiros.

Observa-se diante do exposto, que a principal dificuldade não parece estar em decidir o que pode ser medido, mas em se chegar a um conjunto gerenciável de indicadores realmente críticos. Visando colaborar com a discussão apresenta-se no Apêndice A uma relação dos principais indicadores de desempenho logístico. Tal levantamento foi efetuado com base nos trabalhos de Lambert e Burduroglu (2000), Stank, Keller e Daugherty (2001), Stock e 
Lambert (2001), Bowersox e Closs (2001), Schmitz e Platts (2004), Rafele (2004), Angelo (2005), Seth, Deshmukh e Vrat (2006), Morgan (2007), Gunasekaran e Kobu (2007), Griffis et al. (2007), Neves (2008), buscando-se os indicadores comuns entre as propostas e uma descrição mais detalhada dos mesmos, que abrange objetivo e forma de cálculo.

\subsubsection{Classificação dos indicadores de desempenho utilizados na logística: escolha}

Diante da variedade de indicadores obtidos com o levantamento apresentado no Apêndice A, verifica-se a necessidade de um meio de categorização destes. A literatura apresenta diferentes tipos de classificação para os indicadores de desempenho aplicáveis à logística. Têm-se entre as abordagens apresentadas, que os indicadores de desempenho podem ser classificados em:

- Financeiros x Não financeiros (Kaplan e Norton, 1996); (Gunasekaran, Patel e Tirtiroglu, 2001); (De Toni e Tonchia, 2001);

- De processo x Funcional (Bowersox e Closs, 2001); (Michigan State University, 1995);

- Internos x Externos (Bowersox e Closs, 2001);

- Estratégicos x Táticos x Operacionais (Gunasekaran, Patel e Tirtiroglu, 2001).

Sobre a classificação dos indicadores em financeiros e não-financeiros, é relevante mencionar que a utilização de indicadores capazes de expressar outras realidades fora da visão financeira e contábil tradicionais mostrou-se necessária ao longo do tempo. A logística, antes entendida exclusivamente como centro de custos, passou a ser peça fundamental na agregação de valor em muitos setores da economia. Realizar uma operação com menor custo ou maior rentabilidade não é o único objetivo possível para as operações logísticas. O desempenho assume múltiplas dimensões e as organizações precisam decidir como desejam ser percebidas pelos clientes em cada uma. As novas pressões sobre o processo logístico passaram a ser em muitas empresas, por maior flexibilidade, maior confiabilidade, maior rapidez e melhor qualidade.

Os indicadores funcionais concentram-se em tarefas individuais necessárias para processar e expedir pedidos. Contudo estes indicadores não avaliam o desempenho do processo completo para satisfação dos clientes e sendo assim, são necessários indicadores que avaliem todo o processo, examinando, por exemplo, o tempo total do ciclo de atividades ou a 
qualidade total do serviço e que representam à eficácia coletiva de todas as atividades necessárias para satisfazer aos clientes.

Uma abordagem semelhante, porém mais ampla que a anterior, é a classificação dos indicadores em internos e externos. Os indicadores internos concentram-se na comparação de atividades e processos com metas ou operações anteriores e estão relacionados às dimensões custo, serviço ao cliente, produtividade, gestão de ativos e qualidade. Já os indicadores externos são utilizados para a avaliação organizacional detalhada, focando na percepção do cliente, da cadeia logística e também na comparação com outras organizações.

A classificação quanto aos níveis organizacionais estratégico, tático e operacional surgiu do entendimento que decisões tomadas em um nível influenciam nos demais níveis e conseqüentemente no desempenho global. Contudo tal classificação é dificultada quando não há uma definição clara da abrangência do processo logístico dentro da organização, ou mesmo quando a logística não está formalmente estruturada dentro da organização.

No presente estudo busca-se a identificação de uma classificação que permita uma análise mais abrangente da importância dos indicadores de desempenho logístico para as empresas do segmento foco da pesquisa. Com base nas definições colhidas na literatura sobre cada uma das classificações supracitadas, tem-se como proposta a adoção de uma classificação dupla. Se utilizará as classificações dos indicadores em financeiros e nãofinanceiro e em internos e externos.

Justifica-se a proposta com base no interesse em colaborar com a discussão sobre a necessidade de balanceamento do uso de indicadores financeiros e não financeiros e na abrangência da classificação dos indicadores em internos e externos, que permite uma visualização mais clara do alcance da medição de desempenho da logística, que deve ir além da avaliação operacional e considerar uma visão por processos, tratando do relacionamento com clientes, fornecedores e concorrência (benchmarking). 


\section{MÉTODO DA PESQUISA}

Neste capítulo apresenta-se o método e os procedimentos de pesquisa utilizados para a execução da presente dissertação.

\subsection{Abrangência da pesquisa}

Objetiva-se nesta seção inicial apresentar uma síntese dos principais conceitos levantados na revisão bibliográfica que serviram de base para a condução desta pesquisa.

A medição de desempenho fornece os subsídios para manter alinhados os objetivos estratégicos e os requisitos dos clientes (CROSS e LYNCH, 1990; KAPLAN e NORTON, 1992; BITITCI, CARRIE e MCDEVITT, 1997; NELLY e ADAMS, 2000; GUNASEKARAN e KOBU, 2007). Por meio da medição de desempenho é possível verificar se as operações logísticas estão atingindo as metas de serviços desejadas (BOWERSOX e CLOSS, 2001).

A atividade logística necessita ser avaliada sob diversas dimensões e neste sentido devem ser utilizados indicadores que contemplem as dimensões mais importantes e forneçam aos gestores uma visão tanto de curto como de longo prazo do desempenho da empresa (CHOW et al., 1994). No sistema de medição devem constar indicadores de serviço ao cliente, custo e gerenciamento de ativos (MICHIGAN STATE UNIVERSITY, 1995; FAWCETT e CLINTON, 1996; LAMBERT, STOCK e VANTINE, 1998; BEAMON, 1999; BOWERSOX e CLOSS, 2001; GUNASEKARAN, PATEL e TIRTIROGLU, 2001; CHRISTOPHER, 2007). Os sistemas de medição devem ser balanceados; não devem conter apenas indicadores internos, pois ações tomadas em determinada área influenciam todo o resultado logístico. O desempenho logístico também deve ser avaliado de forma integrada e sob uma perspectiva externa, comparando às melhores práticas do mercado e respeitando a opinião dos clientes (BOWERSOX e CLOSS, 2001). Além disso, devem contemplar perspectivas que vão além da financeira, uma vez que o desempenho assume múltiplas dimensões e as organizações precisam decidir como desejam ser percebidas pelos clientes (KAPLAN e NORTON, 1996).

A medição de desempenho não deve ser aleatória, o processo de medição deve ser sistematizado por meio de práticas que conduzam a uma utilização adequada e balanceada dos indicadores. Os indicadores devem ser definidos de forma a alinhar a estratégia da atividade logística e apoiar a tomada de decisões dos gestores. Os resultados obtidos e as possíveis 
variações devem ser monitorados continuamente, visando a identificação de causas das alterações e a eliminação das mesmas, através de ações corretivas. O sistema deve ser dinâmico, passando por revisões periódicas (FAWCETT e COOPER, 1998; NEELY et al., 2000; KENNERLEY e BOURNE, 2003; NEELY et al., 2005).

A figura 4.1, apresenta uma estrutura que ilustra a abrangência da pesquisa e os pontos destacados pela revisão bibliográfica, que serviram para a análise dos dados da pesquisa de campo.

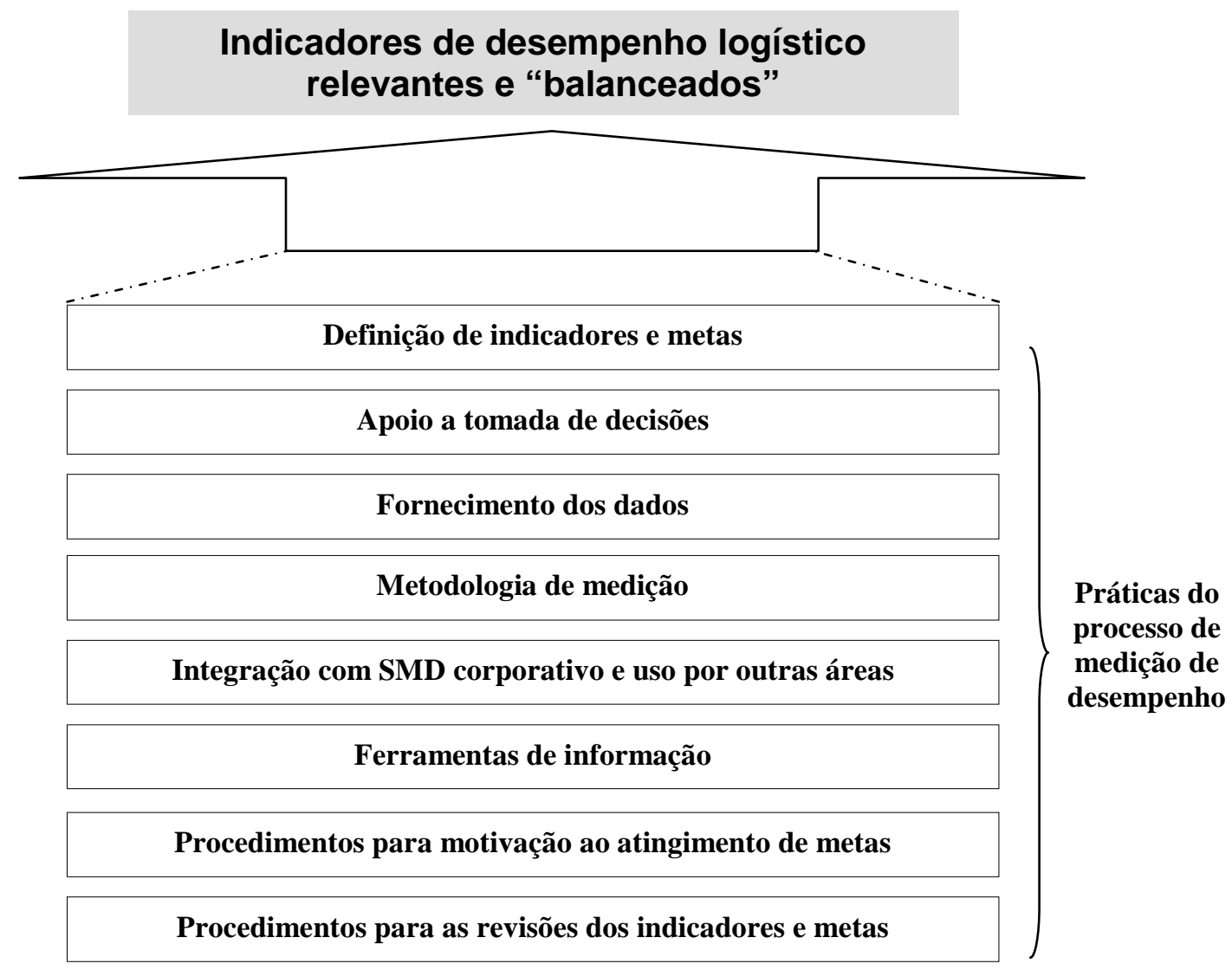

Figura 4.1- Abrangência da pesquisa e pontos de análise

\subsection{Caracterização do método da pesquisa}

Segundo Cervo e Bervian (2002) o interesse e a curiosidade do homem pelo saber levam-no a investigar a realidade sob os mais diversificados aspectos e dimensões. Cada abordagem ou busca admite níveis diferentes de aprofundamento e enfoques específicos conforme o objeto de estudo, objetivos visados e qualificação do pesquisador. É natural, pois, a existência de inúmeros tipos de pesquisa. Cada tipo de pesquisa possui, além do núcleo comum de procedimentos, suas peculiaridades próprias. 
Para Parra Filho e Santos (2002) qualquer trabalho a ser desenvolvido no campo científico exige métodos adequados para facilitar a consecução de seus objetivos, assim como a devida comprovação científica. O método nada mais é do que o caminho a ser percorrido para atingir-se o objetivo proposto. Em função da proposta do trabalho ou da área de concentração da pesquisa, os métodos a serem utilizados podem ser definidos, sendo importante ressaltar que existem métodos gerais aplicados a toda espécie de pesquisa e métodos específicos, cuja utilização vai depender da temática proposta ou do trabalho a ser desenvolvido. A classificação detalhada dos vários campos das ciências facilitará o trabalho do cientista na definição de seu campo de atuação.

Toda classificação se faz mediante algum critério. Para Cervo e Bervian (2002),Gil (2007) e Lakatos e Marconi (2008) é usual a classificação das pesquisas com base em sua abordagem, objetivos e procedimentos técnicos. Portanto, atendo-se a proposta da pesquisa de identificar e analisar os indicadores de desempenho logístico utilizados por empresas do setor de bens de capital agrícolas apresenta-se a seguir sua caracterização.

De acordo com a abordagem dada, uma pesquisa pode ser definida em função de seu caráter qualitativo ou quantitativo. Sobre a diferenciação destas duas perspectivas, Neves (1996) afirma que enquanto os estudos quantitativos geralmente procuram seguir com rigor um plano previamente estabelecido, a pesquisa qualitativa costuma ser direcionada ao longo de seu desenvolvimento, não buscando enumerar ou medir eventos e não empregando instrumentos estatísticos para análise de dados e além disso, seu foco de interesse é mais amplo.

Com base nas afirmações deste autor, pode-se apontar, portanto que a abordagem adotada neste estudo é a qualitativa, uma vez que reconhece que existe uma relação dinâmica entre o mundo real e o sujeito da pesquisa e que a mesma terá o ambiente natural como fonte direta para se coletar os dados, não requerendo a utilização de técnicas estatísticas.

Sobre a classificação quanto ao objetivo, é possível classificar as pesquisas em três grupos: exploratórias, descritivas e explicativas. Dado os objetivos gerais, o presente estudo utilizou a pesquisa exploratória, pois buscou entender e se familiarizar com o fenômeno estudado e obter uma nova compreensão deste. Segundo Gil (2007) pesquisas exploratórias na maioria dos casos, envolvem levantamento bibliográfico, entrevistas com pessoas que tiveram experiências práticas com o problema pesquisado e a análise de exemplos, assumindo a forma de pesquisa bibliográfica ou de estudo de caso.

Para Gil (2007), a classificação das pesquisas em exploratória, descritivas e explicativas é muito útil para o estabelecimento de seu marco teórico, contudo, para analisar 
os fatos do ponto de vista empírico, para confrontar a visão teórica com os dados da realidade, torna-se necessário traçar um delineamento da pesquisa. Este delineamento refere-se ao planejamento da pesquisa em sua dimensão mais ampla, que envolve tanto a diagramação quanto a previsão de análise e interpretação de coleta de dados.

Segundo Gil (2007) o elemento mais importante para a identificação de um delineamento é o procedimento adotado para a coleta de dados. Assim, o autor coloca que podem ser definidos dois grandes grupos de delineamentos: aqueles que se valem das chamadas fontes de "papel" e aqueles cujos dados são fornecidos por pessoas. No primeiro grupo, estão a pesquisa bibliográfica e a pesquisa documental. No segundo, estão a pesquisa experimental, o levantamento e o estudo de caso. Neste último grupo, ainda podem ser incluídas também a pesquisa-ação e a pesquisa participante.

Para execução desta pesquisa foram utilizados os procedimentos de pesquisa bibliográfica, necessária para a elucidação conceitual da pesquisa e o estudo de múltiplos casos.

Conforme Yin (2001), quando o foco se encontra em fenômenos inseridos em algum contexto da vida real o estudo de caso é o procedimento adequado. Estudos de casos podem ser úteis para o propósito de construção de teorias, testes de teorias ou refinamento e complemento de teorias. Conforme Yin (2001) e Voss, Tsikriktsis e Frolich (2002), o estudo de caso é a estratégia adequada quando se colocam questões do tipo "como" e "por que", quando o pesquisador tem pouco controle sobre os eventos e quando o foco se encontra em fenômenos contemporâneos inseridos em algum contexto da vida real. O estudo de caso é a estratégia escolhida ao se examinarem acontecimentos contemporâneos, mas quando não se podem manipular comportamentos relevantes. Esta metodologia se adequou, portanto, aos objetivos do presente estudo.

\subsection{A seleção dos casos}

Os estudos de caso podem ser constituídos tanto de um único quanto de múltiplos casos (GIL, 2007). A utilização de múltiplos casos, abordagem adotada para esta pesquisa, é a situação mais freqüente e de modo geral considera-se que sua utilização proporciona evidências inseridas em diferentes contextos, contribuindo para a elaboração de uma pesquisa de melhor qualidade.

Para composição deste estudo de múltiplos casos, utilizou-se de uma amostra nãoprobabilística e intencional, que contemplou empresas apontadas como líderes de mercado no 
segmento de bens de capital agrícolas, segundo dados estatísticos da Associação Nacional de Fabricantes de Veículos Automotores (ANFAVEA) e identificadas como praticantes de uma atividade logística de excelência, segundo levantamento de BARBOSA (2008), estudo este também pertencente ao projeto IFM II.

Justifica-se a adoção de uma amostra intencional com base nas considerações de Lakatos e Marconi (2008), em que o principal elemento da amostra intencional é a escolha da população propositalmente, feita com base nas contribuições que ela possa oferecer. Dessa maneira, a escolha intencional garante que o elemento selecionado seja relevante ao tema e às questões de análise (YIN, 2001).

\subsection{Coleta de dados}

Segundo Cervo e Bervian (2002) a coleta de dados corresponde a uma fase intermediária da pesquisa. Entre as formas de coleta de dados Yin (2001), Gil (2007) e Lakatos e Marconi (2008), citam a análise de conteúdo, a análise documental, a entrevista, o formulário, a medida de opinião, a observação, a pesquisa de mercado, o questionário, a sociometria e o teste.

No presente estudo se adotou a entrevista, fonte de coleta de dados que corresponde a uma conversação "face a face" e em que um dos participantes formula questões e o outro responde; e também a análise de documentos. Segundo Gil (2007) a entrevista é aplicável a um número maior de pessoas e possibilita o auxílio ao entrevistado com dificuldade para responder, bem como a análise do seu comportamento não verbal. Especificamente utilizouse a entrevista estruturada, guiada por um roteiro previamente estabelecido, necessário para a obtenção junto aos entrevistados, de respostas as mesmas perguntas, o que permitirá a comparação dos casos. O entrevistado em todos os casos é responsável por função gerencial da atividade logística da empresa.

Com base nos objetivos e na estrutura conceitual apresentada na figura 5.1, foi desenvolvido o instrumento de coleta de dados, o roteiro desta pesquisa, dividido em quatro partes:

- Parte I - Identificação da empresa, com questões relacionadas a número de funcionários, faixa de faturamento anual, principais linhas de produtos e sistema de produção adotado;

- Parte II - Identificação da atividade logística. Nesta parte do roteiro busca-se caracterizar a atividade logística desenvolvida na empresa e suas relações 
estratégicas, para verificar se as práticas de gestão da atividade são condizentes com o processo de medição e os indicadores de desempenho utilizados;

- Parte III - Identificação dos indicadores de desempenho logístico. Buscou-se através do preenchimento de um quadro, a identificação de todos os indicadores de desempenho utilizados;

- Parte IV- Identificação do processo de medição de desempenho. Para tanto foram efetuadas perguntas sobre quem são os responsáveis pela criação, fornecimento de dados, cálculo e relato dos resultados dos indicadores logísticos; quais os fatores motivadores para a criação, definição e revisão dos indicadores e suas metas associadas. Além disso, buscou-se verificar a existência de metodologias específicas e ferramentas de informação utilizadas no processo de medição de desempenho, o impacto de resultados dos indicadores nas tomadas de decisões dos gestores, sobre a integração destes indicadores com a avaliação de desempenho de outros setores e do sistema de medição de desempenho da empresa e sobre a utilização dos resultados para motivação dos empregados no atingimento de metas.

O protocolo de pesquisa utilizado para o agendamento das entrevistas, documento composto da solicitação de entrevista e descrição da pesquisa e que segundo Gil (2007) define a conduta de aplicação da pesquisa e o roteiro, encontram-se anexo a este documento, como Apêndices B e C, respectivamente.

\subsection{Tratamento e análise de dados}

O material resultante das entrevistas passou por um tratamento qualitativo, por meio de transcrição das respostas obtidas. Na seqüência como prática adequada a técnica de estudo de caso segundo Yin (2001), a análise dos dados consistiu-se em examinar as evidências levantadas tendo em vista as proposições iniciais do estudo, por meio da estruturação dos dados por meio de tabelas e a confrontação das mesmas com a revisão bibliográfica desenvolvida.

O tratamento dos dados ocorreu por meio da descrição dos dados de identificação das empresas, da atividade logística desenvolvida pelas mesmas, dos indicadores e do processo de medição com a apresentação dos dados de maneira separada, objetivando uma descrição mais aprofundada de cada caso. 
A descrição da atividade logística esteve pautada pelos seguintes aspectos:

- Atividades logísticas desenvolvidas;

- Orientação estratégica;

- Objetivo de desempenho de maior importância para a atividade logística;

- Aspectos considerados na priorização dos objetivos de desempenho;

- Existência de relacionamentos de parceria com fornecedores e clientes.

A descrição dos indicadores se ateve:

- Denominação;

- Objetivo;

- Forma de cálculo;

- Unidade de medida;

- Frequiência de medição e revisão;

- Tempo de uso do indicador na empresa.

A descrição do processo de medição das empresas, focando nos seguintes aspectos:

- Definição de indicadores e metas e envolvidos no processo de definição;

- Apoio a tomada de decisões;

- Fornecimento dos dados;

- Metodologia de medição;

- Integração com SMD corporativo e uso por outras áreas;

- Ferramentas de informação;

- Procedimentos para motivação ao atingimento de metas;

- Procedimentos para as revisões dos indicadores e metas.

A análise dos dados para este estudo se ateve a uma análise comparativa das empresas por meio da síntese dos principais resultados, apresentados por meio de tabelas, com o levantamento dos indicadores comuns as empresas; identificação da abrangência dos indicadores comuns com base na classificação proposta e identificação de um panorama geral da práticas adotadas no processo de medição de desempenho que gere estes indicadores.

O quadro 4.1, apresentado a seguir sintetiza o método proposto para condução desta pesquisa. 


\begin{tabular}{|c|c|c|c|c|c|}
\hline Dados & Origem & Tratamento & $\begin{array}{l}\text { Proposição de } \\
\text { Análise }\end{array}$ & Base teórica & Fonte \\
\hline Indicadores & $\begin{array}{l}\text { Roteiro, } \\
\text { Parte III }\end{array}$ & $\begin{array}{l}\text { Classificação } \\
\text { Relação dos } \\
\text { IDs comuns }\end{array}$ & 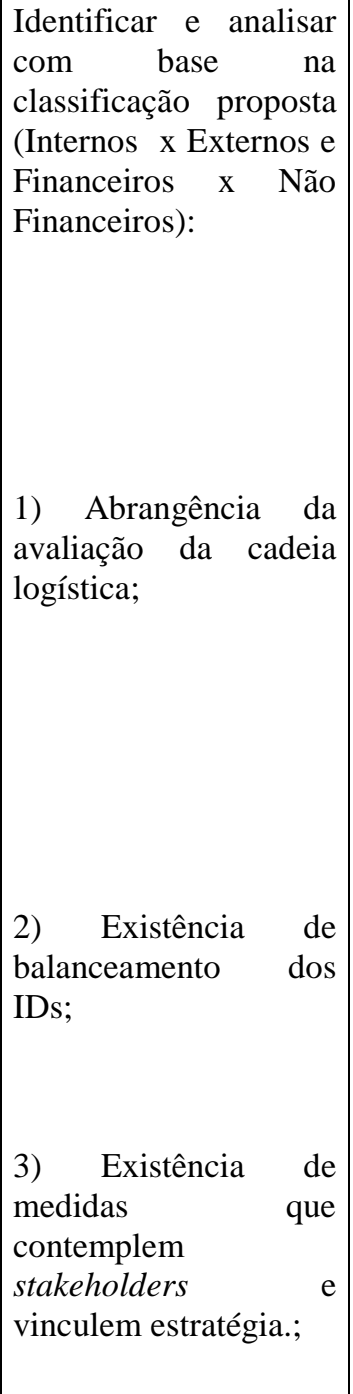 & $\begin{array}{l}\text { Abordagens sobre } \\
\text { medição de desempenho } \\
\text { logístico - Foco em nível } \\
\text { de serviço, custo e } \\
\text { gerenciamento de ativos } \\
\\
\text { Evolução da medição de } \\
\text { desempenho e modelos de } \\
\text { SMD }\end{array}$ & 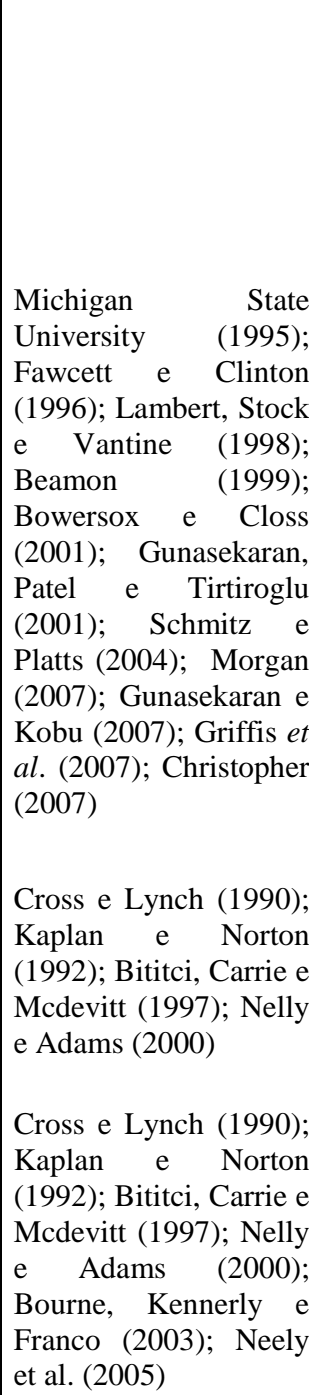 \\
\hline $\begin{array}{l}\text { Processo } \\
\text { de medição }\end{array}$ & $\begin{array}{l}\text { Roteiro, } \\
\text { Parte IV }\end{array}$ & Descrição & 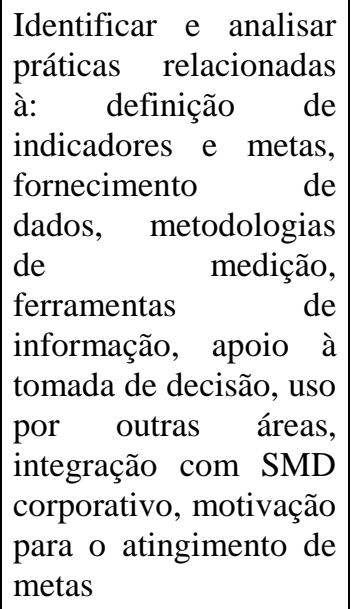 & $\begin{array}{l}\text { Estrutura do processo de } \\
\text { medição de desempenho: } \\
\text { projeto, implementação, } \\
\text { uso e revisão (práticas) }\end{array}$ & $\begin{array}{l}\text { Fawcett e Cooper } \\
\text { (1998); Neely et al. } \\
\text { (2000); Kennerley e } \\
\text { Bourner (2003); } \\
\text { Bourne, Kennerly } \\
\text { Franco (2003); Neely } \\
\text { et al. (2005) }\end{array}$ \\
\hline
\end{tabular}

Quadro 4.1- Síntese do método de pesquisa 


\section{O ESTUDO DE MÚLTIPLOS CASOS}

O setor de bens de capital agrícolas, ao qual pertencem as empresas alvo deste estudo, está inserido à montante da cadeia produtiva do agronegócio brasileiro. Cadeia responsável pela produção, transformação e comercialização de produtos e derivados da agricultura, pecuária e pesca e que nos últimos anos vem contribuindo significativamente para o superávit da balança comercial e em grande parte do crescimento econômico obtido pelo país, em virtude do constante aumento de produtividade aliado à adoção de técnicas de produção e gestão (DUTRA e MONTOYA, 2005).

Segundo o IBGE, no ano de 2008, enquanto a produção industrial na média geral acumulou um crescimento de 3,1\%, o setor de bens de capital agrícolas atingiu 35,1\% de expansão em sua produção física, demonstrando o seu potencial diante da retração da indústria nacional e internacional iniciada no mês de setembro do referido ano.

O setor é constituído por um grande número de empresas de pequeno e médio porte, nacionais e de estrutura familiar, que convivem com poucas empresas multinacionais, principalmente as produtoras de colheitadeiras, em grande parte sob encomenda, que abastecem ao mercado nacional (DUTRA e MONTOYA, 2005).

Segundo Zago (2008), essas empresas adotam como estratégia de distribuição, comercialização e serviços de pós-venda e assistência técnica, uma rede de concessionárias espalhadas pelas diferentes regiões brasileiras, estando próximas dos clientes e dos grandes centros produtores. A comercialização e distribuição das máquinas, pelas diferentes empresas, está diluída por todas as regiões brasileiras, sendo que os clientes da região centro-oeste ainda são os principais consumidores do produto, em virtude de ser um centro produtor aliado aos estados do sul do país.

As condições específicas de culturas e de solo concedem certa proteção natural aos fabricantes locais de máquinas e implementos agrícolas, que não enfrentam muita concorrência de empresas dos países mais desenvolvidos. Outras duas características são muito comuns entre as empresas do segmento de máquinas e implementos agrícolas: verticalização e diversificação da pauta de produtos. A verticalização ainda é muito elevada nessas empresas, sendo que várias delas detêm fundição e realizam serviços de usinagem necessários para suas máquinas. A diversificação de produtos é vista como alternativa para explorar em toda a sua extensão o mercado interno, aproveitando-se a capacitação tecnológica 
e a capacitação produtiva existentes para a fabricação de diferentes famílias de produtos (ZAGO, 2008).

Apresenta-se neste capítulo os dados obtidos com o estudo de múltiplos casos desenvolvido entre 21 de outubro de 2008 e 13 de fevereiro de 2009, em empresas líderes de mercado neste setor. Atendo-se aos objetivos da pesquisa, inicialmente será apresentada a descrição da empresa e da atividade logística desenvolvida pela mesma. Em um segundo momento serão descritos os indicadores adotados por estas empresas, por meio da descrição de nome, objetivo, forma de cálculo e unidade de medida. Finaliza-se com a exposição das principais características do processo de medição logístico.

\subsection{Caso A}

O Caso A corresponde a uma empresa pertencente a uma multinacional norteamericana, que opera no país desde 1990. Produz tratores, colheitadeiras de grãos e retroescavadeiras. Situa-se no estado do Rio Grande do Sul e conta com um faturamento anual acima de 1 bilhão de reais e mais de 1700 funcionários.

\section{A atividade logística do caso $A$}

A atividade logística desenvolvida por esta empresa concentra-se nas funções de planejamento de materiais, follow up de fornecedores, compra de materiais, recebimento, conferência e armazenagem de materiais, movimentação interna dos itens, inventário rotativo e controle de fretes nacionais e internacionais. A atividade é exercida por um total de 161 funcionários.

O gestor principal da atividade logística é o gerente de logística e materiais, que responde diretamente ao vice-presidente de manufatura da corporação. Este gerente coordena as três unidades desta organização no país. Sob sua coordenação encontram-se o supervisor de logística e materiais de cada unidade, que tem sob sua responsabilidade as funções desenvolvidas pelos analistas logísticos e pelo pessoal encarregado pelo recebimento e movimentação de materiais junto a manufatura, conforme o organograma ilustrado na figura 5.1. 


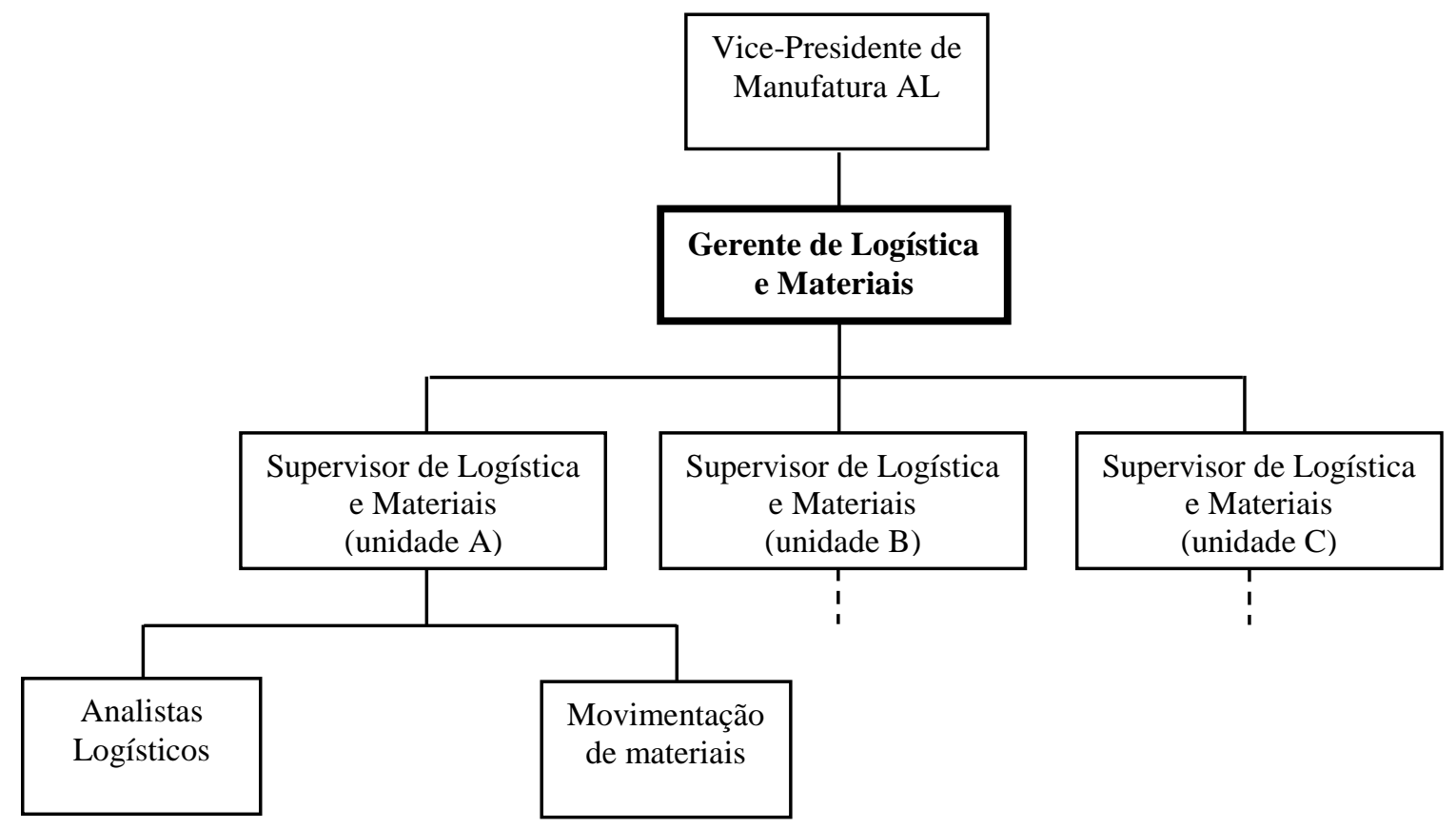

Figura 5.1 - Organograma do caso A

A orientação estratégica seguida pelo gestor principal da atividade na unidade pesquisada, o "supervisor", advém de orientações dadas pela matriz às unidades da América Latina como um todo. O objetivo principal da atividade logística é auxiliar na redução do custo do produto final, nesse sentido seu foco de atuação, como já descrito, está centrado nas funções de suprimentos e apoio a manufatura, com vistas a organizar o fluxo do processo de aquisição de materiais e a redução de estoques e o planejamento de fretes.

Dado o objetivo principal, custo é visto pelo gestor como o objetivo de desempenho de maior importância para a logística. Priorização esta considerada a partir de aspectos como o desempenho frente à concorrência e a estratégia de negócio junto ao mercado, que está diretamente relacionada a demanda pelo produto.

A função de transportes tanto inbound, quanto outbound é terceirizada, neste sentido foi identificado haver uma forte relação de parceria do setor de logística com os transportadores responsáveis pela entrega de matéria-prima e componentes.

\section{Os indicadores de desempenho logístico do caso A}

Os indicadores de desempenho utilizados pelo gestor da atividade logística foram desenvolvido pela corporação e implementados em todas as unidades, contudo quando o gestor necessita de um novo indicador para avaliar uma situação específica, este tem a 
liberdade de desenvolvê-lo e incluí-lo no seu quadro de medidas. A relação de indicadores de desempenho utilizados pelos gestores é apresentada na tabela 5.1.

\begin{tabular}{|c|c|c|c|}
\hline Indicador & Descrição & Forma de cálculo & $\begin{array}{l}\text { Unidade } \\
\text { de medida }\end{array}$ \\
\hline Performance de entrega & $\begin{array}{l}\text { Percentual de entrega do } \\
\text { fornecedor }\end{array}$ & $\begin{array}{c}100-(\text { total de itens entregues } \\
\text { fora da data } x 100) / \text { total de itens } \\
\text { programados }\end{array}$ & $\%$ \\
\hline Faltantes & $\begin{array}{l}\text { Medição dos itens faltantes durante } \\
\text { a montagem no trator }\end{array}$ & $\begin{array}{l}\text { Número de itens faltantes por } \\
\text { estação de trabalho }\end{array}$ & Peças \\
\hline $\begin{array}{l}\text { Percentual de tratores } \\
\text { completos na saída de } \\
\text { linha }\end{array}$ & $\begin{array}{l}\text { Tratores completos saídos da linha } \\
\text { de produção }\end{array}$ & $\begin{array}{l}\text { Quantidade de tratores completos } \\
\qquad / \text { total de tratores }\end{array}$ & $\%$ \\
\hline $\begin{array}{l}\text { Movimentação de } \\
\text { materiais }\end{array}$ & $\begin{array}{l}\text { Calcula as horas de movimentação } \\
\text { de materiais por unidade produzida }\end{array}$ & $\begin{array}{c}\text { Total das horas trabalhadas / } \\
\text { produção }\end{array}$ & Horas \\
\hline Giro de estoque & Giro de estoque & $\begin{array}{l}\text { Somatória do consumo de doze } \\
\text { meses (FAC) / média do } \\
\text { fechamento mensal de estoque de } \\
\text { doze meses }\end{array}$ & $\%$ \\
\hline Frete Premium & Despesas com frete expresso & $\begin{array}{l}\text { Despesas com frete expresso / } \\
\text { total de unidades produzidas }\end{array}$ & $\%$ \\
\hline Frete & $\begin{array}{l}\text { Frete referente aquisição de } \\
\text { matéria prima }\end{array}$ & $\begin{array}{l}\text { Custo de frete / valor do material } \\
\text { FOB }\end{array}$ & $\%$ \\
\hline Custo de importação & Custo de importação & $\begin{array}{c}\text { Custo de importação / valor do } \\
\text { material FOB }\end{array}$ & $\%$ \\
\hline $\begin{array}{l}\text { Divergência de } \\
\text { recebimento }\end{array}$ & $\begin{array}{l}\text { Mede a quantidade de Notas } \\
\text { Fiscais com divergência de } \\
\text { quantidades e/ou identificação }\end{array}$ & $\begin{array}{c}\text { Somatória das notas com } \\
\text { divergências }\end{array}$ & Nota \\
\hline Acuracidade de estoque & $\begin{array}{l}\text { Porcentagem de itens com ajuste } \\
\text { "zero" }\end{array}$ & $\begin{array}{l}\text { (Número de divergência / total } \\
\text { contado) - } 1\end{array}$ & $\%$ \\
\hline $\begin{array}{l}\text { RFT (fazer certo na } \\
\text { primeira vez) }\end{array}$ & $\begin{array}{l}\text { Máquinas montadas sem } \\
\text { problemas }\end{array}$ & $\begin{array}{l}\text { Número de máquinas montadas } \\
\text { sem problemas / número total de } \\
\text { máquinas que saíram da linha de } \\
\text { montagem }\end{array}$ & $\%$ \\
\hline
\end{tabular}

Quadro 5.1 - Indicadores do caso A

A relação contempla 11 indicadores. Observa-se que três são indicadores de nível de serviço voltados o desempenho advindo dos fornecedores e também do desempenho da própria atividade no que tange o atendimento a linha de produção (performance de entrega, 
itens faltantes e percentual de tratores completos na saída de linha). Três estão relacionados a custo do transporte nacional e excepcional de aquisição de material-prima e componentes, além do custos com os encargos administrativos de importação (frete, frete premium e custo e importação). Dois indicadores são voltados ao gerenciamento de ativos (giro de estoque e acuracidade de estoque). Dois avaliam a dimensão qualidade dos procedimentos de recebimentos de notas fiscais e do desempenho integrado de todos os setores na produção das máquinas agrícolas (divergência de recebimento e RFT) e um está relacionado a produtividade (movimentação de materiais).

Cabe destacar que além desta relação, mais dois indicadores foram citados, estes avaliam absentismo e acidentes registráveis, contudo os indicadores são calculados de maneira geral, não podendo o gestor logístico acompanhar de forma mais detalhada os índices específicos da atividade que gere e portanto, não os utilizando para a tomada de decisões.

\section{O processo de medição de desempenho do caso $A$}

Seguindo a estrutura de análise proposta para caracterização do processo de medição de desempenho, apresenta-se a seguir as práticas adotadas pelo caso A.

- Definição de indicadores e metas e envolvidos neste processo - A definição de indicadores e metas associadas é feita pelos gestores logísticos da unidade e pela alta gerência, que neste caso engloba os gestores da matriz da corporação. Como fatores impulsionadores para a definição dos indicadores tem-se apontado a necessidade de controle e a comparação entre unidades, a fim de um nivelamento da estratégia corporativa. Metas para estes indicadores são estabelecidas anualmente e também para intervalos de 5 anos e são baseadas principalmente no desempenho passado, desempenho de outras unidades da corporação (benchmarking interno) e benchmarking externo.

- Fornecimento de dados - Os responsáveis pelo cálculo de dados, quando estes estão relacionados diretamente a atividade logística são efetuados pelos analistas logísticos, contudo, como os indicadores estão atrelados ao sistema de medição de desempenho da empresa, a divulgação dos resultados é feita pela área da qualidade, que consolida os resultados advindos das demais áreas e divulga em uma planilha disponibilidade no sistema ERP da empresa. A comunicação junto ao chão-de-fábrica ocorre por meio da divulgação de planilhas em murais. 
- Apoio à tomada de decisões - Segundo o gestor, o uso de indicadores é essencial para a gestão da atividade logística, os resultados são constantemente observados por este e reuniões semanais junto à área de manufatura são realizadas. Os resultados são reportados mensalmente a alta administração local e corporativa.

- Metodologia de medição - A empresa não utiliza metodologia consagrada na gestão de seu sistema de medição de desempenho, emprega-se uma sistemática corporativa aplicada a realidade e as necessidades da empresa.

- Integração com SMD corporativo e uso por outras áreas - Como mencionado, a relação de indicadores utilizada no momento pelo gestor logístico advém totalmente do SMD corporativo. Por utilizar alguns indicadores abrangentes e integrados a atividade desenvolvido por outros setores (RFT e divergência no recebimento de notas físcais) alguns indicadores são utilizados pelas áreas de compras e qualidade da empresa na formulação de suas estratégias e tomadas de decisão.

- Ferramentas de informação - Não é utilizado pela empresa um sistema informatizado ou um software especifico para a gestão do SMD. Dados são coletados acessando-se o sistema ERP (Enterprise Resource Planning), sistema integrado de gestão empresarial e calculados em planilhas a parte, para posteriormente retornarem ao ERP para divulgação.

- Procedimentos para motivação ao atingimento de metas - A empresa conta com um programa de participação nos lucros atrelado ao desempenho anual e ao cumprimento de metas e diversos programas de melhoria contínua, em que os funcionários são incentivados a sugerirem melhorias de processo.

- Procedimentos para as revisões dos indicadores e metas - Indicadores e metas são revistos anualmente, com base nas condições do mercado (demanda pelo produto) e concorrência (market share).

\subsection{Caso B}

O caso B corresponde a uma unidade de uma multinacional norte-americana, que atua no Brasil desde 1979. Localizada no estado do Rio Grande do Sul, produz colheitadeiras e plantadeiras de grãos. Nela trabalham 2.500 empregados e o faturamento anual está acima de 
1 bilhão de reais. A central de distribuição de peças de reposição, localizada na unidade, é responsável pelo abastecimento de peças dos estados da região sul do país.

\section{A atividade logística do caso $B$}

Atividades logísticas desenvolvidas pela empresa do caso B é executada por 250 funcionários e está basicamente ligada às funções de compras, logística interna e serviço logístico. A função de compras relaciona-se ao follow up de fornecedores e planejamento. A logística interna corresponde as operações de recebimento de matéria-prima e componentes; conferência; armazenagem e abastecimento da linha de produção e ao carregamento do produto final nas carretas dos transportadores. Denomina-se pela empresa, serviços logísticos, as operações responsáveis por armazenagens externas e serviços de conferencia do produto final no processo de embarque nos portos. Cabe ainda a atividade logística desta empresa o controle de frete em todos os tipos de modais utilizados.

O principal gestor da atividade logística na unidade alvo deste estudo é também o responsável pela gestão das demais unidades brasileiras e de um centro de distribuição localizado na região sudeste. Dentro das unidades a execução da atividade logística fica a cargo de analistas e funcionários que desempenham a movimentação de materiais. $\mathrm{O}$ organograma correspondente, está ilustrado na figura 5.2.

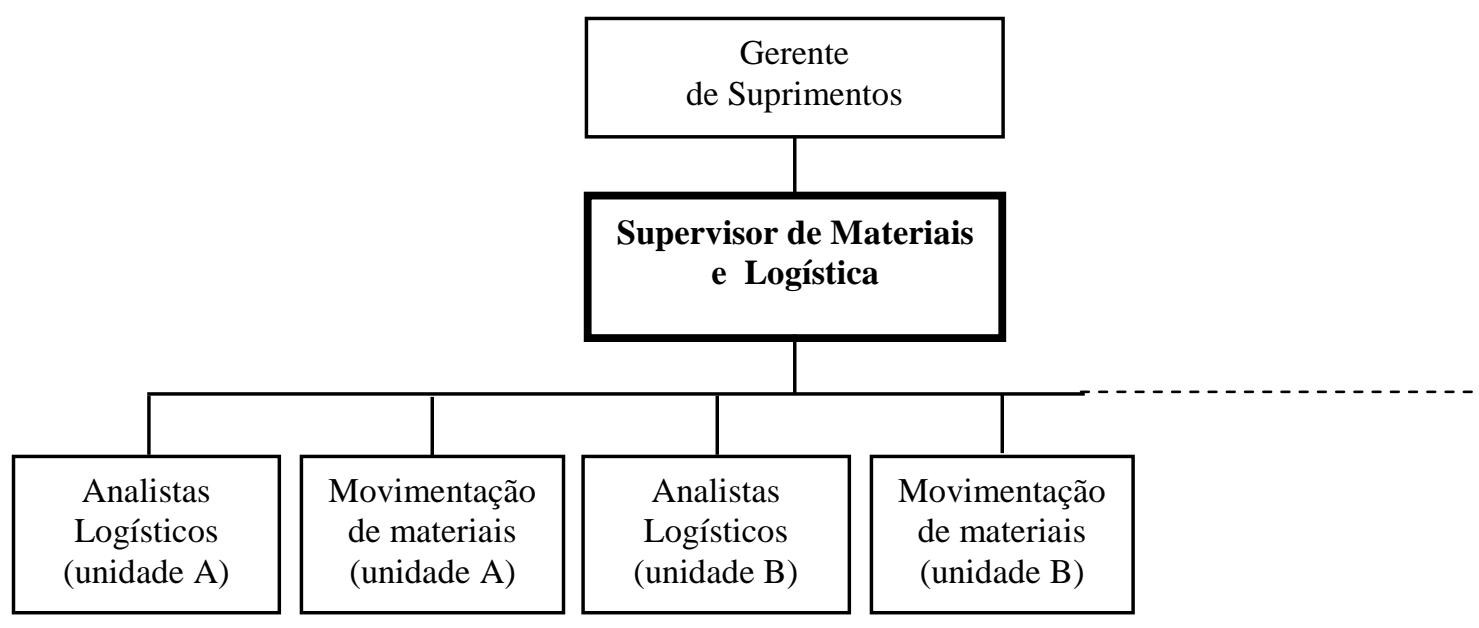

Figura 5.2 - Organograma do caso B

Segundo o respondente, no caso do Brasil a atividade logística é subordinada a diretoria de suprimentos, vinculada a área de compras brasileiras. Nas demais unidades da organização, a logística fica a cargo de uma diretoria mundial denominada de Logística. Contudo quando se questionou sobre o alinhamento da estratégia corporativa com a estratégia 
da atividade logística brasileira, informou-se que a mesma seguia um alinhamento global sugerido por esta diretoria, citando-se até como exemplo da integração, a negociação de compras efetuadas a nível mundial, afim de se garantir um volume e consequentemente uma melhor negociação.

Partindo desta orientação corporativa, o objetivo de desempenho de maior importância para a atividade logística contempla três dimensões: custo, qualidade e flexibilidade. Para o gestor, estes objetivos são constantemente focados, de forma que a empresa se sustente diante da sazonalidade característica do mercado em que atua. E portanto, apesar da concorrência ser considerada, o principal aspecto analisado na priorização destes objetivos de desempenho é o mercado.

Sobre a existência de relacionamentos de parceria com fornecedores e clientes, a empresa segue também uma orientação corporativa de privilegiar relacionamentos de longo prazo e com uma base menor de parceiros. Esta prática pode ser comprovada pela implementação de um programa mundial de avaliação da excelência do desempenho de transportadoras, visando nivelar o desempenho destes em nível mundial,em aspectos como controle de documentação e custos. As unidades brasileiras atualmente contam com três transportadoras para as atividades nacionais de outbound e apenas os serviços de um único transportador inbound, sendo esta parceria exclusiva vista como benchmarking por outras unidades de outros países.

\section{Os indicadores de desempenho logístico do caso $B$}

No momento em que a entrevista com a empresa do caso B ocorreu, a implementação de um programa corporativo de avaliação de transportadoras estava se iniciando. Segundo o gestor, quando implementado, este programa será uma das principais fontes de avaliação da atividade logística, uma vez que permitirá uma integração e um nivelamento global das atividades desenvolvidas no país com as demais unidades e a com a estratégia da corporação. Este novo programa englobará indicadores que visam medir do desempenho das transportadoras quanto a exatidão de documentação enviada para faturamento, valores de frete e desempenho em entrega matéria-prima e componentes e coleta de produto acabado.

Como no momento da coleta de dados para esta pesquisa, o uso deste programa ainda não estava formalizado, o conjunto de indicadores a ser apresentado e caracterizado nesta seção está restrito a cinco métricas. 
Contemplam o conjunto de indicadores utilizados pelo gestor em todas as unidades brasileiras três indicadores que pertencem a dimensão custo (porcentagem de frete sobre material direto e indireto, porcentagem de frete sobre faturamento e custo de importação), um indicador de nível de serviço de terceiros (performance de entrega transportadoras) e um de gerenciamento de ativos (acuracidade de estoque).

Segundo o gestor os resultados advindos do controle de custo do transporte sobre material (inbound) e do indicador de valor do transporte sob faturamento (outbound), métricas estratificadas por tipo de modal, eram até aquele instante os mais monitorados, devido ao grande impacto destes no valor do produto final oferecido pela empresa. O quadro 5.2, apresenta um detalhamento destes indicadores.

\begin{tabular}{|c|c|c|c|}
\hline Indicador & Objetivo & Forma de cálculo & $\begin{array}{l}\text { Unidade } \\
\text { de medida }\end{array}$ \\
\hline $\begin{array}{l}\text { Porcentagem de frete } \\
\text { sobre material direto e } \\
\text { indireto }\end{array}$ & $\begin{array}{l}\text { Valor de mercadorias compradas } \mathrm{x} \\
\text { Fretes pagos }\end{array}$ & $\begin{array}{c}\text { Faz-se uma relação (percentual) } \\
\text { entre os dois valores }\end{array}$ & $\%$ \\
\hline $\begin{array}{l}\text { Porcentagem de frete } \\
\text { sobre faturamento }\end{array}$ & $\begin{array}{l}\text { Valor de vendas de produtos } \mathrm{x} \\
\text { Fretes pagos }\end{array}$ & $\begin{array}{c}\text { Faz-se uma relação (percentual) } \\
\text { entre os dois valores }\end{array}$ & $\%$ \\
\hline $\begin{array}{l}\text { Performance de entrega } \\
\text { transportadoras }\end{array}$ & $\begin{array}{l}\text { Performance do serviços prestados } \\
\text { pelas transportadoras } \\
\text { (cargas avariadas / atraso na Janela } \\
\text { de carregamento / cargas } \\
\text { reprogramadas por falta de veículo / } \\
\text { erros na emissão das faturas de } \\
\text { cobrança / número de cargas } \\
\text { transportadas) }\end{array}$ & $\begin{array}{l}\text { Faz-se uma relação entre o } \\
\text { número total de cargas } \\
\text { transportadas no mês x o } \\
\text { número de cargas com } \\
\text { problema (avaria / atraso / } \\
\text { reprogramação) }\end{array}$ & $\%$ \\
\hline Custo de importação & $\begin{array}{l}\text { Custo de importação de matéria- } \\
\text { prima e componentes }\end{array}$ & $\begin{array}{l}\text { Custo de importação / valor do } \\
\text { material }\end{array}$ & $\%$ \\
\hline Acuracidade de estoque & $\begin{array}{c}\text { Acuracidade na contagem do } \\
\text { estoque }\end{array}$ & $\begin{array}{c}\text { (Número de divergência / total } \\
\text { contado) }-1\end{array}$ & $\%$ \\
\hline
\end{tabular}

Quadro 5.2 - Indicadores do caso B

\section{O processo de medição de desempenho do caso $B$}

Descreve-se a seguir as principais características do processo de medição adotado pelo caso B. 
- Definição de indicadores e metas e envolvidos neste processo - No caso $\mathrm{B}$, a definição de indicadores e metas associadas é feita pelos gestores logísticos da unidade, objetivando fundamentalmente o controle gerencial e o benchmarking interno. Metas associadas a estes indicadores são estabelecidas anualmente, tendo como base o desempenho passado e o desempenho de outras unidades da corporação.

- Fornecimento de dados - Os analistas logísticos são os responsáveis pelo cálculo de dados e divulgação de resultados. Estes acessam manualmente os dados fornecidos pelas áreas de compras e vendas e de sistemas de desempenho das transportadoras parceiras, para elaboração de um relatório consolidado. Este relatório é apresentado mensalmente a gerência local, que irá posteriormente submetê-lo a diretoria de suprimentos na matriz da corporação.

Existe a intenção do gestor em desenvolver um relatório específico que possibilite o acompanhamento da evolução do desempenho da atividade logística por parte de seus clientes internos, as concessionárias. Segundo o respondente, em muitos momentos as concessionárias trazem reclamações sem conhecerem a realidade e as ações que são tomadas para correção de falhas percebidas pelos mesmas. A divulgação de resultados seria portanto, uma forma de demonstrar o comprometimento da atividade logística com seus clientes.

- Apoio à tomada de decisões - Conforme o respondente, os indicadores de desempenho auxiliam na detecção de desvios e garantem ações imediatas; ajudam a discutir a utilização de recursos e possibilitam uma leitura clara dos parceiros, servindo como argumento em negociações. Além disso, no caso desta empresa, atuam como ferramenta de avaliação dos funcionários, possibilitando o reconhecimento dos esforços destes no cumprimento de metas.

- Metodologia de medição - A empresa não utiliza metodologia específica de medição de desempenho. Com a adoção do programa de avaliação de transportadoras, passará a contar com uma técnica corporativa, mas que não está vinculada a nenhuma metodologia difundida academicamente ou comercialmente.

- Integração com SMD corporativo e uso por outras áreas - Segundo o respondente, não há um alinhamento formalizado dos indicadores logísticos com o SMD da unidade ou da corporação, as métricas logísticas não são empregadas no SMD, apenas suportam os indicadores gerais que estão diretamente relacionados ao 
desempenho percebido pelo cliente final. Neste sentido, os indicadores também não são utilizados por outras áreas da empresa.

- Ferramentas de informação - O uso de sistemas de informação ocorre somente para a coleta de dados, que depois são processados manualmente em planilhas. Dados sobre as áreas de compras e vendas são acessados via sistema ERP e dados de desempenho de transportadoras parceiras são obtidos por meio sistemas de gestão das próprias.

- Procedimentos para motivação ao atingimento de metas - A empresa conta com um programa de metas de desempenho para todos os funcionários. Todos têm metas de desempenho específicas desdobradas de metas gerais, que são previamente estabelecida por seu superior. Ao final do período de uma ano, caso o funcionário tenha atingido ou extrapolado esta meta, receberá uma recompensa financeira.

- Procedimentos para as revisões dos indicadores e metas - Revisões em indicadores e metas ocorrem por padrão anualmente, com base nas condições do mercado. Contudo caso ocorra uma grande oscilação no mercado, um fator atípico que impacte na demanda ou variações de um determinado resultado, medidas de revisão são tomadas imediatamente.

\subsection{Caso C}

A empresa do caso C, é uma subsidiária italiana, que atua no país desde 1975. Produz tratores e colheitadeiras de grãos. A unidade pesquisada situa-se no estado do Paraná e conta com um faturamento anual acima de 1 bilhão de reais e um quadro de 1500 funcionários.

\section{A atividade logística do caso $C$}

São 247 funcionários distribuídos em funções relacionadas a logística inbound, que contemplam recebimento, armazenagem e distribuição de matéria-prima e componentes à manufatura e a logística interna, direcionada a programação da produção, fluxo físico de materiais, fluxo de informações logísticas e também a gestão de projetos logísticos.

Trata-se de uma unidade complexa, que trabalha com linhas distintas de duas marcas da qual a corporação é proprietária. O principal gestor logístico da unidade é o supervisor de logística que se reporta a duas diretorias e tem sob seu comando uma equipe composta por 
analistas e operadores que atuam na movimentação de materiais. A figura 5.3, ilustra o organograma desta empresa.

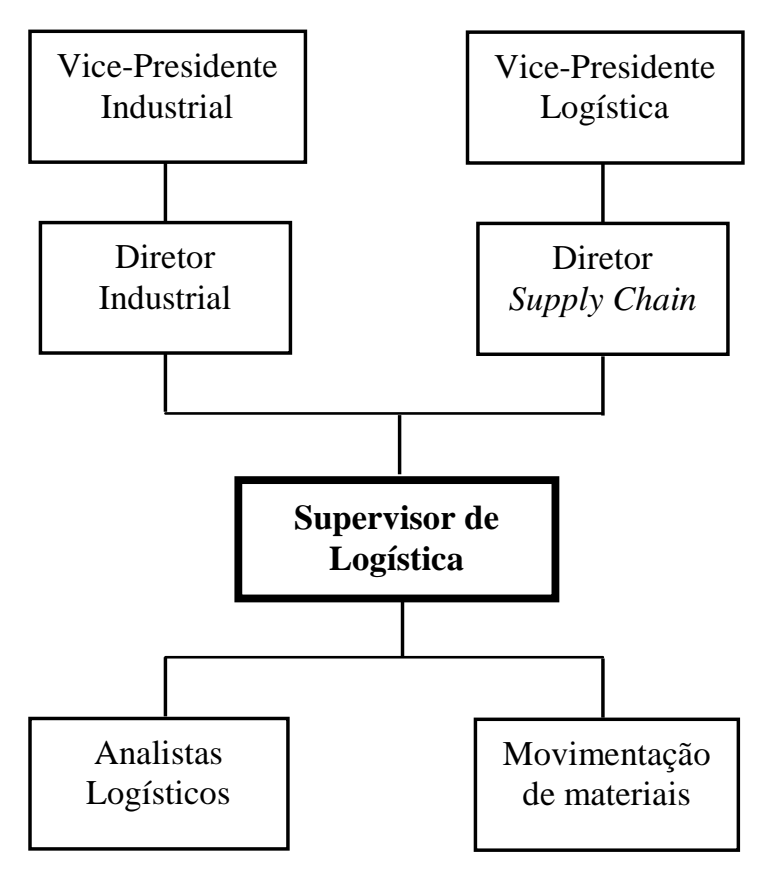

Figura 5.3 - Organograma do caso C

O gestor logístico segue a orientação estratégia advinda destas diretorias, tendo como principal objetivo de desempenho a redução de custo gerada pela atividade de movimentação de matéria-prima e componentes até sua entrega à linha de produção. Neste sentido, o aspecto analisado na priorização de custo como objetivo estratégico da atividade logística é o desempenho frente a concorrência.

Com vistas ao alcance da redução de custos, a área de logística estabelece relacionamentos de parceria com fornecedores, principalmente com transportadoras. Estes parceiros auxiliam a atividade logística no cumprimento das metas do sistema just in time que rege a produção, evidenciando o papel de destaque a logística exerce como apoio a gestão da manufatura.

\section{Os indicadores de desempenho logístico do caso C}

Cabe inicialmente destacar que em um primeiro contato com esta empresa, um ano antes da pesquisa de campo utilizada nesta pesquisa, a mesma utilizava um conjunto de indicadores composto por 47 métricas. Estes indicadores eram divididos em dimensões relacionadas a qualidade, produtividade, custo, segurança, moral e ambiental. Contudo com a 
implementação de um programa corporativo de gestão denominado Word Class Manufacturing, esta relação foi revista. Objetivando alinhar a atividade logística da empresa com o novo programa de gestão, passou-se a utilizar um número bem menor de indicadores, estes são descritos no quadro 5.3 a seguir.

\begin{tabular}{|c|c|c|c|}
\hline Indicador & Objetivo & Forma de cálculo & $\begin{array}{c}\text { Unidade } \\
\text { de medida }\end{array}$ \\
\hline $\begin{array}{c}\text { Produtos incompletos } \\
\text { por abastecimento }\end{array}$ & $\begin{array}{c}\text { Mede o número de produtos que não } \\
\text { estavam completos devido } \\
\text { problemas de abastecimento }\end{array}$ & $\begin{array}{c}\text { Número de produtos completos } \\
\text { / total de produtos }\end{array}$ & $\%$ \\
\hline Nível de estoque & Valorização do volume em estoque & $\begin{array}{c}\text { Saldo em R\$ no final do mês / } \\
\text { consumo médio dos próximos } \\
3 \text { meses }\end{array}$ & $\$$ \\
\hline Custo logístico & $\begin{array}{c}\text { Mede o custo com armazenagem e } \\
\text { transporte }\end{array}$ & $\begin{array}{c}\text { Somatória dos valores } \\
\text { despendidos com armazenagem } \\
\text { e transporte }\end{array}$ & $\$$ \\
\hline Segurança & Número de acidentes de trabalho \\
registráveis & $\begin{array}{c}\text { Somatória dos acidentes } \\
\text { registráveis com funcionários }\end{array}$ & Acidentes \\
\hline
\end{tabular}

Quadro 5.3 - Indicadores do caso C

Para o gestor, estes são os indicadores que permitem a ele uma visualização global do desempenho da atividade que gere. O indicador de nível de serviço, que avalia a porcentagem de produtos incompletos por problema de abastecimento de linha, possibilita a análise da atividade logística como apoio à manufatura. $\mathrm{O}$ indicador de nível de estoque, aponta o valor investido em ativos. $\mathrm{O}$ indicador de custo, trata-se de uma métrica conjugada, medida pela somatória dos valores gastos com a armazenagem e transporte de matéria-prima e componentes. Já o indicador segurança, que foge das perspectivas tradicionais de avaliação, advém de uma política da corporação de controle de acidentes de trabalho.

\section{O processo de medição de desempenho do caso $C$}

- Definição de indicadores e metas e envolvidos neste processo - Os indicadores atualmente em uso advém totalmente do novo sistema de gestão implementado pelos gestores da matriz da corporação. A definição destes indicadores ocorreu por necessidade de controle corporativo, visando padronizar os dados e consequentemente obter um melhor acompanhamento dos resultados entre todas as 
unidades da corporação. Metas foram estabelecidas para um período de 3 anos, baseadas no desempenho histórico e em benchmarking desenvolvido junto ao setor automotivo, segmento industrial no qual a corporação também opera.

- Fornecimento de dados - Os responsáveis pelo cálculo de dados são os analistas logísticos, contudo, como estes indicadores estão vinculados ao sistema corporativo, o reporte ao sistema via intranet é efetuado pelo supervisor. Os resultados são divulgados mensalmente, entretanto reuniões semanais ocorrem entre os níveis operacionais e a supervisão, com o objetivo de divulgar a evolução do desempenho junto aos executores das atividades.

- Apoio à tomada de decisões - Devido a integração com o SMD corporativo, os resultados dos indicadores são diariamente acompanhados pelo gestor logístico, que os utiliza como base de argumentação em processos de negociação com alta direção. Além disso, variações nos resultados são imediatamente avaliados por meio de métodos de resolução de problemas como "Análise de Causa" e "5 Porquês".

- Metodologia de medição - Como mencionado, a metodologia utilizada pela empresa é uma sistemática corporativa, com foco no programa de gestão da manufatura.

- Integração com SMD corporativo e uso por outras áreas - A relação de indicadores advém do SMD corporativo e é diretamente acessada pelas áreas de manufatura, compras, qualidade e financeira.

- Ferramentas de informação - Não há o emprego de um sistema específico para gestão dos indicadores. A coleta de dados é efetuada pelo acesso ao sistema ERP e à planilhas isoladas. Após a coleta, os dados são consolidados em uma planilha, que é divulgada na intranet da empresa.

- Procedimentos para motivação ao atingimento de metas - Não é política da empresa vincular o desempenho à programas com foco em recompensas financeiras. Os programas que são instaurados visam motivar o funcionário a sugerir melhorias em processos, mas mesmo nestes casos, não há vínculo com a remuneração dada ao funcionário.

- Procedimentos para as revisões dos indicadores e metas: Como o sistema foi implementado a pouco tempo, ainda não ocorreram revisões dos indicadores. Foi estipulado um processo anual de revisão das metas associadas a estes indicadores, 
contudo caso ocorram oscilações nas condições do mercado, estas metas poderão ser revistas em um período inferior ao estabelecido.

\subsection{Caso D}

Atuando no Brasil desde 1997, a empresa do caso D, pertence a uma multinacional italiana. Produz colhedoras de cana, colhedoras de café e pulverizadores, além de peças de reposição. Localizada no estado de São Paulo, apresenta um faturamento entre 500 milhões e 1 bilhão de reais e emprega 200 pessoas.

\section{A atividade logística do caso $D$}

Um total de 30 funcionários estão dedicados a atividade logística desenvolvida nesta empresa, que contempla a função inbound, relacionada à conexão com fornecedores, o recebimento e armazenamento, a função de apoio à manufatura através do abastecimento e movimentação interna e a entrega do produto final a área comercial.

O principal gestor da atividade logística na unidade é o supervisor. Este gestor é subordinado diretamente ao diretor industrial da planta, mas também ao diretor mundial de supply chain. O organograma ilustrado na figura 5.4, representa este relacionamento hierárquico.

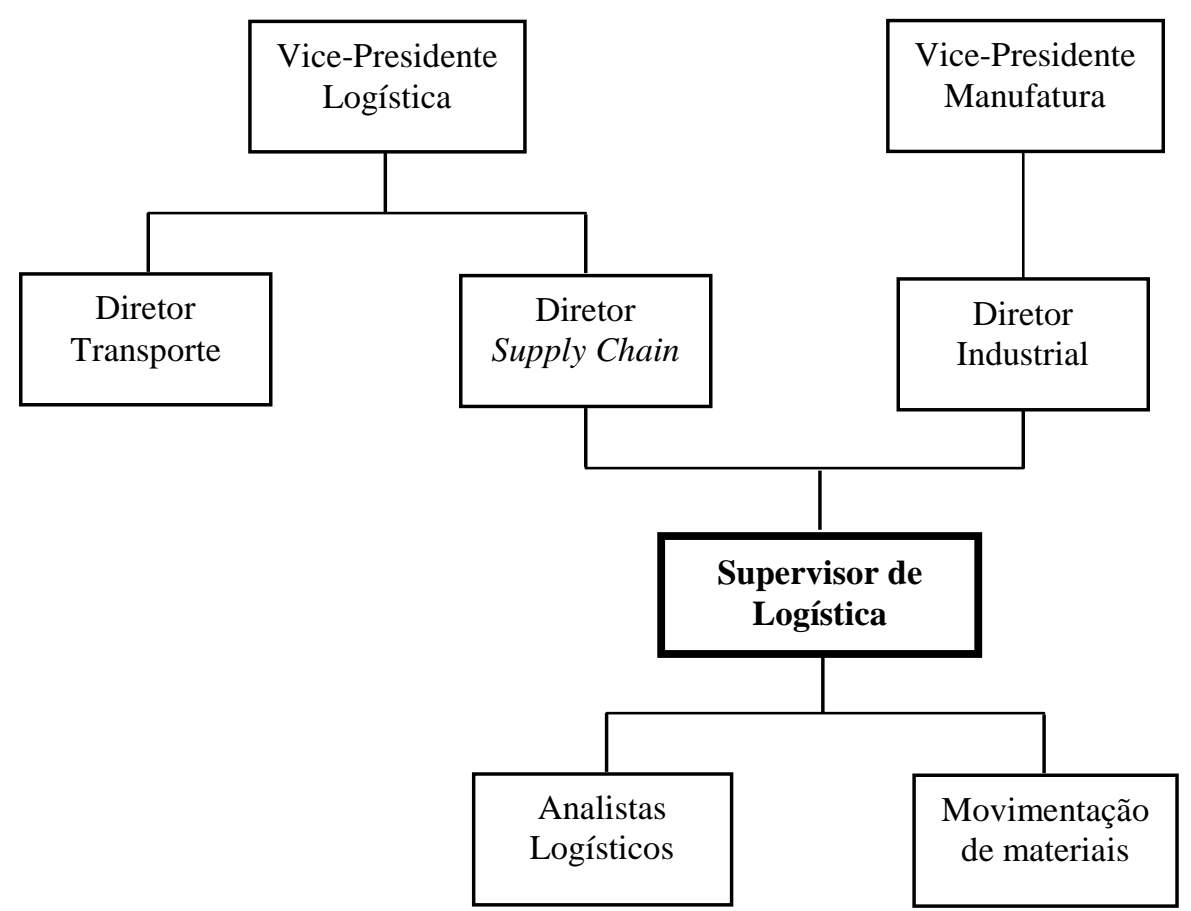

Figura 5.4 - Organograma do caso D 
Apesar do vínculo com a diretoria mundial de supply chain, segundo o gestor não existe um relacionamento estratégico formalizado da atividade desenvolvida com as diretrizes desta diretoria, a planta atua de maneira independente quanto a gestão da atividade logística. Existe porém, um desdobramento de estratégias advindas da diretoria mundial de transporte, que atua como consultora para a planta brasileira e direciona algumas negociações de maneira integrada com esta e outras unidades da corporação.

Mesmo identificando esta autonomia com relação a estratégia corporativa, o objetivo de desempenho de maior importância para a atividade logística, origina-se de uma prioridade global da empresa que é o cumprimento de prazo e conformidade na entrega do produto acabado. Esta estratégia corporativa de negócio é o principal aspecto que direciona os esforços do gestor logístico.

Visando otimização de processos, a empresa estabelece relacionamentos de parceria com fornecedores. Estes estão diretamente relacionados a gestão de estoques, por meio da manutenção de "lojas" dentro da empresa e negociações sob regime de consignação.

\section{Os indicadores de desempenho logístico do caso $D$}

A afirmação do gestor de inexistência de um relacionamento formalizado da estratégia corporativa com as operações logísticas da empresa, é contraposta pela declaração de que os indicadores utilizados derivam de um sistema de medição corporativo. Conforme o gestor, a relação de indicadores que este aplica na avaliação da atividade logística foi originada de um "scorecard" (modelo de medição de desempenho) mundial concentrado na gestão da manufatura.

São 13 indicadores divididos em quatro dimensões: nível de serviço, gerenciamento de ativos, qualidade e custo. Existem ainda indicadores que avaliam desempenho relacionado à absenteísmo e acidentes de trabalho, mas como os resultados são apurados a partir do total de funcionários da unidade, estes não são considerados pelo gestor logístico.

Dos indicadores de nível de serviço, três avaliam o desempenho interno e um o desempenho de fornecedores. Indicadores de gerenciamento de ativo, estão diretamente relacionados ao controle de estoque. Os indicadores de qualidade tem forte relação com o objetivo de desempenho da atividade logística de apoio ao processo de entrega do produto acabado em conformidade. E os indicadores de custo estão focados na avaliação do custo do frete de aquisição de matéria-prima e componentes. A relação completa dos indicadores é descrita em detalhes no quadro 5.4. 


\begin{tabular}{|c|c|c|c|}
\hline Indicador & Objetivo & Forma de cálculo & $\begin{array}{l}\text { Unidade } \\
\text { de medida }\end{array}$ \\
\hline $\begin{array}{l}\text { Confiabilidade de } \\
\text { produção }\end{array}$ & $\begin{array}{c}\text { Porcentagem de máquinas } \\
\text { planejadas que são realmente } \\
\text { produzidas }\end{array}$ & $\begin{array}{l}\text { Número de máquinas entregues } \\
\text { ao comercial no mês / número } \\
\text { de máquinas planejadas }\end{array}$ & $\%$ \\
\hline $\begin{array}{l}\text { Confiabilidade de } \\
\text { peças de reposição }\end{array}$ & $\begin{array}{c}\text { Porcentagem de peças de reposição } \\
\text { planejadas que realmente são } \\
\text { entregues }\end{array}$ & $\begin{array}{c}\text { Número de peças de reposição } \\
\text { entregues no mês / número de } \\
\text { peças planejadas }\end{array}$ & $\%$ \\
\hline $\begin{array}{l}\text { Saída de linha de } \\
\text { produção }\end{array}$ & $\begin{array}{l}\text { Quantidade de máquinas saída da } \\
\text { linha de produção }\end{array}$ & $\begin{array}{l}\text { Número de máquinas saídas da } \\
\text { linha de produção / número de } \\
\text { máquinas planejadas }\end{array}$ & $\%$ \\
\hline $\begin{array}{l}\text { Números de peças em } \\
\text { atraso (fornecedor) }\end{array}$ & Peças em atraso junto ao fornecedor & Somatória das peças em atraso & Peças \\
\hline Dias de estoque & $\begin{array}{l}\text { Quantos dias o estoque existente } \\
\text { cobre a produção }\end{array}$ & $\begin{array}{l}\text { Valor do inventário / consumo } \\
\text { médio do inventário dia }\end{array}$ & Dias \\
\hline Valor de estoque & Valor do estoque existente & Somatória do estoque em valor & $\$$ \\
\hline $\begin{array}{l}\text { Máquinas completas } \\
\text { saídas da linha }\end{array}$ & $\begin{array}{l}\text { Máquinas completas saídas da linha } \\
\text { de produção }\end{array}$ & $\begin{array}{c}\text { Número de máquinas } \\
\text { completas dia / número total de } \\
\text { máquinas }\end{array}$ & $\%$ \\
\hline $\begin{array}{l}\text { Máquinas OK fora da } \\
\text { linha }\end{array}$ & $\begin{array}{l}\text { Máquinas completas e sem defeitos } \\
\text { saídas da linha }\end{array}$ & $\begin{array}{l}\text { Número de máquinas OK dia / } \\
\text { número total de máquinas }\end{array}$ & $\%$ \\
\hline Frete local & $\begin{array}{l}\text { Frete referente aquisição de matéria } \\
\text { prima em fornecedor nacional }\end{array}$ & $\begin{array}{l}\text { Valor do frete pago / valor } \\
\text { material transportado }\end{array}$ & $\%$ \\
\hline Frete importado & $\begin{array}{l}\text { Frete referente aquisição de matéria } \\
\text { prima fora do país }\end{array}$ & $\begin{array}{l}\text { Valor do frete pago / valor } \\
\text { material transportado }\end{array}$ & $\%$ \\
\hline Frete aéreo & $\begin{array}{l}\text { Frete referente aquisição de matéria } \\
\text { prima transportada via aérea }\end{array}$ & $\begin{array}{l}\text { Somatória dos gastos com } \\
\text { aquisições via aérea }\end{array}$ & $\$$ \\
\hline $\begin{array}{l}\text { Acuracidade de } \\
\text { estoque }\end{array}$ & $\begin{array}{c}\text { Acuracidade na contagem do } \\
\text { estoque }\end{array}$ & $\begin{array}{c}1 \text { - (Divergência em \$ / valor } \\
\text { total contado) }\end{array}$ & $\%$ \\
\hline Despesa departamental & Apura as despesas departamentais & Somatória das despesas & $\$$ \\
\hline
\end{tabular}


Com vistas ao atendimento de seu objetivo de desempenho principal, o gestor logístico indica dar maior atenção aos indicadores: confiabilidade de produção, dias de estoque e máquinas completas saídas da linha.

\section{O processo de medição de desempenho do caso $D$}

Apresenta-se a seguir as principais características do processo de medição seguido pelo caso $\mathrm{D}$.

- Definição de indicadores e metas e envolvidos neste processo - A definição de indicadores é feita na maioria das vezes por meio de imposição ou recomendação das vice-presidências, entretanto quando os gestores sentem necessidade de um melhor detalhamento para adequação e entendimento da realidade local, são criados novos indicadores por meio do desmembramento das métricas corporativas. O estabelecimento de metas é anual, para os indicadores operacionais e de 3 anos para indicadores considerados estratégicos para a corporação; estas metas são definidas com base nas variações dos resultados passados e também por imposição da alta administração.

- Fornecimento de dados - O responsável pelo cálculo dos indicadores é um analista. A apuração é diária e o relato estruturado em uma planilha, é divulgado mensalmente. De posse desta planilha o gestor logístico analisa os resultados, conjuntamente com a diretoria da planta e lideranças de outras áreas, em uma reunião. $\mathrm{O}$ envio dos resultados a administração corporativa é realizado pelo diretor da planta.

- Apoio à tomada de decisões - Avalia-se a tendência dos resultados dos indicadores, com vistas à ações preventivas. Em caso de necessidade de ações corretivas, estas são formalizadas em documentos, gerando em casos específicos o desenvolvimento de projetos que visam corrigir e coibir futuras oscilações de desempenho.

- Metodologia de medição - Como referido, a empresa utiliza uma metodologia corporativa na gestão de seu sistema de medição de desempenho.

- Integração com SMD corporativo e uso por outras áreas - O conjunto de indicadores está integrado ao SMD corporativo, sendo utilizado pelas áreas de manufatura e vendas. 
- Ferramentas de informação - Planilhas isoladas obtidas junto ao operacional e o sistema ERP, são as fontes de dados para cálculo dos indicadores, que após serem obtidos pelo analista logístico, são processados sem o auxílio de um sistema de informação específico para a gestão de SMDs.

- Procedimentos para motivação ao atingimento de metas - A empresa conta com um sistema de gestão de recursos humanos, que avalia o desempenho do funcionário anualmente. A partir do atingimento de metas estabelecidas pelo seu superior, o funcionário poderá receber a recomendação para promoção ou reajuste de salário. Cabe lembrar que este sistema de avaliação recompensa com bônus exclusivamente os funcionário com cargos de confiança, os mensalistas recebem apenas um percentual de aumento previamente estabelecido.

- Procedimentos para as revisões dos indicadores e metas - Segundo o gestor, poucas revisões são executadas em indicadores e metas, uma vez que estes advêm de recomendações da corporação. Estas quando ocorrem estão relacionadas a busca de adequação as variações do mercado. Revisões locais tanto em indicadores e metas somente são instauradas para ajuste dos mesmos a realidade da unidade. Busca-se nesta empresa, o alinhamento do SMD local com as recomendações e com o SMD corporativo.

\subsection{Caso E}

O caso E corresponde a uma empresa de origem nacional, atuante desde 1949. Localizada no estado de São Paulo, produz pulverizadores, colhedoras de café e adubadeiras. Com um faturamento entre 500 milhões e 1 bilhão de reais, conta com um quadro acima de 1700 empregados.

\section{A atividade logística do caso $E$}

A atividades logísticas executada por 46 funcionários, constitui-se da distribuição interna de materiais, através do recebimento, armazenagem, manuseio e abastecimento de linha de produção. Atua também na logística reversa e na área de embalagens. 
O responsável pelas operações logísticas é um analista que responde diretamente ao chefe da área de programação e controle de produção. O organograma desta empresa é apresentado na figura 5.5.

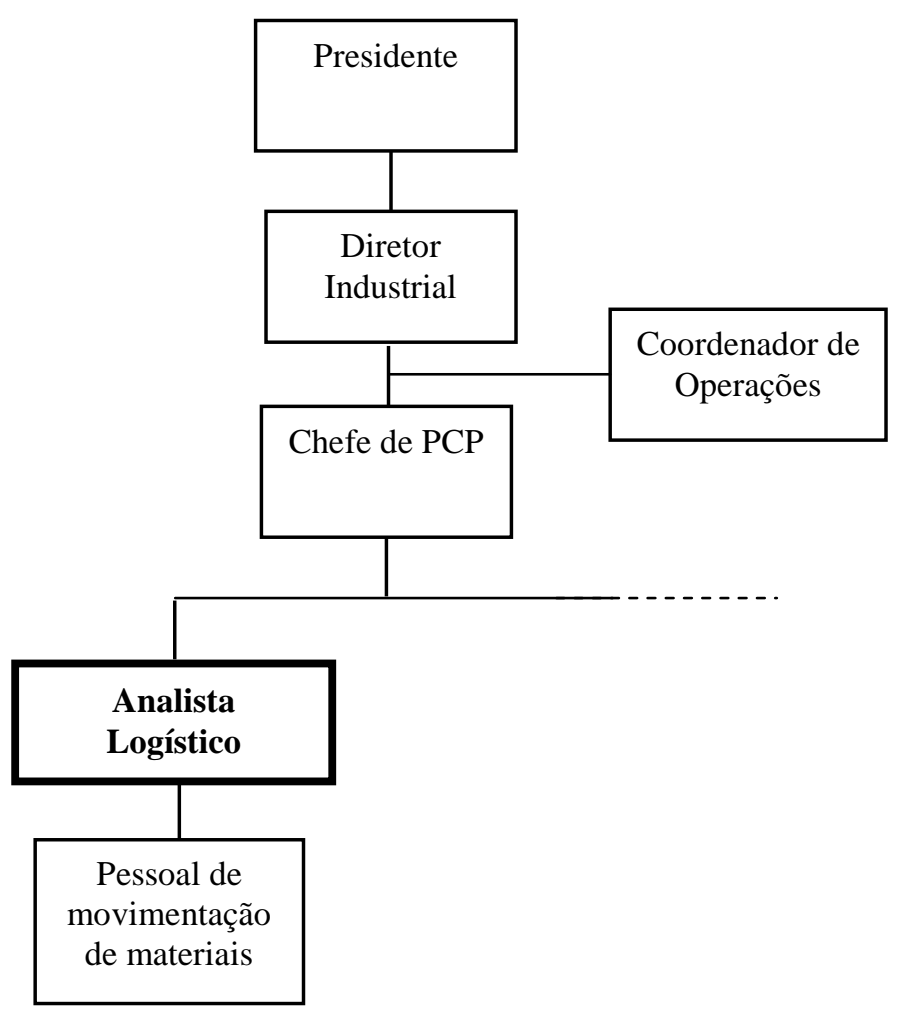

Figura 5.5 - Organograma do caso E

Como observado no organograma a atividade logística está vinculada diretamente à manufatura e neste sentido a estratégia que rege a atividade está focada no abastecimento interno da linha de produção, visando auxiliar no cumprimento da estratégia de produção enxuta. É relevante mencionar que toda a função de distribuição do produto acabado fica a cargo de uma transportadora, empresa pertencente a corporação ao qual a empresa de equipamento agrícolas também faz parte.

Demonstrando a relação direta que tem com a estratégia corporativa, o respondente afirma que os objetivos de desempenho de maior importância para a atividade logística são os mesmo que são priorizados em todas as áreas da empresa, advindos de recomendações da corporação e estão relacionados à segurança, custo, entrega e moral.

A fim de facilitar a execução do regime de produção enxuta, a atividade logística conta com parcerias com alguns fornecedores que executam distribuição de matéria-prima e componentes via sistema milk run junto aos estoques e linhas de produção. 


\section{Os indicadores de desempenho logístico do caso $E$}

Um sistema ERP foi implementado a cerca de dois anos na empresa. A partir da inserção deste sistema foi instituída uma nova área, denominada de coordenadoria de processos, responsável pela gestão do ERP. Devido a problemas no início da operacionalização, os gestores desta coordenadoria resolveram desenvolver indicadores que facilitassem a detecção de falhas de processo e a melhor acuracidade do sistema como um todo. Surgiu desta iniciativa, os indicadores atualmente utilizados na avaliação da atividade logística na empresa, estes são detalhados no quadro 5.5 apresentado a seguir.

\begin{tabular}{|c|c|c|c|}
\hline Indicador & Objetivo & Forma de cálculo & $\begin{array}{l}\text { Unidade } \\
\text { de medida }\end{array}$ \\
\hline $\begin{array}{l}\text { Dias para fechamento } \\
\text { mensal contábil }\end{array}$ & $\begin{array}{l}\text { Avalia quanto eficiente é o processo, } \\
\text { no que se refere à disponibilidade de } \\
\text { informações }\end{array}$ & $\begin{array}{l}\text { Contagem dos dias passados } \\
\text { entre fechamento real e } \\
\text { fechamento contábil }\end{array}$ & Dias \\
\hline $\begin{array}{l}\text { Acuracidade de } \\
\text { inventário em } \\
\text { quantidade }\end{array}$ & $\begin{array}{l}\text { Mede a confiabilidade na contagem } \\
\text { do inventário }\end{array}$ & $\begin{array}{c}\text { (Itens com saldo correto / } \\
\text { quantidade de itens verificados) } \\
\text { x } 100\end{array}$ & $\%$ \\
\hline $\begin{array}{c}\text { Acuracidade de } \\
\text { inventário em valor }\end{array}$ & $\begin{array}{l}\text { Valorização da confiabilidade na } \\
\text { contagem do inventário }\end{array}$ & $\begin{array}{c}\text { (Somatória da diferença em } \$ \\
\text { dos itens positivos com a } \\
\text { diferença em } \$ \text { dos itens } \\
\text { negativos dividido pelo estoque } \\
\text { final) - } 1 \\
\end{array}$ & $\$$ \\
\hline Volume de estoque & Mede o valor investido em estoque & Somatória do saldo & $\$$ \\
\hline $\begin{array}{l}\text { Volume de estoque em } \\
\text { cobertura de dias }\end{array}$ & $\begin{array}{l}\text { Mede quantos dias o estoque cobre } \\
\text { as necessidades da produção }\end{array}$ & $\begin{array}{l}\text { Estoque mês atual / custo } \\
\text { produto vendido do mês futuro }\end{array}$ & Dias \\
\hline $\begin{array}{l}\text { Cumprimento do } \\
\text { programa de produção } \\
\text { (desdobrado por linhas } \\
\text { de produtos) }\end{array}$ & $\begin{array}{l}\text { Mede o nivelamento da produção, } \\
\text { com base na previsão passada por } \\
\text { vendas }\end{array}$ & $\begin{array}{l}\text { Quantidade de máquinas } \\
\text { completas / Quantidade } \\
\text { máquinas batidas }\end{array}$ & $\%$ \\
\hline
\end{tabular}

Quadro 5.5 - Indicadores do caso E

Os indicadores são abrangentes, integrando o desempenho de atividades além da logística. A relação é composta por seis indicadores. Dois destes indicadores estão vinculados a dimensão nível de serviço, sendo um específico à disponibilidade de informação para a área contábil e outro ao cumprimento do programa de produção. Os outros quatro indicadores dizem respeito ao gerenciamento de ativos, relacionados no caso desta empresa, ao estoque e sua versão mensal em valores monetários, o inventário. Conforme o respondente existe ainda 
o indicador de segurança que contabiliza acidentes de trabalho, contudo esta métrica não está integrada ao SMD da empresa.

\section{Processo de medição de desempenho do caso $E$}

- Definição de indicadores e metas e envolvidos neste processo - A definição de indicadores e metas associadas foi efetuada pelos coordenadores operacionais do ERP juntamente com a diretoria industrial, como mencionado, devido a necessidade de controle dos resultados que estavam sendo gerados pelo sistema. A definição dos indicadores e metas ocorreu com base em parâmetros obtidos uma pesquisa bibliográfica desenvolvida pelos coordenadores e negociados posteriormente com a diretoria. Metas inicias focaram resultados a de curto prazo, objetivando validar a implementação do SMD. Anteriormente a este processo só existia um índice de valor agregado para avaliação da atividade logística.

- Fornecimento de dados - Os responsáveis pelo cálculo de dados e divulgação dos resultados são os coordenadores, estes extraem, manipulam e divulgam os resultados via ERP. Além disso, reuniões mensais com os coordenadores do ERP, gerentes e diretoria são desenvolvidas, a fim de discutir de maneira integrada os resultados. Não há murais para divulgação dos dados junto ao nível operacional.

- Apoio à tomada de decisões - Os resultados derivados dos indicadores são usados para nivelar os processos. Para o respondente, os indicadores são utilizados como "termômetro" para esforços de melhoria nos processos produtivos da empresa. Quando são localizados de desvios de desempenho, utiliza-se o método de análise solução de problemas (MASP) para discutir as ações a serem instauradas.

- Metodologia de medição - A empresa utiliza uma metodologia de gestão do processo de medição de desempenho desenvolvida pela mesma.

- Integração com SMD corporativo e uso por outras áreas - Os indicadores são constituintes do SMD da empresa e envolvem o desempenho de atividades desenvolvidas por mais áreas além da logística, deste modo são acessados por todas as áreas que atuam no processo avaliado.

- Ferramentas de informação - Apenas o sistema ERP é utilizado no acesso aos dados. Resultados são obtidos de calculados gerados em planilhas isoladas e regressam ao ERP para divulgação. 
- Procedimentos para motivação ao atingimento de metas - A empresa não recompensa por meta alcançadas. Segundo o respondente, o fato de se trabalhar em um ambiente com alto desempenho, estável, facilita o trabalho do funcionário e consequentemente gera motivação e bem estar ao mesmo. O nível de desempenho obtido sob metas, é apenas uma dos fatores utilizado em um programa de participação de lucros.

- Procedimentos para as revisões dos indicadores e metas - Indicadores e metas ainda não passaram por processos revisão.

Buscou-se apresentar neste capítulo um resumo categorizado das entrevistas efetuadas com as cinco empresas alvo do estudo. Diante da descrição aqui exposta se passará na sequência deste trabalho, a apresentação da análise dos dados, que foi desenvolvida com base no confronto dos dados com as práticas recomendadas pela literatura. 


\section{ANÁLISE DOS DADOS}

Tendo como base o referencial teórico, apresenta-se neste capítulo a análise conjunta dos indicadores e aspectos que caracterizam o processo de medição de desempenho.

\subsection{Os indicadores de desempenho logístico das empresas do setor BK agrícola}

Apesar de apontar a necessidade de se chegar a um conjunto gerenciável de indicadores, a literatura não sugere um número ideal de métricas para a medição das operações logísticas. No levantamento efetuado verificou-se que o número de indicadores utilizados pelas empresas variou de 4 a 13 métricas. O quadro 6.1, apresenta estes indicadores.

\begin{tabular}{|c|c|c|c|c|}
\hline Caso A & Caso B & Caso $\mathrm{C}$ & Caso D & Caso $\mathbf{E}$ \\
\hline $\begin{array}{l}\text { Performance de } \\
\text { entrega }\end{array}$ & $\begin{array}{l}\text { Porcentagem de } \\
\text { frete sobre material } \\
\text { direto e indireto }\end{array}$ & 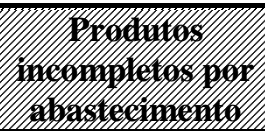 & $\begin{array}{l}\text { Confiabilidade de } \\
\text { produçãa }\end{array}$ & $\begin{array}{c}\text { Dias para } \\
\text { fechamento } \\
\text { mensal }\end{array}$ \\
\hline Faltantes & $\begin{array}{c}\text { Porcentagem de } \\
\text { frete sobre } \\
\text { faturamento }\end{array}$ & \multirow[t]{2}{*}{ Nível de estoque } & $\begin{array}{l}\text { Confiabilidade de } \\
\text { peças de reposição }\end{array}$ & $\begin{array}{l}\text { Acuracidade de } \\
\text { inventário em } \\
\text { quantidade }\end{array}$ \\
\hline 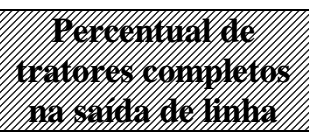 & \multirow{2}{*}{$\begin{array}{c}\text { Performance de } \\
\text { entrega } \\
\text { transportadoras } \\
\text { Custo de importação }\end{array}$} & & 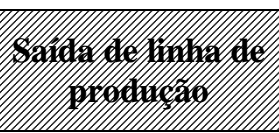 & $\begin{array}{c}\text { Acuracidade de } \\
\text { inventário em } \\
\text { valor }\end{array}$ \\
\hline $\begin{array}{l}\text { Movimentação de } \\
\text { materiais }\end{array}$ & & \multirow[t]{10}{*}{ Segurança } & $\begin{array}{l}\text { Números de peças } \\
\text { em atraso }\end{array}$ & $\begin{array}{l}\text { Volume de } \\
\text { estoque }\end{array}$ \\
\hline Giro de estoque & \multirow[t]{9}{*}{$\begin{array}{l}\text { Acuracidade de } \\
\text { estoque }\end{array}$} & & Dias de estoque & $\begin{array}{l}\text { Volume de } \\
\text { estoque } \\
\text { (cobertura) }\end{array}$ \\
\hline Frete Premium & & & Valor de estoque & $\begin{array}{l}\text { Cumprimento do } \\
\text { programa de } \\
\text { produção }\end{array}$ \\
\hline Frete & & & conom & \\
\hline Custo de importação & & & $\begin{array}{c}\text { Máquinas OK fora } \\
\text { da linha }\end{array}$ & \\
\hline $\begin{array}{l}\text { Divergência de } \\
\text { recebimento }\end{array}$ & & & Frete local & \\
\hline $\begin{array}{c}\text { Acuracidade de } \\
\text { estoque }\end{array}$ & & & Frete importado & \\
\hline \multirow[t]{3}{*}{$\begin{array}{l}\text { RFT (fazer certo na } \\
\text { primeira vez) }\end{array}$} & & & Frete aéreo & \\
\hline & & & $\begin{array}{l}\text { Acuracidade de } \\
\text { estoque }\end{array}$ & \\
\hline & & & $\begin{array}{c}\text { Despesa } \\
\text { departamental }\end{array}$ & \\
\hline IDs custo $\mathrm{d}$ & & $\mathrm{s}$ acuracidade & IDs nív & serviço interno \\
\hline
\end{tabular}

Quadro 6.1 - Indicadores de desempenho logístico comuns entre as empresas 
Dentre os 39 indicadores levantados na pesquisa de campo, verificou-se que não há uma métrica que seja adotada por todas as 5 empresas. Contudo alguns indicadores surgem com certa freqüência.

Os indicadores mais utilizados são relacionados a medição do custo de frete. Foram identificados 7 métricas, em 3 empresas, em versões que avaliam o custo do frete na aquisição em fornecedores locais e aquisições de importados, o custo de fretes especiais (não programados), o custo do frete mensurado por tipo de modal e a porcentagem deste custo sobre faturamento. O uso mais freqüente dos indicadores ligados ao custo da função de transportes, pode guardar relação com a alta representatividade que esta tem frente aos custos totais, conforme apontam Fleury et al. (2000) e também pelo fato de que a logística inbound é apontada por quatro empresas como função gerida pela atividade logística.

$\mathrm{Na}$ sequência aparecem 5 indicadores sob uma mesma perspectiva, são indicadores relacionados à acuracidade de estoque e inventário. Estas métricas de gerenciamento de ativo, localizados em 4 empresas, são uma das principais preocupações da logística e são medidas tanto em termos monetários quanto em volume. Os gestores logísticos com freqüência têm a responsabilidade sobre ativos como equipamentos de transporte, instalações, estoques, equipamentos de manuseio e pessoal. O gerenciamento destes ativos logísticos exige decisões tanto a respeito do investimento inicial quanto de seu eventual descarte ou expansão do seu uso ou na redução dos custos. Michigan State University (1995) recomenda que o gerenciamento dos ativos logísticos seja realizado através do monitoramento de nível e giro de estoque; obsolescência do estoque; retorno sobre o capital próprio (ROE) e retorno sobre o investimento (ROI). Estes indicadores citados, não são considerados pelas empresas pesquisadas.

Outros 4 indicadores presentes em 3 empresas, foram identificados, estes estão relacionados ao desempenho de uma das principais funções de responsabilidade da atividade logística entre as empresas pesquisadas, o apoio à manufatura. Estes indicadores medem principalmente a quantidade ou percentual de máquinas que saem da linha de produção completas, ou seja, máquinas que não tiveram falhas durante a montagem devido a função de abastecimento executada pela logística. São indicadores de nível de serviço interno, que demonstram o quanto adequado está o processo da logística inbound. O bom desempenho nestes indicadores se reflete no processo produtivo como um todo, podendo ser percebido pelo cliente final.

Tem-se portanto como indicadores comuns entre as empresas: custo de frete, acuracidade de estoque e nível de serviço à linha de produção, estes indicadores pertencem às 
dimensões custo, gestão de ativos e nível de serviço, que correspondem justamente as três dimensões com maiores frequências de citações entre a revisão bibliográfica efetuada junto as abordagens sobre medição de desempenho em logística (MICHIGAN STATE UNIVERSITY, 1995; FAWCETT e CLINTON, 1996; LAMBERT, STOCK e VANTINE, 1998; BOWERSOX e CLOSS, 2001; GUNASEKARAN, PATEL e TIRTIROGLU, 2001).

No entanto uma crítica deve ser feita, poucos são os indicadores de qualidade (apenas dois) e inexistem métricas sobre produtividade que segundo o estudo de Michigan State University (1995) são apontados como de destaque para empresas líderes. Conforme a literatura revisada, os indicadores de desempenho empregados pelas empresas com logística de classe mundial pertencem às dimensões custo, serviço ao cliente, produtividade, gerenciamento de ativos e qualidade, enquanto que as empresas em geral, mensuram com maior freqüência o desempenho nas dimensões custo e serviço ao cliente.

As empresas investigadas utilizam indicadores de desempenho logístico de custo, nível de serviço, gerenciamento de ativos, qualidade e segurança. Entretanto o esforço não é distribuído de forma equivalente entre os tipos de indicadores.

Em uma análise caso a caso, verifica-se que o caso A foca em indicadores ligados a dimensão custo e nível de serviço; são 3 indicadores em cada uma destas dimensões. O caso B foca em custo, 3 dos 5 indicadores que possuem estão sob esta dimensão. O caso C mantêm equilíbrio entre os quatro indicadores que utiliza, cada um avalia uma perspectiva diferente. $\mathrm{O}$ caso D possui uma maior quantidade de indicadores de nível de serviço e custo, 4 indicadores em cada. E o caso E foca na gestão de ativos; são 4 entre os 6 indicadores em uso. Observa-se de maneira geral que empresas $\mathrm{A}$ e $\mathrm{C}$ são as que fazem uso de conjunto de indicadores mais equilibrados, seguindo portanto, de forma mais adequada as recomendações da literatura quanto a necessidade de uma visão abrangente do desempenho organizacional .

Pode-se verificar também que as empresas não adotam indicadores voltados à dimensões sociais ou ambientais. Não são utilizados também indicadores sobre a percepção de clientes, nem internos ou externos, como por exemplo, índices de reclamação. O uso de indicadores atrelados aos interesses dos stakeholders de modo geral é insuficiente. Isto pode indicar que, apesar das empresas monitorarem suas falhas, através de medidas ligadas ao nível do serviço logístico, a recuperação dessas falhas pode estar sendo negligenciada pelos sistemas de medição. 
Contudo tal característica pode ser justificada pelo foco que estas empresas atribuem a atividade logística, ligada a função inbound e de apoio à manufatura, sem se relacionar diretamente com o cliente final. Nestas empresas este contato é feito pelas transportadoras terceirizadas e principalmente pelas concessionária, levando a dedução de que apesar de serem líderes de mercado e identificadas como praticantes de uma logística bem estruturada quando a estratégia (BARBOSA, 2008), estas possuem uma visão limitada da importância da logística na integração de processos.

\subsubsection{Alinhamento dos indicadores com a estratégia logística}

Conforme a literatura, deve-se buscar selecionar indicadores que estejam alinhados com a estratégia (KAPLAN e NORTON, 1996; GUNASEKARAN, PATEL e TIRTIROGLU, 2001; KENNERLEY e NEELY, 2003). Indicadores comunicam valores estratégicos e fornecem subsídios para alinhar e manter alinhados estes objetivos e os requerimentos de mercado, coordenar o uso dos recursos e monitorar a evolução da empresa.

Com base na caracterização da atividade logística buscou-se analisar se havia e como se dá o vínculo entre os objetivos estratégicos citados e os indicadores utilizados. Para tanto foi solicitado ao respondente que apontasse dentre a relação de indicadores existente, aqueles que o mesmo considerava como de maior relevância para a sua gestão. De posse desta classificação, buscou-se destacar aqueles com maior grau de importância e confrontar estes indicadores prioritários com o objetivo de desempenho declarado na entrevista.

Os indicadores considerados de maior importância para os gestores logístico são apresentados no quadro 6.2 a seguir, estes estão destacados na cor cinza. 


\begin{tabular}{|c|c|c|c|c|}
\hline Caso A & Caso B & Caso C & Caso D & Caso E \\
\hline $\begin{array}{c}\text { Performance de } \\
\text { entrega }\end{array}$ & $\begin{array}{l}\text { Porcentagem de } \\
\text { frete sobre } \\
\text { material direto e } \\
\text { indireto }\end{array}$ & $\begin{array}{c}\text { Produtos } \\
\text { incompletos por } \\
\text { abastecimento }\end{array}$ & $\begin{array}{c}\text { Confiabilidade de } \\
\text { produção }\end{array}$ & $\begin{array}{c}\text { Dias para } \\
\text { fechamento mensal }\end{array}$ \\
\hline Faltantes & $\begin{array}{c}\text { Porcentagem de } \\
\text { frete sobre } \\
\text { faturamento }\end{array}$ & Nível de estoque & $\begin{array}{l}\text { Confiabilidade de } \\
\text { peças de reposição }\end{array}$ & $\begin{array}{c}\text { Acuracidade de } \\
\text { inventário em } \\
\text { quantidade }\end{array}$ \\
\hline $\begin{array}{c}\text { Percentual de } \\
\text { tratores completos } \\
\text { na saída de linha }\end{array}$ & $\begin{array}{l}\text { Performance de } \\
\text { entrega } \\
\text { transportadoras }\end{array}$ & Custo logístico & $\begin{array}{l}\text { Saída de linha de } \\
\text { produção }\end{array}$ & $\begin{array}{l}\text { Acuracidade de } \\
\text { inventário em valor }\end{array}$ \\
\hline $\begin{array}{l}\text { Movimentação de } \\
\text { materiais }\end{array}$ & \multirow{8}{*}{$\begin{array}{c}\text { Custo de } \\
\text { importação } \\
\text { Acuracidade de } \\
\text { estoque }\end{array}$} & \multirow[t]{8}{*}{ Segurança } & $\begin{array}{c}\text { Números de peças } \\
\text { em atraso }\end{array}$ & \multirow{8}{*}{$\begin{array}{l}\text { Volume de estoque } \\
\text { Volume de estoque } \\
\text { cobertura } \\
\text { Cumprimento do } \\
\text { programa de } \\
\text { produção }\end{array}$} \\
\hline Giro de estoque & & & Dias de estoque & \\
\hline Frete Premium & & & Valor de estoque & \\
\hline Frete & & & $\begin{array}{c}\text { Máquinas } \\
\text { completas saídas } \\
\text { da linha }\end{array}$ & \\
\hline $\begin{array}{c}\text { Custo de } \\
\text { importação }\end{array}$ & & & $\begin{array}{c}\text { Máquinas OK fora } \\
\text { da linha }\end{array}$ & \\
\hline $\begin{array}{l}\text { Divergência de } \\
\text { recebimento } \\
\text { Acuracidade de } \\
\text { estoque }\end{array}$ & & & $\begin{array}{c}\text { Frete local } \\
\text { Frete importado }\end{array}$ & \\
\hline \multirow[t]{2}{*}{$\begin{array}{l}\text { RFT (fazer certo } \\
\text { na primeira vez) }\end{array}$} & & & Frete aéreo & \\
\hline & & & $\begin{array}{c}\text { Acuracidade de } \\
\text { estoque } \\
\text { Despesa } \\
\text { departamental }\end{array}$ & \\
\hline
\end{tabular}

Quadro 6.2 - Indicadores com maior grau de importância segundo os gestores logísticos

Segundo os gestores e a análise pôde se perceber alinhamento das medidas atualmente em uso com a estratégia logística de suas empresas, nos casos A, B, C e D.

A empresa do caso A declarou que o objetivo principal da atividade logística é auxiliar na redução do valor do produto final e deste modo, o gestor se atem ao custo que a execução de suas operações gera. Ao afirmar que os indicadores de frete são prioritários, este gestor validou o vínculo destes indicadores, diretamente ligado a custos, com o objetivo almejado pela logística. Entretanto, em uma visão mais ampla da importância da logística para todo processo produtivo, o gestor identificou também como significativos, os indicadores que medem peças faltantes em linha e a performance de entrega dos fornecedores. Esta afirmação indica que problemas no desempenho das funções inbound e de apoio a manufatura também 
são consideradas para alcance do objetivo estratégico final e tem impacto direto sobre o desempenho global.

No caso B, o objetivo da atividade logística é executar suas operações de modo a contemplar três dimensões: custo, qualidade e flexibilidade. Segundo o gestor, estes critérios essenciais e que devem ser alcançados de modo integrado, devido a característica de demanda sazonal do mercado em que atua. Neste sentido o conjunto de indicadores que o mesmo selecionou como prioritários, atende de forma pontual aos objetivos da atividade. O custo frete inbound tanto é avaliado em relação ao valor do material adquirido quanto em relação ao faturamento, o que possibilita uma visão abrangente do impacto do valor gasto com frete, já o indicador de desempenho das transportadoras, mensura vários aspectos que podem impactar no tempo e qualidade do recebimento.

No caso $C$, a redução de custo gerada pela atividade de movimentação de matériaprima e componentes até sua entrega à linha de produção é o objetivo da atividade logística. Neste caso os três indicadores relacionados diretamente a logística foram apontados como importantes. É possível afirmar que há relação entre os indicadores e a estratégia ao se entender que os indicadores pertencem a uma visão macro de como a logística atua. Na busca por esta visão ampla o sistema de medição corporativo eliminou indicadores pontuais e implementou indicadores abrangentes que contemplam diversos aspectos da atividade logística em um só indicador. Contudo, visualiza-se que este gestor possa ter dificuldades em gerir problemas pontuais de desempenho com o uso destes indicadores muito amplos, como é o caso do indicador de custo total logístico, que engloba armazenagem e transporte.

A empresa do caso D apresenta como objetivo da atividade logística a precisão na entrega, cumprimento de prazo e conformidade na entrega do produto acabado. Dentro do escopo de atuação da logística desta empresa, se vê claramente que os indicadores mais importantes estão atrelados ao atendimento deste objetivo, uma vez que tanto a falta de peças na linha de produção, quanto a falta de matérias em estoque podem comprometer a entrega do produto.

No caso E, a atividade logística é vista como apoio ao processo produtivo, o respondente afirma que os objetivos de desempenho de maior importância para a atividade logística são os mesmo que são priorizados em todas as áreas da empresa: segurança, custo, entrega e moral. O indicador de maior importância para o gestor é o de acuracidade do inventário. Trata-se de um caso em que é difícil inferir a existência de vínculo direto, uma vez que se trata de uma métrica de amplitude pequena frente aos objetivos declarados como buscados pela atividade logística. 
A falta de informações sobre desempenho é um dos motivos mais importantes para a dificuldade que muitas companhias têm em adotar uma atividade logística integrada. Segundo Dornier et al. (2000), a base de uma medição eficaz é uma análise de fatores de sucesso para todo o processo logístico, que deve ser orientado pela estratégia, garantindo assim, coerência entre as ações e as medidas utilizadas para a monitoria do processo. Observou-se na análise exposta que a estratégia corporativa tanto foi implementada diretamente como foi desdobrada pelas empresas. Nos casos A, C e D os indicadores corporativos foram integrados a atividade logística local, no caso B os indicadores forma criados dentro da realidade da unidade, mas sem deixar de considerar o objetivo corporativo.

\subsubsection{A abrangência dos indicadores de desempenho logísticos}

Um dos grandes desafios da medição de desempenho logístico está relacionada a escolha de quais aspectos das operações devem ser medidos e de quais indicadores devem ser usados para medí-los. Os indicadores devem ser dinâmicos e abrangentes para que gestor tenha a real noção do ambiente em que opera e das necessidades de seus stakeholders.

Para análise da abrangência dos indicadores, efetuou-se inicialmente uma classificação dos indicadores relatados pelas empresas. Visando colaborar com a discussão sobre a importância de indicadores que avaliem aspectos não apenas financeiros da atividade logística e obter a abrangência dos indicadores quanto a avaliação de funções internas e externas da atividade da logística, apresenta-se nesta seção a classificação efetuada e discussão desenvolvida sobre o assunto.

\section{Indicadores financeiros e não-financeiros}

A literatura não é precisa na distinção entre indicador financeiro e não-financeiro, alguns autores o relacionam os financeiros à métricas contábeis (KAPLAN e NORTON, 1996; NEELY, GREGORY e PLATTS, 2005), outros autores o relacionam à medidas que avaliam custo (BOWERSOX e CLOSS, 2001; GUNASEKARAN, PATEL e TIRTIROGLU, 2001). Na presente analise se adotou a definição dada por autores que tratam de medição de desempenho no âmbito da logística, a maioria destes relacionam a questão financeira a custos, em que há a valorização monetária do desempenho e uso pela área financeira. O quadro 6.3 apresenta a classificação efetuada, os indicadores financeiros estão destacados na cor cinza. 


\begin{tabular}{|c|c|c|c|c|}
\hline Caso A & Caso B & Caso C & Caso D & Caso E \\
\hline $\begin{array}{c}\text { Performance de } \\
\text { entrega }\end{array}$ & $\begin{array}{l}\text { Porcentagem de } \\
\text { frete sobre } \\
\text { material direto e } \\
\text { indireto }\end{array}$ & $\begin{array}{l}\text { Produtos } \\
\text { incompletos por } \\
\text { abastecimento }\end{array}$ & $\begin{array}{l}\text { Confiabilidade de } \\
\text { produção }\end{array}$ & $\begin{array}{c}\text { Dias para } \\
\text { fechamento mensal }\end{array}$ \\
\hline \multirow{3}{*}{$\begin{array}{c}\text { Percentual de } \\
\text { tratores completos } \\
\text { na saída de linha } \\
\text { Movimentação de } \\
\text { materiais }\end{array}$} & $\begin{array}{c}\text { Porcentagem de } \\
\text { frete sobre } \\
\text { faturamento }\end{array}$ & Nível de estoque & $\begin{array}{l}\text { Confiabilidade de } \\
\text { peças de reposição }\end{array}$ & $\begin{array}{c}\text { Acuracidade de } \\
\text { inventário em } \\
\text { quantidade }\end{array}$ \\
\hline & $\begin{array}{l}\text { Performance de } \\
\text { entrega } \\
\text { transportadoras }\end{array}$ & Custo logístico & \multirow{2}{*}{$\begin{array}{l}\text { Saída de linha de } \\
\text { produção } \\
\text { Números de peças } \\
\text { em atraso }\end{array}$} & $\begin{array}{l}\text { Acuracidade de } \\
\text { inventário em valor }\end{array}$ \\
\hline & $\begin{array}{c}\text { Custo de } \\
\text { importação }\end{array}$ & \multirow[t]{10}{*}{ Segurança } & & Volume de estoque \\
\hline Giro de estoque & \multirow[t]{9}{*}{$\begin{array}{l}\text { Acuracidade de } \\
\text { estoque }\end{array}$} & & Dias de estoque & $\begin{array}{c}\text { Volume de estoque } \\
\text { cobertura }\end{array}$ \\
\hline Frete Premium & & & Valor de estoque & $\begin{array}{c}\text { Cumprimento do } \\
\text { programa de } \\
\text { produção }\end{array}$ \\
\hline Frete & & & $\begin{array}{c}\text { Máquinas } \\
\text { completas saídas da } \\
\text { linha }\end{array}$ & \\
\hline $\begin{array}{l}\text { Custo de } \\
\text { importação }\end{array}$ & & & $\begin{array}{c}\text { Máquinas OK fora } \\
\text { da linha }\end{array}$ & \\
\hline $\begin{array}{l}\text { Divergência de } \\
\text { recebimento }\end{array}$ & & & Frete local & \\
\hline $\begin{array}{c}\text { Acuracidade de } \\
\text { estoque }\end{array}$ & & & Frete importado & \\
\hline \multirow[t]{3}{*}{$\begin{array}{l}\text { RFT (fazer certo na } \\
\quad \text { primeira vez) }\end{array}$} & & & Frete aéreo & \\
\hline & & & $\begin{array}{l}\text { Acuracidade de } \\
\text { estoque }\end{array}$ & \\
\hline & & & $\begin{array}{c}\text { Despesa } \\
\text { departamental }\end{array}$ & \\
\hline
\end{tabular}

Quadro 6.3 - Indicadores financeiros e não-financeiros

Indicadores financeiros não oferecem o foco necessário ao gerenciamento. A dificuldade destes indicadores de medirem as atividades sob uma perspectiva mais ampla encoraja uma otimização local, o que resulta numa sub-otimização do sistema (BOURNE et al., 2000). Outra percepção comum é que os indicadores financeiros, por serem focados internamente, não observam clientes e concorrentes e, portanto, não refletem o foco estratégico e as mudanças no ambiente competitivo.

Dos 39 indicadores de desempenho levantados nas empresas, 17 são financeiros, evidenciando um certo balanceamento entre os indicadores financeiros e não-financeiros. Entre os casos, a empresa B é a que proporcionalmente ao seu total de indicadores, mais foca em métricas financeiras. Este resultado demonstra que a dimensão não-financeira do desempenho logístico encontra espaço entre as medidas de monitoramento de desempenho das empresas do setor de bens de capital. Por outro lado, deve-se observar que, apesar de não 
haver exclusivamente indicadores financeiros neste grupo, há predominância de indicadores de diferentes custos logísticos, podendo-se deduzir que as medidas não financeiras ainda estejam numa fase inicial de entendimento e adoção junto as práticas de medição.

\section{Indicadores internos e externos}

A utilização de medidas externas que avaliam o impacto que a cadeia de atividades que a logística executa é necessária, uma vez que existe um grande potencial para melhorar a eficiência e a eficácia de toda a cadeia através da prática de integração externa, com clientes e fornecedores. Vale porém destacar que estas medidas são difíceis de serem implementadas, em função dos diferentes interesses envolvidos. O quadro 6.4 apresenta a classificação dos indicadores das empresas pesquisadas em indicadores internos e externos, os indicadores externos estão destacados na cor cinza.

\begin{tabular}{|c|c|c|c|c|}
\hline Caso A & Caso B & Caso C & Caso D & Caso E \\
\hline $\begin{array}{c}\text { Performance de } \\
\text { entrega }\end{array}$ & \multirow{2}{*}{$\begin{array}{l}\text { Porcentagem de } \\
\text { frete sobre material } \\
\text { direto e indireto } \\
\text { Porcentagem de } \\
\text { frete sobre } \\
\text { faturamento }\end{array}$} & \multirow{3}{*}{$\begin{array}{l}\text { Produtos } \\
\text { incompletos por } \\
\text { abastecimento } \\
\text { Nível de estoque }\end{array}$} & $\begin{array}{l}\text { Confiabilidade de } \\
\text { produção }\end{array}$ & \multirow{3}{*}{$\begin{array}{c}\text { Dias para } \\
\text { fechamento mensal } \\
\text { Acuracidade de } \\
\text { inventário em } \\
\text { quantidade } \\
\text { Acuracidade de } \\
\text { inventário em valor }\end{array}$} \\
\hline Faltantes & & & $\begin{array}{l}\text { Confiabilidade de } \\
\text { peças de reposição }\end{array}$ & \\
\hline $\begin{array}{l}\text { Percentual de } \\
\text { tratores completos } \\
\text { na saída de linha }\end{array}$ & $\begin{array}{c}\text { Performance de } \\
\text { entrega } \\
\text { transportadoras }\end{array}$ & & $\begin{array}{l}\text { Saída de linha de } \\
\text { produção }\end{array}$ & \\
\hline $\begin{array}{l}\text { Movimentação de } \\
\text { materiais }\end{array}$ & \multirow{9}{*}{$\begin{array}{c}\text { Custo de } \\
\text { importação } \\
\text { Acuracidade de } \\
\text { estoque }\end{array}$} & \multirow[t]{9}{*}{ Segurança } & $\begin{array}{c}\text { Números de peças } \\
\text { em atraso }\end{array}$ & \multirow{9}{*}{$\begin{array}{l}\text { Volume de estoque } \\
\text { Volume de estoque } \\
\text { - cobertura } \\
\text { Cumprimento do } \\
\text { programa de } \\
\text { produção }\end{array}$} \\
\hline Giro de estoque & & & Dias de estoque & \\
\hline Frete Premium & & & Valor de estoque & \\
\hline Frete & & & $\begin{array}{c}\text { Máquinas } \\
\text { completas saídas da } \\
\text { linha }\end{array}$ & \\
\hline $\begin{array}{c}\text { Custo de } \\
\text { importação }\end{array}$ & & & $\begin{array}{c}\text { Máquinas OK fora } \\
\text { da linha }\end{array}$ & \\
\hline $\begin{array}{l}\text { Divergência de } \\
\text { recebimento }\end{array}$ & & & Frete local & \\
\hline $\begin{array}{c}\text { Acuracidade de } \\
\text { estoque }\end{array}$ & & & Frete importado & \\
\hline $\begin{array}{l}\text { RFT (fazer certo na } \\
\text { primeira vez) }\end{array}$ & & & Frete aéreo & \\
\hline & & & $\begin{array}{c}\text { Acuracidade de } \\
\text { estoque } \\
\text { Despesa } \\
\text { departamental }\end{array}$ & \\
\hline
\end{tabular}


Dentre os 39 indicadores, apenas 4 monitoram o desempenho externo. Especificamente estas medidas avaliam o desempenho dos fornecedores em relação a função inbound de entrega.

Uma possível justificativa para este resultado pode estar no foco de atuação da atividade logística desenvolvida pelas empresa. O resultado indica que a abrangência da avaliação da cadeia logística é falha, deixando de contemplar a visão de stakeholders de extrema relevância para o processo produtivo, aqueles que estão no início e no final do processo, os fornecedores e os clientes.

Os indicadores de desempenho externos são necessários para monitorar, entender e manter uma perspectiva orientada ao cliente. No caso da atividade logística destas empresas, nem ao menos os clientes internos são considerados, através de indicadores de satisfação ou reclamação.

Os indicadores externos também são indispensáveis para a comparação com outras organizações cujas atividades guardem alguma semelhança com as atividades logísticas da organização em foco. As empresas A, B e C declaram utilizar o processo de benchmarking interno. Segundo a revisão de literatura, a prática de benchmarking é fundamental para o alcance da competência logística e obtenção de vantagens competitivas. A prática é necessária para que as empresas adquiram consciência das melhores práticas e mudem suas perspectivas a respeito do que é possível ser alcançado, uma vez que a tradicional comparação com o desempenho anterior adotado por várias empresas, gera uma falsa percepção de segurança e da realidade.

\subsection{O processo de medição de desempenho logístico}

A sequência adotada para descrever o processo de medição de desempenho logístico segue a estrutura de análise proposta apresentada no capítulo de metodologia.

\section{Definição de indicadores e metas e envolvidos no processo de definição}

Nas empresas pesquisadas existe a preocupação em alinhar os objetivos da área logística aos da corporação, seja através do desdobramento dos objetivos corporativos para a área de logística ou através do uso de metas definidas pelas matrizes. A empresa E é o único caso em que devido a origem do SMD corporativo (ligado a necessidade de controle do sistema ERP), não foi possível identificar uma relação direta das dimensões a serem 
priorizadas pela organização, no escopo de avaliação da atividade logística, contudo a existência deste vínculo foi declarada pelo respondente.

A preocupação com este alinhamento também é percebido pelo rol de participantes na fase de definição dos indicadores; são envolvidos tanto gestores locais da atividade logística, quanto a alta direção da corporação. O que indica ao mesmo tempo, que há a imposição dos interesses da corporação na definição dos indicadores utilizados.

Diversos autores concordam que os indicadores devem possuir metas definidas. Estas podem ser determinadas com base no desempenho passado ou de outras áreas da empresa. Eccles (1991) critica o uso do desempenho passado ou de outras áreas da empresa como base para definição das metas futuras. Alguns defendem, a prática de benchmarking com outros setores ou com competidores como base mais adequada (NEELY et al., 1997; CHRISTOPHER, 2007). No caso das empresas pesquisadas, talvez devido a sazonalidade do mercado em que atuam, o desempenho logístico frente as condições do mercado encontram ampla adoção entre as empresas como forma de sustentação para a definição de indicadores e metas associadas $\mathrm{O}$ segundo critério mais usado é a imposição interna, que parece atuar complementarmente a outros critérios. Cabe o destaque a prática de benchmarking interno utilizada pelas empresas A e B e a de benchmarking externo utilizado pelas empresa $\mathrm{C}$.

Ainda em relação a metas, verificou-se entre os casos que o prazo estabelecido para as mesmas, de maneira geral é curto, para períodos de 1 a 3 anos, indicando portanto o forte impacto que a sazonalidade e a inconstância de demanda exercem sobre a atividade produtiva destas empresas.

Uma falha encontrada na fase de definição dos indicadores e meta é a ausência da participação dos demais stakeholders no processo. Clientes e fornecedores não participam do processo de criação dos indicadores, o que indica que a medição do desempenho logístico das empresas ainda possui um foco predominantemente interno às mesmas.

\section{Apoio à tomada de decisões}

A utilização dos indicadores no apoio às decisões do dia-a-dia é de fundamental importância para que se possa usufruir dos benefícios da medição de desempenho. (NEELY et al., 1997). Neste ponto os gestores pesquisados foram unânimes em relatar que os indicadores logísticos exercem extrema influência nas suas decisões do dia-a-dia. Indicando que as empresas parecem ter efetivamente uma gestão logística fundamentada na medição de desempenho, sendo os indicadores os principais norteadores das decisões tomadas. 
Segundo os autores pesquisados, uma das chaves da melhoria contínua é o processo constante de monitoramento que identifica as variações e age corretivamente para eliminar as causas das variações. Nas empresas pesquisadas, o feedback sobre os resultados parece ser rápido, uma vez que todos os gestores declararam acompanhar os indicadores considerados mais relevantes para a gestão logística diariamente. Além disso as reuniões mensais de divulgação dos resultados, possibilitam aos níveis corporativo um melhor acompanhamento da evolução do desempenho logístico.

O uso de indicadores para auxiliar a previsão do desempenho futuro é discutido pela literatura, como necessária a identificação de ações corretivas (BOURNE, 2003). Neste sentido Bourne et al. (2000) ressaltaram a importância de reuniões para discussão dos resultados e ações possíveis sobre eles. Entre as empresas pesquisadas, todas disseram realizar reuniões com este propósito. Este resultado indica a existência de um trabalho das empresas de sistematizarem seus processos de medição de desempenho logístico. Isto porque, com a utilização de reuniões periódicas para discussão dos resultados, são reduzidas as possibilidades de que esta avaliação esteja atrelada apenas a percepções individuais. Nas empresas, a realização de reuniões para avaliação dos resultados dos indicadores, ocorrem mensalmente, porém em alguns momentos estas realizam reuniões semanais e até diárias com diferentes níveis hierárquicos. Esta predominância de reuniões mensais é coerente com a frequiência de cálculo dos indicadores que é também, predominantemente, mensal.

\section{Fornecimento dos dados}

Todas as empresas afirmam monitorar variações de desempenho de seus indicadores ao longo do dia. Entretanto o reporte destes indicadores logísticos calculados ocorre numa base mensal. Isto indica que as empresas consideram o período de um mês é um prazo razoável para que as ações corretivas e decisões tomadas tenham um efeito significativo nos resultados que justifique novo cálculo dos indicadores. Por outro lado, talvez, o corpo gerencial não disponha de tempo suficiente para um monitoramento eficiente de indicadores com uma freqüência maior.

Sobre os responsáveis pelos cálculos dos indicadores, a literatura recomenda a prática de responsabilizar uma pessoa ou área pela atividade de medição como um todo (LOHMAN, FORTUIN e WOUTERS, 2004). Nas empresas pesquisadas o que se observou é que não existe uma pessoa ou área responsável, não apenas por calcular, mas também por relatar o resultado dos indicadores. Como a atividade logística está relacionada em muitos momentos 
com a manufatura, o que se observa é o uso de indicadores destes setores, alguns obtidos por funcionários da logística (geralmente analistas) e consolidados pela área de qualidade. Ou como no caso da empresa E, pelo setor responsável pela gestão do ERP.

Um indicativo da tentativa das empresas de sistematizar e dar relevância à medição de desempenho é o envolvimento dos níveis gerenciais e estratégicos nas discussões dos resultados. No caso das empresas pesquisadas, fica evidenciada a percepção de que a medição do desempenho logístico tem relevância junto a gestão organizacional, uma vez que os participantes pertencem aos maiores níveis gerenciais. Em nenhuma empresa pesquisada, as reuniões de discussão dos resultados são realizadas estritamente no nível dos técnicos e analistas de logística, o que significa que em todas as empresas algum nível gerencial participa deste processo. Cabe destacar que executivos nos níveis de presidência ou vicepresidência não participam das discussões locais, uma vez que as empresas A, B, C e D são multinacionais. Contudo uma falha foi detectada no prática de fornecimento de dados, nas empresas B, C, D e E, não há divulgação dos resultados dos indicadores junto ao nível operacional. Segundo a literatura, a divulgação de resultados é um fator motivador para o entendimento e envolvimento com as metas, como isso não ocorre nas empresas, acredita-se que ganhos de desempenho junto aos operados poderiam ocorrer caso a prática fosse implementada.

\section{Metodologia de medição}

A medição de performance não deve ser aleatória, mas sistematizada para que tenha impacto sobre as operações (FAWCETT e COPPER, 1998). Em relação à sistematização das medidas, verifica-se que em todas as empresas a coleta de dados, consolidação dos resultados e freqüência de mensuração, são executadas segundo metodologia corporativa. Este aspecto pode indicar que estas empresas optam pelo uso de sistemas de monitoramento do desempenho logístico que sejam compatíveis com a suas reais necessidades e realidade da corporação ao qual pertencem.

\section{Integração com SMD corporativo e uso por outras áreas}

Uma forma de se identificar a relevância dos indicadores é verificar a existência de integração com as demais áreas da empresa e da corporação. Nos casos pesquisados esta integração ocorre, com exceção da empresa B. 


\section{Ferramentas de informação}

Conforme a literatura revisada, o sistema de medição do desempenho necessita do suporte de tecnologia de informação. Caso este suporte não exista, é provável que a capacidade dos gestores de utilizar o sistema de medição de desempenho seja inferior a de um que utilize um sistema de informação como suporte. Os sistemas de informação também são considerados críticos para o sucesso da implementação do conceito de logística integrada e no fornecimento de informações para a identificação rápida e precisa de oportunidades aumento de níveis de serviço e redução de custos.

Todas as empresas estudadas utilizam sistemas de informação para coletar informações sobre o desempenho logístico. Contudo nenhuma empresa conta com um sistema de informação que centraliza todos os indicadores mensurados, facilitando o acesso e o gerenciamento dos resultados. Nas empresas pesquisadas o acesso aos dados ocorre pelo acesso ao ERP, a consolidação dos resultados em planilhas e a divulgação ocorre via intranet.

\section{Procedimentos para motivação ao atingimento de metas}

$\mathrm{Na}$ literatura, defende-se que o comprometimento dos funcionários com o resultado dos indicadores pode ser aumentado caso este resultado esteja atrelado à sua avaliação e, especialmente, à sua remuneração. (ECCLES, 1991; KAPLAN e NORTON, 1996; BOURNE, KENNERLEY e FRANCO, 2003). No caso das empresas pesquisadas, o resultado dos indicadores logísticos influencia a avaliação dos funcionários, através de avaliações anuais, contudo apenas as empresas B e D atrelam diretamente a remuneração dos funcionários aos resultados. Indicando portanto não ser uma política comum entre as empresas do setor.

\section{Procedimentos para as revisões dos indicadores e metas}

Para que estratégia e medidas de performance estejam alinhadas, e o sistema de medição se mantenha integrado ao longo do tempo, é necessário que os indicadores empregados sejam revisados sistematicamente (Bititci et al, 2000). A revisão do sistema de medição deve ser feita a partir da avaliação das condições do ambiente externo e seus efeitos sobre o ambiente interno da empresa. Nas empresas A, B e C a revisão de indicadores ocorre anualmente e em períodos menores, quando alguma grande oscilação no mercado ocorre. $\mathrm{Na}$ 
empresa $D$, declarou-se não haver revisões, uma vez que a empresa segue regiamente as recomendações da corporação. No caso da empresa E, o sistema de medição de desempenho foi implantados recentemente e por isso, não sofreu ainda alterações significativas.

Não é possível inferir sobre a efetividade destas iniciativas de revisão quanto à manutenção do alinhamento estratégico das medidas. Revisões muito freqüentes não são utilizadas, sendo que na maioria dos casos as empresas revêem seu conjunto de medidas somente quando os objetivos estratégicos da corporação são revistos.

Apresenta-se no quadro 6.5 a síntese da análise desenvolvida neste capítulo.

\begin{tabular}{|c|c|c|}
\hline $\begin{array}{c}\text { Aspectos } \\
\text { analisados }\end{array}$ & Recomendações da literatura & Práticas identificadas nas empresas \\
\hline $\begin{array}{l}\text { Indicadores } \\
\text { comuns na } \\
\text { medição da } \\
\text { atividade } \\
\text { logística }\end{array}$ & $\begin{array}{l}\text { Os indicadores de desempenho } \\
\text { empregados pelas empresas com logística } \\
\text { de classe mundial pertencem às dimensões } \\
\text { custo, serviço ao cliente, produtividade, } \\
\text { gestão de ativos e qualidade, enquanto que } \\
\text { as empresas em geral, mensuram com } \\
\text { maior freqüência o desempenho nas } \\
\text { dimensões custo e serviço ao cliente }\end{array}$ & $\begin{array}{l}\text { Indicadores levantados contemplam custo, } \\
\text { gestão de ativos e nível de serviço }\end{array}$ \\
\hline $\begin{array}{l}\text { Alinhamento } \\
\text { dos indicadores } \\
\text { com a estratégia } \\
\text { logística }\end{array}$ & $\begin{array}{l}\text { O meio adequado para traduzir em } \\
\text { objetivos da organização e permitir o } \\
\text { controle destes objetivos é alinhar os } \\
\text { indicadores à estratégia da organização }\end{array}$ & $\begin{array}{l}\text { Apenas em um dos casos não foi possível } \\
\text { definir claramente a existência de } \\
\text { alinhamento dos indicadores com a } \\
\text { estratégia da atividade logística }\end{array}$ \\
\hline $\begin{array}{l}\text { Abrangência } \\
\text { dos indicadores }\end{array}$ & $\begin{array}{l}\text { Deve ser utilizados indicadores não- } \\
\text { financeiras no escopo de avaliação, deve } \\
\text { ainda se contemplar dimensões externas na } \\
\text { medição de desempenho da atividade } \\
\text { logística }\end{array}$ & $\begin{array}{l}\text { De forma geral as empresas utilizam tanto } \\
\text { indicadores financeiros quanto não- } \\
\text { financeiros, contudo inexistem indicadores } \\
\text { que avaliem a atividade logística junto aos } \\
\text { clientes }\end{array}$ \\
\hline $\begin{array}{l}\text { Definição de } \\
\text { indicadores e } \\
\text { metas e } \\
\text { envolvidos no } \\
\text { processo de } \\
\text { definição }\end{array}$ & $\begin{array}{l}\text { Indicadores devem ter seus objetivos } \\
\text { explicitados e comunicados a toda a } \\
\text { organização; todos os envolvidos devem } \\
\text { participar do processo de definição das } \\
\text { medidas; a definição de metas devem estar } \\
\text { associadas à desempenhos passados e } \\
\text { benchmarking }\end{array}$ & $\begin{array}{l}\text { Existe o desdobramento dos objetivos } \\
\text { corporativos para a área de logística; metas } \\
\text { são definidas em grande parte pelas } \\
\text { matrizes, destaque à } \text { prática de } \\
\text { benchmarking interno em A e B e à } \\
\text { ausência da participação dos demais } \\
\text { stakeholders no processo de definição }\end{array}$ \\
\hline $\begin{array}{l}\text { Apoio à tomada } \\
\text { de decisões }\end{array}$ & $\begin{array}{l}\text { Indicadores de desempenho devem } \\
\text { influenciar a tomada de decisões; reuniões } \\
\text { são necessárias para a discussão dos } \\
\text { resultados e das ações a serem tomadas }\end{array}$ & $\begin{array}{l}\text { Entrevistados declararam acompanhar os } \\
\text { indicadores considerados mais relevantes } \\
\text { para a gestão logística diariamente; reuniões } \\
\text { mensais de divulgação dos resultados, } \\
\text { possibilitam um melhor acompanhamento da } \\
\text { evolução do desempenho logístico }\end{array}$ \\
\hline
\end{tabular}




\begin{tabular}{|c|c|c|}
\hline $\begin{array}{c}\text { Aspecto } \\
\text { analisado }\end{array}$ & Recomendações da literatura & Práticas identificadas nas empresas \\
\hline $\begin{array}{l}\text { Fornecimento } \\
\text { dos dados }\end{array}$ & $\begin{array}{l}\text { A disponibilização de dados deve ser } \\
\text { abrangente; a existência de um responsável } \\
\text { por coordenar a medição, relatando os } \\
\text { resultados dos indicadores } \\
\text { acompanhando a implementação das } \\
\text { ações, deve facilitar o processo }\end{array}$ & $\begin{array}{l}\text { O reporte dos resultados ocorre } \\
\text { mensalmente, efetuado por analistas } \\
\text { logísticos em quatro das empresa, há } \\
\text { envolvimento gerencial neste processo, } \\
\text { contudo não há um compartilhamento de } \\
\text { informações formalizado junto ao nível } \\
\text { operacional }\end{array}$ \\
\hline $\begin{array}{l}\text { Metodologia de } \\
\text { medição }\end{array}$ & $\begin{array}{l}\text { A medição de desempenho deve ser } \\
\text { sistematizada }\end{array}$ & $\begin{array}{l}\text { Em todas as empresas a coleta de dados, } \\
\text { consolidação dos resultados e freqüência de } \\
\text { mensuração, são executadas segundo } \\
\text { metodologia corporativa }\end{array}$ \\
\hline $\begin{array}{l}\text { Integração com } \\
\text { SMD } \\
\text { corporativo e } \\
\text { uso por outras } \\
\text { áreas }\end{array}$ & $\begin{array}{l}\text { A integração dos indicadores ao SMD } \\
\text { corporativo indica a importância destes }\end{array}$ & $\begin{array}{l}\text { Nos casos pesquisados esta integração } \\
\text { ocorre, com exceção da empresa B }\end{array}$ \\
\hline $\begin{array}{l}\text { Ferramentas de } \\
\text { informação }\end{array}$ & $\begin{array}{l}\text { É desejável que os dados estejam } \\
\text { disponíveis, os procedimentos para sua } \\
\text { coleta sejam implementados e o processo } \\
\text { seja automatizado }\end{array}$ & $\begin{array}{l}\text { Nenhuma das empresas conta com um } \\
\text { sistema de informação que centraliza todos } \\
\text { os indicadores mensurados, facilitando o } \\
\text { acesso e o gerenciamento dos resultados }\end{array}$ \\
\hline $\begin{array}{l}\text { Procedimentos } \\
\text { para motivação } \\
\text { ao atingimento } \\
\text { de metas }\end{array}$ & $\begin{array}{l}\text { Programas de remuneração baseados em } \\
\text { resultados podem aumentar o } \\
\text { comprometimento dos funcionários }\end{array}$ & $\begin{array}{l}\text { O atingimento de metas é valorizado na } \\
\text { avaliação do funcionário de três empresas, } \\
\text { mas não é política presente entre as } \\
\text { empresas investigadas o atrelamento a } \\
\text { remuneração }\end{array}$ \\
\hline $\begin{array}{l}\text { Procedimentos } \\
\text { para as revisões } \\
\text { dos indicadores } \\
\text { e metas }\end{array}$ & $\begin{array}{l}\text { As empresas devem ter um processo } \\
\text { estruturado de revisão do sistema de } \\
\text { medição, com periodicidade e com base } \\
\text { nas mudanças de estratégia }\end{array}$ & $\begin{array}{l}\text { Adota-se processos sistematizados de } \\
\text { revisão em três empresas, nestes casos os } \\
\text { indicadores são revistos anualmente e } \\
\text { quando os objetivos estratégicos da } \\
\text { corporação são revistos }\end{array}$ \\
\hline
\end{tabular}

Quadro 6.5 - Síntese da análise de dados 


\section{CONCLUSÕES}

Apresenta-se neste capítulo as considerações finais quanto aos objetivos e resultados alcançados pelo presente estudo, além de sugestões para trabalhos futuros.

\subsection{Quanto aos objetivos e questão de pesquisa}

Este estudo buscou responder a seguinte questão:

Quais são os indicadores de desempenho logístico e como estes se inserem no processo de medição de desempenho adotado por empresas do segmento de bens de capital agrícolas?

Partindo de um tema abrangente, este estudo analisou aspectos de relevância para discussões mais aprofundadas entre os praticantes da medição de desempenho. Estes aspectos estão relacionados a abrangência dos indicadores e as características principais do processo de medição de desempenho, no que tange a gestão dos indicadores.

A pesquisa identificou, caracterizou e analisou os indicadores de desempenho logístico utilizados por empresas do segmento de bens de capital agrícolas.

Primeiramente a pesquisa identificou por meio de uma revisão bibliográfica, as características fundamentais dos indicadores de desempenho utilizados para avaliação da atividade logística e as boas práticas do processo de medição de desempenho.

Esta revisão possibilitou a proposição de uma classificação para os indicadores de desempenho logístico e de uma estrutura para análise das práticas, que por meio de um estudo de múltiplos casos, identificou e caracterizou os indicadores comumente utilizados, o escopo de avaliação destas métricas e as práticas de gestão da medição de desempenho entre empresas líderes de mercado do setor de bens de capital agrícolas.

\subsection{Quanto aos resultados}

Este estudo teve como objetivo colaborar com a identificação de um panorama, com a proposição de hipóteses e recomendações a respeito do uso de indicadores de desempenho nas empresas de bens de capital agrícolas. 
A partir dos casos foi possível identificar que na avaliação da atividade logística, as empresas pesquisadas adotam três indicadores em comum. Estes indicadores contemplam três importantes funções desenvolvidas pela atividade logística destas empresas: o transporte inbound, o abastecimento de linhas de produção e a gestão de estoques. Os indicadores comuns identificados são: frete de aquisição de matéria-prima e componentes, máquinas completas por linha e acuracidade de estoque. São indicadores de custo, nível de serviço e gestão de ativo, respectivamente.

Verificou-se que as empresas pesquisadas utilizam indicadores de desempenho logístico e procuram alinhar estas medidas aos objetivos da corporação. Além de possibilitar o alinhamento com os objetivos corporativos, nestas empresas os indicadores são utilizados como argumento em negociações com a alta direção, ajudam a discutir a utilização de recursos e possibilitam em determinados casos, a leitura do desempenho de seus parceiros. Contudo na análise do uso dos indicadores e dos procedimentos de gestão destas medidas, verificou-se a existência de algumas diferenças entre as práticas adotadas pelas empresas e o recomendado pela literatura.

O uso de indicadores de desempenho não somente relacionados à dimensões financeiras é prática comum. No entanto, as empresas não utilizam com o mesmo equilíbrio, indicadores que avaliam o desempenho da atividade logística mediante o ambiente em que está inserida. As empresas pesquisadas, focam na medição do desempenho interno, deixando de considerar a percepção de stakeholders, presentes nos extremos da cadeia, os fornecedores e os clientes finais. Além disso, não desenvolvem um trabalho abrangente com vistas a obter dados que possibilitem a comparação de seu desempenho diante da concorrência e quando praticam benchmarking, consideram apenas as outras unidades da corporação a qual são vinculados.

O baixo emprego de indicadores de dimensões externas na medição do desempenho logístico, ficou evidente apesar do conceito de logística integrada estar amplamente difundido e sua aplicação ser considerada fundamental para o desempenho adequado da atividade logística. Neste caso, é preciso considerar que esta deficiência pode ser justificada pelo foco que as empresas dão à atividade logística. Nas cinco empresas investigadas a atividade logística está atrelada as funções inbound e de apoio à manufatura.

Quanto ao processo de medição, verificou-se que as empresas pesquisadas adotam em grande parte as práticas sugeridas pela literatura. 
Todos os gestores entrevistados afirmam utilizar os resultados dos indicadores para as suas tomadas de decisões. Neste sentido verifica-se que a medição de desempenho logístico está consolidada como prática gerencial, dado o impacto que exercem nas decisões diárias destes gestores e o nível dos profissionais participantes do processo de medição, em grande parte do nível gerencial e estratégico.

A definição de metas para os indicadores logísticos esta ligada principalmente às condições do mercado, que no caso destas empresas tem um impacto significante sobre as decisões gerenciais e à imposição dos interesses corporativos, que são desdobrados até as unidades. Existe ainda como prática presente em algumas das empresas, o uso de benchmarking interno, para definição de metas e monitoramento de desempenho.

A periodicidade de cálculo dos indicadores adotada pelas empresas é mensal. Periodicidade esta, relacionada diretamente com as reuniões realizadas para discussão dos resultados dos indicadores, que também são mensais.

Os resultados dos indicadores são considerados na avaliação dos funcionários, porém a prática de atrelar a remuneração a estes resultados não é difundida, uma vez que apenas duas empresas exercem este tipo de vinculação.

A revisão dos indicadores é feita anualmente, contudo quando há alterações nos objetivos de desempenho, os indicadores também são alterados, indicando portanto, um esforço em sustentar o alinhamento entre o sistema de medição de desempenho e a estratégia das empresas.

Apesar do grande vínculo com as boas práticas, foi possível verificar em alguns pontos analisados, um distanciamento das práticas das empresas e as recomendações da literatura.

No que se refere a definição dos indicadores, verificou-se a ausência da participação de stakeholders externos a gestão da atividade logística, o que é criticado pela literatura. No fornecimento de informações, em grande parte das empresas, não há a divulgação de resultados e metas aos funcionários do nível operacional, prática que poderia auxiliar no processo de motivação e comprometimento com o alcance de metas. No que tange ao uso de sistemas de informação, verificou-se a inexistência do uso de sistemas para cadastro dos indicadores logísticos, coleta automática de dados, emissão de relatórios e outras funcionalidades. A maior parte das empresas acessa dados do sistema ERP, consolida os resultados em planilhas isoladas e posteriormente divulga esta planilha na rede da empresa. Neste sentido, pode se inferir que o esforço direcionado à medição de desempenho poderia ser reduzido com o uso de sistemas específicos para a gestão da medição de desempenho. 
Outro resultado da pesquisa refere-se a identificação da abrangência da atividade logística destas empresas, que esta vinculada a logística inbound e interna. Esta característica, pode ser um dos fatores que levam estas empresas a utilizarem os indicadores da forma como foi detectada, sem priorizar o cliente final. O mercado em que atuam pode ser outro fator que leva estas empresas a este tipo de comportamento frente a medição de desempenho.

Cabe portanto para um estudo futuro, uma discussão mais ampla sobre a importância que a atividade logística tem para estas empresas. Se a sazonalidade e um fator de impacto para este mercado, se faz necessário investigar por quê estas empresas não adotam a logística como atividade de relevância para a redução destes impactos. Uma vez que a sazonalidade exerce influencia no estoque gerido, o acompanhamento deste cenário por métricas que considerem o ambiente externo e conseqüentemente o cliente, podem agregar informação adequada para a tomada de decisão do gestor logístico e ser um diferencial para a empresa.

Por fim, o levantamento da literatura e a identificação das práticas dos casos, permitem a sugestão de alguns aspectos, a serem considerados pelas empresas como forma de sustentar os benefícios do uso de indicadores de desempenho logísticos.

Em primeiro lugar destaca-se a necessidade do envolvimento de clientes e fornecedores na criação das medidas, dado que alguns aspectos a serem medidos na operação sofrem influência e têm conseqüências diretas no processo produtivo ao qual este atores estão vinculados. Em segundo lugar, esta a necessidade de adequação da abrangência dos indicadores logísticos, visto que algumas dimensões que a literatura sugere para um gerenciamento integrado da logística não são utilizadas pelas empresas investigadas. Em terceiro lugar, o aumento do vínculo entre os funcionários e os resultados dos indicadores, pode ser um instrumento importante para se obter maiores ganhos de desempenho e a remuneração tende a ser um diferencial neste processo. E finalmente, a busca de maior velocidade no acesso dos indicadores, com o uso de ferramentas da tecnologia da informação é fundamental para que os indicadores exerçam seu papel, de modo a não ocasionar esforços desnecessários e dispêndio de recursos.

Ao se utilizar casos de empresas de destaque no segmento de bens de capital agrícolas, espera-se que os resultados a serem apontados sirvam para empresas menos estruturadas deste segmento direcionarem avanços nos seus processos de avaliação da atividade logística. 


\subsection{Sugestões para trabalhos futuros}

Devido a extensão do assunto abordado nesta pesquisa, muitas são as possibilidades de estudos. Um estudo relevante seria o uso do mesmo método de análise empregado nesta pesquisa em um outro segmento industrial e até mesmo em outro segmento do setor de bens de capital, como o segmento de transporte, de forma a visualizar a característica das práticas de medição de desempenho adotadas no país.

Como a pesquisa se baseou na análise de casos de empresas líderes de mercado e bem estruturadas em relação atividade logística, sugere-se que pesquisas sejam desenvolvidas em realidades diferentes, como em empresas de pequeno porte e deficientes na condução da atividade logística. O uso do método de levantamento (survey) seria adequado na identificação de um cenário que contemplasse os diversos níveis de empresas do segmento industrial alvo deste estudo. A aplicação das boas práticas relacionadas neste estudo em uma empresa com baixo nível de desempenho logístico, seria outra abordagem relevante. 


\section{REFERÊNCIAS}

ALEM, A. C.; PESSOA, R. M. (2005). O setor de bens de capital e o desenvolvimento econômico: quais são os desafios?. BNDES Setorial, Rio de Janeiro, n. 22, p. 71-88.

ANGELO, L. B. (2005). Indicadores de desempenho logístico. Estudos realizados. GELOG-UFSC.

ATTADIA, L. C.; MARTINS, R. A. (2003). Medição de desempenho como base para evolução da melhoria contínua. Revista Produção, v. 13, n. 2, p. 33-41.

AVELLAR, A. P. (2008). Bens de capital. Relatório setorial preliminary. Finep - Rede DPP.

BAARK, E. (1991). The Accumulation of technology: Capital goods production in developing countries revisited. World Development, v.19, n.7, p. 903-914.

BALLOU, R. H. (1993). Logística Empresarial: transportes, administração de materiais e distribuição física. São Paulo: Atlas, 1993.

BALLOU, R. H. (2007). The evolution and future of logistics and supply chain management. European Business Review, v. 19, n. 4, p. 332-348.

BALlOU, R. H.(2006). Gerenciamento da cadeia de suprimentos: planejamento, organização e logística empresarial. Porto Alegre: Bookman.

BARBOSA, D. H. (2008). Processos de mudanças relacionados à logística no setor de bens de capital agrícolas: uma análise de sua gestão e relações com áreas-chave de excelência logística. São Carlos. Dissertação (Mestrado em Engenharia de Produção). Escola de Engenharia de São Carlos, Universidade de São Paulo.

BEAMON, B. (1999). Measuring supply chain performance. International Journal of Operations and Production Management, v. 19, n. 3, p. 275-292.

BITITCI, U. S.; CARRIE, A.S.; McDEVITT, L. (1997). Integrated performance measurement systems. International Journal of Operations \& Productions Management, v.17, n.5, p.522-534.

BOND, E. (2002). Medição de desempenho para gestão da produção em um cenário de cadeia de suprimentos. São Carlos. Dissertação (Mestrado em Engenharia de Produção). Escola de Engenharia de São Carlos, Universidade de São Paulo.

BOURNE, M.; KENNERLEY, M.; FRANCO, M. (2003). Managing through measures: a study of the impact of performance measurement on performance. Proceedings of the EurOMA Conference, Italy.

BOURNE, M., MILlS, J., WILCOX, M., NEELY, A., PLATTS, K., (2000). Designing, implementing and updating performance measurement systems. International Journal of Operations and Production Management, v. 20, n. 7, p. 754-771. 
BOWERSOX, D. J.; DAUGHERTY, P. J.; DROGE, C. L.; WARDLOW, D. L. (1992). Logistical Excellence: it`s not business as usual. Burlinton, MA:Digital Equipment.

BOWERSOX, D. J.; CLOSS, D. J. (1997). Brazilian logistics: a time for transition. Gestão e Produção. São Paulo, v. 4, n. 2, p. 130-139.

BOWERSOX, D. J.; CLOSS, D. J. (2001). Logística Empresarial: o processo de integração da cadeia de suprimento. São Paulo: Atlas.

BOWERSOX, D. J.; CLOSS, D. J.; COOPER, M. B.(2006). Gestão logística de cadeias de suprimentos. Porto Alegre: Bookman.

BRANDÃO, F. (2003). Sinopse competitivo da indústria de máquinas agrícolas. In: II Congresso Sul Brasileiro da Indústria Automotiva. Disponível em: <http://www.igea.org.br>. Acesso em: 13 abr. 2008.

BROWN, M. G. (1996). Keeping Score: Using the right metrics to drive world-class performance. Quality Resources: New York.

CASTRO, B. H. R. (2004). Estratégias de inovação: um estudo na indústria de máquinas e implementos agrícolas no Brasil. Dissertação (Mestrado em Administração). Instituto COPPEAD de Administração. Universidade Federal do Rio de Janeiro, Rio de Janeiro.

CERVO, A. L.; BERVIAN, P. A. (2002). Metodologia científica. 5.ed. São Paulo: Prentice Hall.

CHOW, G., HEAVER, T., HENRIKSSON, L. (1994) Logistics Performance: Definition and Measurement. International Journal of Physical Distribution \& Logistics Management, v. 24, p. 17-28.

CHRISTOPHER, M. (2007). Logística e gerenciamento da cadeia de suprimentos: estratégias para redução de custos e melhoria de serviços. São Paulo: Pioneira.

COOPER, M.; LAMBERT, D.; PAGH, J. (1997). Supply chain management: more than a new name for logistics. International Journal of Logistics Management, v. 8 n. 1 p. 1-13.

COUNCIL OF SUPPLY CHAIN MANAGEMENT PROFESSIONALS (CSCMP) (2009).

Definition of logistics management. Disponível em:
<http://cscmp.org/Website/AboutCSCMP/Definitions/Definitions.asp>. Acesso em: 19 mar. 2009.

CROSS, K. F.; LYNCH, R. L. (1990). Managing the corporate warrions. Quality Progress, v. 23, n. 4, p.54-59.

DAUGHERTY, P. J.; ELLINGER, A. E.; GUSTIN, G. M. (1996). Integrated logistics: achieving logistics performance improvements. Supply Chain Management, v. 1, n. 3, p. $25-33$.

DE TONI, A.; TONCHIA, S. (2001). Performance measurement systems. International Journal of Operations and Prodution Management, v. 21, p. 46-70 
DORNIER, P. P.; ERNEST, R.; FENDER, M. \& KOUVELIS, P. (2000). Logística e operações globais: textos e casos. São Paulo: Atlas, 2000.

DUTRA, A. S.; MONTOYA, M. A. (2005). Tendência das estruturas de mercado a montante e a jusante da agricultura brasileira no período de 1990 a 2002 . Texto para discussão 23/2005. Centro de Pesquisa e Extensão da FEAC,Universidade Federal de Passo Fundo.

ECCLES, R. (1991). The performance measurement manifesto. Harvard Business Review, Jan-Feb.

FAWCETT, S. E.; CLINTON, S. R. (1996). Enhancing logistics performance to improve the competitiveness of manufacturing organizations. Production and Inventory Management Journal, p 40-46, First Quarter, 1996.

FAWCETT, S. E.; CLINTON, S. R. (1997). Enhancing logistics performance to improve the competitiveness of manufacturing organizations: a triad perspective. Transportation Journal, Fall, p. 18-28.

FAWCETT, S. E. COPPER, M. B. (1998). Logistics Performance Measurement and Customer Success. Industrial Marketing Management, v.27, p. 341-357, 1998.

FIGUEIREDO, K; ARKADER, R. (2000). Da distribuição física ao supply chain management. In: FLEURY, P. F.; WANKE, P.; FIGUEIREDO, K. F. (org.). Logística Empresarial: a perspectiva brasileira. Coleção COPPEAD de Administração. São Paulo: Atlas.

FLEURY, P. F. (2000). A Logística Brasileira em Perspectiva. In: FLEURY, F.; WANKE, P.; FIGUEIREDO, K.F. Logística Empresarial: a perspectiva brasileira. Coleção COPPEAD de Administração. São Paulo: Atlas.

FORSLUND, H. (2007). The impact of performance management on customers'expected logistics performance. International Journal of Operations \& Production Management, v. 27, n. 8, p. 901-918.

GALDÁMEZ. E. V. C. (2007). Medição de desempenho em clusters industriais: clusters de Ibitinga e Jaú. Tese (Doutorado em Engenharia de Produção). Escola de Engenharia de São Carlos, Universidade de São Paulo.

GARENGO, P.; BIAZZO, S.; BITITCI, U. S. (2005). Performance measurement systems in SMEs: a review for a research agenda. International Journal of Management Reviews. v.17, n.1, p.25-47.

GIL, A. C. (2007). Como elaborar projetos de pesquisa. 4.ed. São Paulo: Atlas.

GUNASEKARAN, A., PATEL, C., TIRTIROGLU, E. (2001). Performance measures and metrics in a supply chain environment. International Journal of Operations and Production Management, v. 21, n. 1/2, p. 71-87. 
GUNASEKARAN, A.; KOBU, B.(2007). Performance measures and metrics in logistics and supply chain management: a review of recent literature (1995-2004) for research and applications. International Journal of Production Research, v. 45, n. 12, p. 2819-2840.

GRIFFIS, S. E.; GOLDSBY, J. T.; COOPER, M.; CLOSS, D. J. (2007). Aligning logistics performance measures to the information needs of the firm. Journal of Business Logistics, Vol. 28, n. 2, p. 35-56.

HARRINGTON, H. J. (1993). Aperfeiçoando processos empresariais. Tradução de Luiz Liske. São Paulo: Makron Books.

HILL, A. (2005). Competitiveness and processes: integrating engineering in the capital goods industry. World Class Design to Manufacture, v. 2, n. 5.

HUDSON, M. (2001). Introducing integrated performance measurement into small and medium sized enterprises. 2001. 189p. Thesis - PhD - Plymouth Business School, University of Plymouth.

HOLMBERG, S. (2000). A systems perspective on supply chain measurements. International Journal of Physical Distribution \& Logistics Management, v. 30, n. 10, p. 847-868.

HRONEC, S. M. (1994). Sinais vitais: usando medidas do desempenho da qualidade, tempo e custo para traçar a rota para o futuro de sua empresa. São Paulo: Makron Books.

INSTITUTO BRASILEIRO DE GEOGRAFIA E ESTATÍSTICA. (2008). Índices conjunturais da indústria. Disponível em: <http://www.ibge.gov.br/home/estatitística/indústria/pimpfbk/pim-bk_150209>. Acesso em: 25 mar. 2009.

INSTITUTO BRASILEIRO DE GEOGRAFIA E ESTATÍSTICA. (2009). Produção física dos segmentos do setor de bens de capital. Disponível em: <http://www.ibge.gov.br/home/estatistica/indicadores/industria/pimpfbk/pimbk_200903_1.shtm>. Acesso em: 01 jun. 2009.

KAPLAN, R., NORTON, D. (1992). The Balanced Scorecard - Measures that drive performance. Harvard Business Review, Jan-Feb 1992.

KAPLAN, R., NORTON, D. (1996). Using the Balanced Scorecard as a Strategic Management System. Harvard Business Review, Jan-Feb 1996.

KAYDOS, W. (1991). Performance measurement and performance management. In: Measuring managing and maximizing performance. Portland: Productivity, cap.3, p.33-52.

KEEBLER, J. S. et al.(1999). Keeping Score: measuring the business value of logistic in the supply chain. Oak Brook: The Council of Logistics Management.

KENNERLEY, M.; BOURNE, M. (2003). Assessing and maximizing the impact of measuring business performance. Proceedings of the EurOMA Conference, 16th to 18th June, 2003, Como, Italy. 
KENNERLEY, M., NEELY, A. (2003). Measuring performance in a changing business environment. International Journal of Operations and Production Management, v. 23, n. 2, p. 213-229.

LA LONDE, B. J. L. (1994). Evolution of the integrated logistics concept. In: ROBESON, J. F; COPACINO, W. C. The Logistics Handebbok. New York: The Free Press.

LAMBERT, D. M.; BURDUROGLU, R. (2000). Measuring and selling the value of logistics. International Journal of Logistics Management, v. 11, n. 1, p.1-17.

LAMBERT, D.M.; STOCK, J. R.; VANTINE, J. G. (1998). Administração estratégica da logística. São Paulo: Vantine Consultoria.

LAKATOS, E. M.; MARCONI, M. A. (2008). Técnicas de pesquisa: planejamento e execução de pesquisas, amostragens e técnicas de elaboração, análise e interpretação de dados. São Paulo: Atlas.

LAPIDE, L. (2006). MIT`s SC2020 Project: the essence of excellence. Supply Chain Management Review, v. 10, n. 3, p. 18-24.

LEBAS, M. J. (1995) Performande measurement and performance management. International Journal of Production Economics, v.41, n.1/3, p.23-35.

LOHMAN, C., FORTUIN, L., WOUTERS, M. (2004). Designing a performance measurement system: a case study. European Journal of Operational Research, n.156, p. 267-286.

MARTINS, R. A. (1999). Sistemas de medição de desempenho: um modelo para estruturação do uso. Tese (Doutorado em Engenharia de Produção). Escola Politécnica, Universidade de São Paulo.

MICHIGAN STATE UNIVERSITY(1995). World class logistics: the challenger of managing continuous change. Oak Brook: The Council of Logistics Management.

MORASH, E. A. (2001). Supply chain strategies, capabilities and performance. Transportation Journal, v. 41, n. 1, p. 37-54.

MORGAN, C. (2007). Supply network performance measurement: future challenges? International Journal of Logistics Management , v. 18, n. 2,p. 255-273.

MUSETTI, M. A. (2000). A identificação da entidade gestora logística: uma contribuição para o seu processo de formação e educação. São Carlos. (Tese de Doutorado). Escola de Engenharia de São Carlos, Universidade de São Paulo, 2000.

NEELY, A.; ADAMS, C. A. (2000). Perspectives on performance: the performance prism. Measuring Business Excellence, v. 4, n. 3, p. 19-23.

NEELY, A. (1998). The performance measurement revolution: why now and what next? International Journal of Operations and Production Management, v. 19, n 2, p. 205-228. 
NEELY, A., GREGORY, M., PLATTS, K. (1995). Performance measurement system design: a literature review and research agenda. International Journal of Operations and Production Management, v. 15, n. 4, p. 80-116.

NEELY, A., GREGORY, M., PLATTS, K. (2005). Performance measurement system design: A literature review and research agenda. International Journal of Operations and Production Management, v. 25, n. 12, p. 1228-1263.

NEELY, A., MILlS, J., PlATtS, K., RICHARDS, H., GREGORY, M., BOURNE, M., KENNERLEY, M. (2000). Performance measurement system design: developing and testing a process-based approach. International Journal of Operations and Production Management, v. 20, n. 10, p. 1119-1145.

NEELY, A., RICHARDS, H., MILLS, J., PLATTS, K., BOURNE, M.(1997). Designing performance measures: a structured approach. International Journal of Operations and Production Management, v. 17, n. 11, p. 1131-1152.

NEVES, M. A. O. (2008). Indicadores de desempenho em logística. Revista Mundo Logística, v. 1, n. 3, p. 6-14.

PARRA FILHO, D; SANTOS, J. M. (2002). Metodologia científica. São Paulo: Futura.

PASQUAL, C. A.; PEDROZO, E. A. (2007). Características do negócio no setor de máquinas agrícolas. RAE-eletrônica, v. 6, n. 1, jan./jun.

PIRES, S. R. I. (2001). Gestão da cadeia de suprimentos: conceitos, estratégias, práticas e casos. São Paulo: Atlas, 2004.

PORTER, M. E. (1992). Vantagem Competitiva. Rio de Janeiro: Campus.

RAFELE, C. (2004). Logistic service measurement: a reference. Journal of Manufacturing Technology Management, v. 15, n. 3, p. 280-290.

RESENDE, M. F. C.; ANDERSON, P. (1999). Mudanças Estruturais na Indústria Brasileira de Bens de Capital. Texto para discussão no 658 do IPEA; ISSN 1415-4765; Brasília, julho de 1999.

SCHMITZ, J; PLATTS, K. W. (2004). Supplier logistics performance measurement: Indications from astudy in the automotive industry. International Journal of Production Economics, v. 89, p. 231-243.

SETH, N; DESHMUKH, S. G.; VRAT, P. (2006). A framework for measurement of quality of service in supply chains. Supply Chain Management, v. 11, n. 1, p. 82-94.

SINK, D. S.; TUTTLE, T. C. (1993). Planejamento e medição para a performance. Rio de Janeiro: QualityMark, 1993. 
SOUZA, J. H. (2004). A viabilidade do fomento tecnológico para a indústria de bens de capital em economias emergentes. Revista Spacios, v. 25, n. 1.

STANK, T.; CRUM, M.; ARANGO, M. (1999). Benefits of interfirm coordination in food industry supply chains. Journal of Business Logisitcs, v. 20, n. 2, p. 21-41.

STANK, T.; KELLER, S. C., DAUGHERTY, P. J. (2001). Supply chain collaboration and logistical service performance. Journal of Business Logistics, v. 22, n. 1, p. 29-49.

STOCK, J. R.; LAMBERT, D. M. (1992). Becoming a word class company with logistics service quality. International Journal of Logistics Management, v. 3, n. 1, p. 73-81.

TATSCH, A. L. (2008). O arranjo de máquinas e implementos agrícolas do Rio Grande do Sul: infra-estrutura produtiva, educacional e institucional. Ensaios FEE, v. 28, p. 755-774.

VERMULM, R. O setor de bens de capital. Departamento de Economia da FEA/USP. Abril, 1993.

VERMULM, R. (2003). A indústria de bens de capital seriados. CEPAL - Comissão Econômica para a América Latina E O Caribe, dezembro, 2003

VERMULM, R.; ERBER, F. (2002). Estudo da competitividade de cadeias integradas no Brasil: impactos das zonas de livre comércio. Cadeias: bens de capital. Universidade Estadual de Campinas. Campinas: dezembro, 2002.

VOSS, C.; TSIKRIKTSIS, N.; FROLICH, M. (2002). Case research in operations management. International Journal of Operation e Production Management, v. 22, n. 2, p. 195-219.

WEISE, M. R. O comportamento da indústria de bens de capital após o Plano Real. Revista FAE, Curitiba, v.3, n.3, p.31-38, set./dez. 2000.

WOUTERS, M.; WILDEROM, C. (2008). Developing performance-measurement systems as enabling formalization: A longitudinal field study of a logistics department. Accounting, Organizations and Society, v. 33, p. 488-516.

WOUTERS, M. (2009). A developmental approach to performance measures: results from a longitudinal case study. European Management Journal, v. 27, p. 64-78.

WOOD, T. J.; ZUFFO, P. K. (1998). Supply chain management. Revista de Administração de Empresas, v. 38, n. 3, p. 55-63.

YIN, R. K. (2001). Estudo de caso: planejamento e métodos. Porto Alegre: Bookman, 2 ed, 2001.

ZAGO, C. A. (2008). Conformidade da logística empresarial com as características de supply chain management: um estudo de duas indústrias de máquinas agrícolas automotrizes. Dissertação (Mestrado em Engenharia de Produção). Centro de Tecnologia, Universidade Federal de Santa Maria. 
ZAWISLAK, P. (2000). Identificação e análise de informações sobre os sistema locais de produção do Rio Grande do Sul. Relatório para o arranjo industrial de máquinas e implementos agrícolas. Universidade Federal do Rio Grande do Sul. 


\section{APÊNDICE A - Indicadores de desempenho logístico segundo a literatura}

Levantamento efetuado com base nos trabalhos de Lambert e Burduroglu (2000), Stank, Keller e Daugherty (2001), Stock e Lambert (2001), Bowersox e Closs (2001), Schmitz e Platts (2004), Rafele (2004), Angelo (2005), Seth, Deshmukh e Vrat (2006), Morgan (2007), Gunasekaran e Kobu (2007), Griffis et al. (2007), Neves (2008).

\begin{tabular}{|c|c|c|}
\hline Indicador & Objetivo & Forma de cálculo \\
\hline Pedido Perfeito & $\begin{array}{l}\text { Mede o \% de pedidos } \\
\text { entregues no prazo } \\
\text { negociado com o cliente, } \\
\text { completo, sem avarias e } \\
\text { sem problemas na } \\
\text { documentação fiscal }\end{array}$ & $\mathrm{PP}=\frac{\text { número de pedidos perfeitos entregues x } 100}{\text { total de pedidos expedidos }}$ \\
\hline $\begin{array}{l}\text { Porcentagem de } \\
\text { entregas (ou coletas) } \\
\text { realizadas no prazo }\end{array}$ & $\begin{array}{l}\text { Mede o \% de entregas (ou } \\
\text { coletas) realizadas dentro } \\
\text { do prazo combinado com o } \\
\text { cliente }\end{array}$ & $\% \mathrm{ERP}=\frac{\text { número de entregas realizadas no prazo } \times 100}{\text { total de entregas realizadas }}$ \\
\hline $\begin{array}{l}\text { Custo do transporte } \\
\text { como um \% das } \\
\text { vendas }\end{array}$ & $\begin{array}{l}\text { Aponta a participação dos } \\
\text { custos totais de transporte } \\
\text { sobre a receita de vendas } \\
\text { da empresa (Pode-se } \\
\text { trabalhar com a receita } \\
\text { líquida ou bruta) }\end{array}$ & $\mathrm{CT} \% \mathrm{~V}=\frac{\text { custo total de transporte } \times 100}{\text { receita de vendas }}$ \\
\hline $\begin{array}{l}\text { Custo com não- } \\
\text { conformidade no } \\
\text { transporte }\end{array}$ & $\begin{array}{l}\text { Mede a participação de } \\
\text { custos decorrentes de não- } \\
\text { conformidades no processo } \\
\text { de planejamento, gestão e } \\
\text { operação de transportes } \\
\text { (devoluções, reentregas, } \\
\text { sobre-estadias, multas por } \\
\text { atraso, indenizações de } \\
\text { avarias, frete premium ou } \\
\text { carga expressa, gastos com } \\
\text { frete não estimado, etc. }\end{array}$ & CFUE $=\frac{\text { custo adicional de transporte com não-conforme }}{\text { custo total de frete }}$ \\
\hline Avarias no transporte & $\begin{array}{l}\text { Mede as avarias ocorridas } \\
\text { durante a operação de } \\
\text { transporte }\end{array}$ & Avarias $=\frac{\text { avarias no transporte em } \$ \times 100}{\text { valor total das mercadorias transportadas em } \$}$ \\
\hline $\begin{array}{l}\text { Custo de devolução } \\
\text { como um \% do custo } \\
\text { das mercadorias } \\
\text { vendidas }\end{array}$ & $\begin{array}{l}\text { Mede o custo total para a } \\
\text { operação do fluxo reverso, } \\
\text { envolvendo gastos com } \\
\text { embalagens, manuseio, } \\
\text { movimentação, } \\
\text { armazenagem e transporte, } \\
\text { expressando-o como um } \\
\text { percentual do CMV (custo } \\
\text { das mercadorias vendidas) }\end{array}$ & TCLR $=\frac{\text { custo total com o fluxo reverso x } 100}{\text { custo das mercadorias vendidas }}$ \\
\hline $\begin{array}{l}\text { Índice de } \\
\text { atendimento do } \\
\text { pedido (Order Fill } \\
\text { Rate) }\end{array}$ & $\begin{array}{l}\text { Mede o \% de pedidos } \\
\text { atendidos em sua } \\
\text { totalidade, na quantidade e } \\
\text { na diversidade de itens, no } \\
\text { primeiro envio ao cliente }\end{array}$ & OFR $=\frac{\text { número de pedidos atendidos na totalidade } \times 100}{\text { total de pedidos expedidos }}$ \\
\hline
\end{tabular}




\begin{tabular}{|c|c|c|}
\hline Indicador & Objetivo & Forma de cálculo \\
\hline $\begin{array}{l}\text { Tempo de ciclo do } \\
\text { pedido (Order Cycle } \\
\text { Time) }\end{array}$ & $\begin{array}{l}\text { Tempo decorrido entre o } \\
\text { recebimento do pedido do } \\
\text { cliente e data efetiva de } \\
\text { entrega }\end{array}$ & $\begin{aligned} \mathrm{OCT}= & (\text { data/hora de entrega do pedido ao cliente })- \\
& (\text { data/hora de recebimento do pedido do cliente })\end{aligned}$ \\
\hline $\begin{array}{l}\text { Acuracidade do } \\
\text { inventário }\end{array}$ & $\begin{array}{l}\text { Mede o \% de acuracidade } \\
\text { entre o estoque físico e } \\
\text { contábil (mede-se } \\
\text { primeiramente a } \\
\text { acuracidade item a item e } \\
\text { depois, para se obter o } \\
\text { índice geral, deve-se } \\
\text { verificar o número de itens } \\
\text { corretos em relação ao } \\
\text { total de itens } \\
\text { inventariados) }\end{array}$ & $\begin{array}{l}\text { AI por item }=\frac{\text { quantidade física do item } \times 100}{\text { quantidade do item no sistema }} \\
\text { AI geral }=\frac{\text { número de itens com } 100 \% \text { acuracidade } \times 100}{\text { total de itens inventariados }}\end{array}$ \\
\hline $\begin{array}{l}\text { Produtividade na } \\
\text { separação de pedidos }\end{array}$ & $\begin{array}{l}\text { Mede a produtividade da } \\
\text { mão-de-obra na atividade } \\
\text { de separação de pedidos }\end{array}$ & $\begin{aligned} \text { PSP }= & \text { total de pedidos/linhas/itens separados e } \\
& \frac{\text { embalados }}{\text { total de horas trabalhadas }}\end{aligned}$ \\
\hline $\begin{array}{l}\text { Utilização da } \\
\text { capacidade de } \\
\text { estocagem }\end{array}$ & $\begin{array}{l}\text { Mede o nível de utilização } \\
\text { da capacidade de } \\
\text { estocagem }\end{array}$ & $\mathrm{UCE}=\frac{\text { área ou número de posições ocupadas x } 100}{\text { área ou total de posições disponíveis }}$ \\
\hline $\begin{array}{l}\text { Custo de } \\
\text { armazenagem como } \\
\text { um } \% \text { das vendas } \\
\text { (Warehousing Cost } \\
\text { as } \% \text { of Sales) }\end{array}$ & $\begin{array}{l}\text { Aponta a participação dos } \\
\text { custos totais de } \\
\text { movimentação e } \\
\text { armazenagem (M\&A) da } \\
\text { empresa sobre a sua receita } \\
\text { de vendas (envolve o custo } \\
\text { com mão-de-obra, espaço, } \\
\text { equipamentos, água e } \\
\text { energia elétrica e outros) }\end{array}$ & $\mathrm{CA} \% \mathrm{~V}=\frac{\text { custo total de } \mathrm{M} \& \mathrm{~A} \times 100}{\text { receita de vendas }}$ \\
\hline $\begin{array}{l}\text { Custos operacionais } \\
\text { com estoques (Fator } \\
\mathrm{K} \text { ) }\end{array}$ & $\begin{array}{l}\text { Indica quantos R\$ por R\$ } \\
\text { em estoque a empresa } \\
\text { gasta na movimentação e } \\
\text { armazenagem de sues } \\
\text { materiais (envolve o custo } \\
\text { com mão-de-obra, espaço, } \\
\text { equipamentos, água e } \\
\text { energia elétrica e outros } \\
\text { custos operacionais) }\end{array}$ & Fator $K=\frac{\text { custo total de M\&A x } 100}{\text { estoque médio }}$ \\
\hline $\begin{array}{l}\text { Custos associado à } \\
\text { falta de estoque de } \\
\text { produtos acabados }\end{array}$ & $\begin{array}{l}\text { Mede a perda na } \\
\text { lucratividade devido à falta } \\
\text { de estoques para o } \\
\text { atendimento de uma } \\
\text { demanda existente }\end{array}$ & $\begin{aligned} \text { FE_PA }= & (\text { venda perdida por indisponibilidade de } \\
& \text { produtos }) \times(\text { margem de contribuição })\end{aligned}$ \\
\hline Giro de estoques & $\begin{array}{l}\text { Fornece o número de vezes } \\
\text { que os estoques foram } \\
\text { utilizados em um } \\
\text { determinado período }\end{array}$ & $\mathrm{GE}=\frac{\text { custo das mercadorias vendida }}{\text { valor médio dos estoques }}$ \\
\hline $\begin{array}{l}\text { Pedidos Completos e } \\
\text { no Prazo ou \% OTIF } \\
\text { (On Time in Full) }\end{array}$ & $\begin{array}{l}\text { Corresponde às entregas } \\
\text { realizadas dentro do prazo } \\
\text { e atendendo as quantidades } \\
\text { e especificações do pedido }\end{array}$ & $\mathrm{OTIF}=\frac{\text { entregas perfeitas }}{\text { total de entregas realizadas } \mathrm{x} 100}$ \\
\hline
\end{tabular}




\begin{tabular}{|c|c|c|}
\hline Indicador & Objetivo & Forma de cálculo \\
\hline $\begin{array}{l}\text { Custos de Transporte } \\
\text { como um \% das } \\
\text { Vendas (Freight } \\
\text { Costs as \% of Sales) }\end{array}$ & $\begin{array}{l}\text { Mostra a participação dos } \\
\text { custos de transportes nas } \\
\text { vendas totais da empresa }\end{array}$ & $\mathrm{CT} \% \mathrm{~V}=\frac{\text { custo total de transportes }}{\text { vendas totais }}$ \\
\hline $\begin{array}{l}\text { Custo do Frete por } \\
\text { Unidade Expedida } \\
\text { (Freight Cost per } \\
\text { Unit Shipped) }\end{array}$ & $\begin{array}{l}\text { Revela o custo do frete por } \\
\text { unidade expedida. Pode } \\
\text { também ser calcula do por } \\
\text { modal de transporte }\end{array}$ & $\mathrm{CFUE}=\frac{\text { custo total de transporte }}{\text { total de unidades expedidas }}$ \\
\hline $\begin{array}{l}\text { Entregas realizadas } \\
\text { dentro do prazo } \\
\text { negociado }\end{array}$ & $\begin{array}{l}\text { Calcula a taxa de entregas } \\
\text { realizadas dentro do prazo } \\
\text { negociado com o } \\
\text { fornecedor }\end{array}$ & $\mathrm{EP}=\frac{\text { número de entregas realizadas dentro do prazo }}{\text { número de entregas totais }}$ \\
\hline $\begin{array}{l}\text { Recebimento de } \\
\text { produtos dentro das } \\
\text { especificações }\end{array}$ & $\begin{array}{l}\text { Corresponde a quantidade } \\
\text { de produtos que foram } \\
\text { entregues dentro das } \\
\text { especificações previamente } \\
\text { acordadas com o } \\
\text { fornecedor }\end{array}$ & $\mathrm{RE}=\frac{\text { produtos recebidos dentro das especificações }}{\text { total de produtos aceitos } \mathrm{x} 100}$ \\
\hline $\begin{array}{l}\text { Obsolescência do } \\
\text { estoque }\end{array}$ & $\begin{array}{l}\text { É o custo de cada unidade } \\
\text { que precisa ser descartada } \\
\text { ou não pode mais ser } \\
\text { comercializada no preço } \\
\text { normal }\end{array}$ & $\begin{aligned} \mathrm{OE}= & (\text { custo original do produto descartado })- \\
& (\text { valor residual do produto descartado })\end{aligned}$ \\
\hline
\end{tabular}




\title{
APÊNDICE B - Protocolo de Pesquisa
}

\author{
UNIVERSIDADE DE SÃO PAULO \\ ESCOLA DE ENGENHARIA DE SÃO CARLOS \\ DEPARTAMENTO DE ENGENHARIA DE PRODUÇÃO \\ Av. Trabalhador São-carlense, 400 - Fone: (0xx16) 3373-9428 \\ CEP 13566-590 - São Carlos - SP - Brasil \\ Home Page: http://www.prod.eesc.usp.br
}

\section{PROTOCOLO DE PESQUISA}

Prezado Senhor (a)

Tenho a satisfação de informar que como aluna do Programa de Mestrado do Departamento de Engenharia de Produção da Escola de Engenharia de São Carlos da Universidade de São Paulo (EESC-USP), estou desenvolvendo minha dissertação, cujo objetivo é o estudo dos indicadores de desempenho logístico utilizados por empresas líderes de mercado no setor de máquinas e implementos agrícolas. Este estudo está sob a orientação do Prof. Marcel Andreotti Musetti.

Por este motivo, vimos solicitar o apoio de vossa renomada empresa para o agendamento de uma entrevista com o profissional responsável pela área de Logística e se possível, a inclusão de uma visita às instalações da empresa. A entrevista contemplará questões sobre definição, apuração e importância de indicadores de desempenho para a gestão das atividades logísticas. Estima-se uma duração de 1 hora e 30 minutos para a realização da entrevista.

As informações coletadas serão mantidas em sigilo. Para a definição da forma de publicação e apresentação dos resultados será solicitada uma autorização prévia junto às empresas colaboradoras da pesquisa.

Contando com o apoio de Vossa Senhoria no acolhimento a nossa solicitação, que terá uma grande contribuição para o enriquecimento da nossa pesquisa, colocamo-nos à disposição para quaisquer outros esclarecimentos e aproveitamos para manifestarmos o nosso elevado apreço.

Atenciosamente,

Mestranda Catarina Barbosa Careta Escola de Engenharia de São Carlos - EESC/USP Departamento de Engenharia de Produção

Prof. Dr. Marcel Andreotti Musetti Escola de Engenharia de São Carlos - EESC/USP

Departamento de Engenharia de Produção 


\title{
APÊNDICE C - Roteiro de entrevista
}

\author{
UNIVERSIDADE DE SÃO PAULO \\ ESCOLA DE ENGENHARIA DE SÃO CARLOS \\ DEPARTAMENTO DE ENGENHARIA DE PRODUÇÃO \\ Av. Trabalhador São-carlense, 400 - Fone: (0xx16) 3373-9428 \\ CEP 13566-590 - São Carlos - SP - Brasil \\ Home Page: http://www.prod.eesc.usp.br
}

ROTEIRO DE ENTREVISTA

Dissertação: Indicadores de desempenho logístico - estudo de múltiplos casos no setor de bens de capital agrícolas

Este roteiro tem por objetivo orientar o levantamento de informações sobre os indicadores de desempenho logístico utilizados em empresas do setor de bens de capital agrícolas. Visa-se com a análise do conjunto, identificar e caracterizar indicadores e práticas do processo de medição comuns ao setor. 


\section{Parte I - Identificação da empresa}

Nome da empresa:

Número de funcionários:

Faixa de faturamento anual (em $\mathrm{R} \$$ milhões):

$\begin{array}{llll}\text { ( ) menor que } 100 & \text { ( ) } 100-500 & \text { ( ) } 500 \text { - } 1 \text { bilhão ( ) acima de } 1 \text { bilhão }\end{array}$

Principais linhas de produtos:

1)

2)

3)

\section{Identificação do respondente}

Nome do respondente:

Função:

Tempo de atuação na empresa:

Tempo de atuação na função:

Formação: 


\section{Parte II - Identificação do processo logístico}

Número de funcionários:

Atividades logísticas desenvolvidas:

Qual é a estratégia de negócio da área logística?

Qual o objetivo de desempenho (custo, qualidade, flexibilidade, rapidez, confiabilidade) de maior importância para área de logística? Existe diferenciação desta importância entre as linhas de produtos e entre clientes?

Que aspectos são considerados na priorização dos objetivos de desempenho:
( ) clientes atuais
( ) estratégia do negócio/mercado
( ) clientes em potenciais
( ) outros:
( ) desempenho frente a concorrência

A área de logística estabelece relacionamentos de parceria com fornecedores e clientes? 


\section{Parte III - Identificação dos indicadores de desempenho logístico}

Identifique os indicadores de desempenho utilizados pelo departamento de Logística. Utilize a tabela.

\begin{tabular}{|c|c|c|c|c|c|c|c|}
\hline & Indicador & Objetivo & $\begin{array}{l}\text { Forma de } \\
\text { cálculo }\end{array}$ & $\begin{array}{l}\text { Unidade de } \\
\text { medida }\end{array}$ & $\begin{array}{l}\text { Frequiência } \\
\text { de medição }\end{array}$ & $\begin{array}{l}\text { Freqüiência } \\
\text { de revisão }\end{array}$ & $\begin{array}{l}\text { Grau de } \\
\text { importância } \\
\text { para gestor }\end{array}$ \\
\hline 1 & & & & & & & \\
\hline 2 & & & & & & & \\
\hline 3 & & & & & & & \\
\hline 4 & & & & & & & \\
\hline 5 & & & & & & & \\
\hline 6 & & & & & & & \\
\hline 7 & & & & & & & \\
\hline 8 & & & & & & & \\
\hline 9 & & & & & & & \\
\hline 10 & & & & & & & \\
\hline 11 & & & & & & & \\
\hline 12 & & & & & & & \\
\hline 13 & & & & & & & \\
\hline 14 & & & & & & & \\
\hline 15 & & & & & & & \\
\hline
\end{tabular}

Identifique junto à relação de indicadores disposta na tabela 1 o grau de importância atribuído ao indicador para o controle gerencial do departamento de Logística. Utilize a escala de 1 a 5 (1 - Irrelevante; 2 - Pouco importante; 3 - Importante; 4 - Muito importante; 5 Extremamente importante). 
Parte IV - Identificação do processo de medição de desempenho logísticos

Como funciona o processo de definição dos indicadores de desempenho logístico?

Quem foram os responsáveis (área de logística ou alta direção da empresa) pela definição dos indicadores logísticos?

Quais os fatores impulsionadores para a definição dos indicadores?

Como são estabelecidas as metas de desempenho?

As metas estão baseadas em:

( ) desempenho passado/histórico

( ) desempenho de outras áreas/unidades da empresa

( ) benchmarking

( ) negociação interna/imposição da alta administração

( ) mercado

( ) outros

Quem são os responsáveis pelo fornecimento de dados, cálculo dos indicadores e relato dos resultados dos indicadores?

Como são comunicados as metas e os resultados dos indicadores logísticos? 
Adota-se algum método específico para a medição de desempenho (Balanced Scorecard, Performance Prism....)?

Utiliza-se algum sistema de informação para apoiar a medição de desempenho logístico? Que instrumentos são utilizados na coleta, armazenagem e divulgação de resultados?

Como os resultados dos indicadores utilizados influenciam nas tomadas de decisões? Que ações são tomadas a partir dos resultados obtidos?

Outros departamentos da empresa utilizam os resultados apurados na área logística? Os indicadores logísticos estão integrados ao sistema de medição de desempenho da empresa?

Como funciona o processo de revisão dos indicadores de desempenho logístico?

Resultados são utilizados para motivar os empregados? Existem programas de recompensa para o atingimento de metas? 